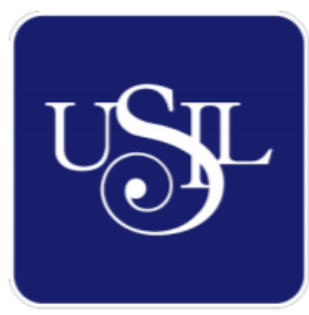

UNIVERSIDAD

SAN IGNACIO

DE LOYOLA

FACULTAD DE CIENCIAS EMPRESARIALES

Carrera de International Business

\title{
FACTORES ASOCIADOS A LA COMERCIALIZACIÓN DE COLORANTE DE MAIZ MORADO EN LA INDUSTRIA ALIMENTARIA Y SU RELACIÓN CON LAS EXPORTACIONES A ESTADOS UNIDOS PERIODO 2015 $-2019$
}

Tesis para optar el Título Profesional de Licenciado en International Business

DORIS PAULA ROMERO ORTEGA (0000-0001-9795-8685)

PRISCILLA NICOLLE SCAMARONE CORNEJO (0000-0002-5227-7533)

\author{
Asesor: \\ Mag. Jimmy Elías Sánchez Gómez
}

(0000-0002-0425-6404)

Lima - Perú 


\section{Dedicatoria}

La presente tesis va dedicada a nuestros padres que con mucho esfuerzo han logrado que seamos excelentes profesionales.

A todos aquellos que han influenciado en nuestra vida personal y profesional.

Finalmente, a los colegas que, al realizar una investigación relacionada al tema, esta tesis

les pueda servir de ayuda. 


\section{Agradecimientos}

Agradecemos con todo nuestro amor, respeto y cariño:

A Dios por sobre todas las cosas.

A nuestros padres y familiares por su paciencia, motivación y tiempo.

A nuestro asesor Jimmy Sánchez por sus enseñanzas y

orientaciones a lo largo del desarrollo de la tesis. 


\section{Resumen}

El objetivo del presente trabajo de investigación es determinar si los factores asociados a la comercialización del colorante de maíz morado, con la subpartida número 320300160000 , tiene relación significativa con las exportaciones del producto a Estados Unidos en la industria alimentaria en el periodo 2015 al 2019. Dentro los factores mencionados anteriormente, se consideraron: el apoyo del estado peruano, la competitividad de empresas de productos orgánicos en Estados Unidos y la tendencia por el consumo de productos saludables.

Para analizar los factores asociados con la comercialización de colorante de maíz morado en este periodo se ha realizado una investigación cuantitativa, utilizando la herramienta encuesta con el instrumento cuestionario dirigido a 30 expertos entre gerentes generales, gerentes del área de exportaciones y gerentes del área operativa y/o logística, extraídos de un total de 7 empresas que exportan colorante de maíz morado a Estados Unidos. Cabe resaltar que estas empresas representan el $80 \%$ de las exportaciones en el periodo analizado. Para hacer este análisis se ha utilizado el programa estadístico SPSS, con el fin de evaluar las hipótesis planteadas.

De esta manera se encontró que los factores más resaltantes y significativos que facilitan la comercialización de colorante de maíz morado a Estados Unidos fueron: el apoyo por parte del estado peruano y la tendencia por el consumo de productos saludables. Sin embargo, la competitividad entre empresas que comercializan productos orgánicos en Estados Unidos no presentó relación con las exportaciones.

Palabras clave: exportación, comercialización, maíz morado y colorantes. 


\begin{abstract}
The objective of this research is to determine if the factors associated with the commercialization of anthocyanin purple corn extract, with HS code 320300160000 , have a significant relationship with the exports to the United States in the food industry in the period 2015 to 2019. Among the factors mentioned before, the following were considered: the support of the Peruvian government, the competitiveness of organic product companies in the United States and the trend towards the consumption of healthy products.
\end{abstract}

To analyze the factors associated with the commercialization of anthocyanin purple corn extract in the period mentioned above, a quantitative analysis has been carried out, using the survey tool with the questionnaire instrument addressed to 30 experts among CEOs, managers of the foreign trade area and managers of the operational or logistics area, extracted from a total of 7 companies that export anthocyanin purple corn extract to the United States. It should be noted that these companies represent $80 \%$ of exports in the analyzed period. To carry out this analysis, the statistical program SPSS has been used, in order to evaluate the hypotheses raised.

In this way, it was found that the most outstanding and significant factors that facilitate the commercialization of anthocyanin purple corn extract to the United States were: the support from the Peruvian government and the trend towards the consumption of healthy products. However, competitiveness between companies that commercialize organic products in the United States did not show a relationship with exports.

Key words: commercialization, exportation, anthocyanin and purple corn. 


\section{Índice}

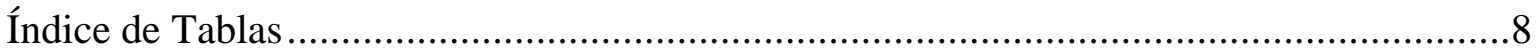

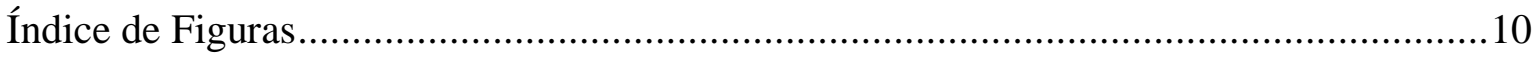

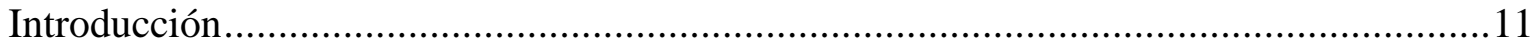

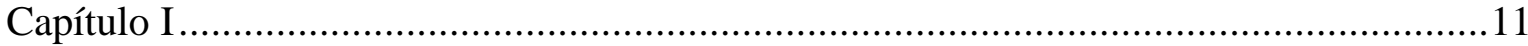

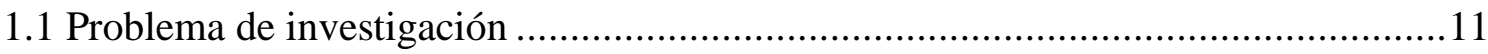

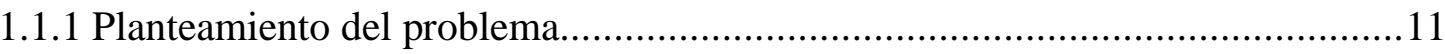

1.1.2 Formulación del problema.......................................................................13

1.1.2.1 Problema general. .............................................................................13

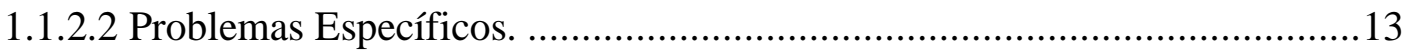

1.1.3 Justificación de la investigación. ………………........................................13

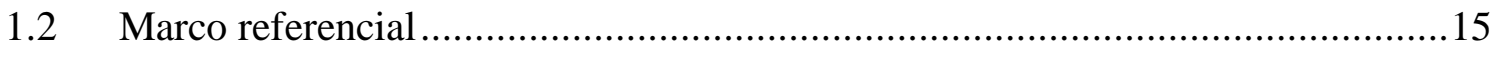

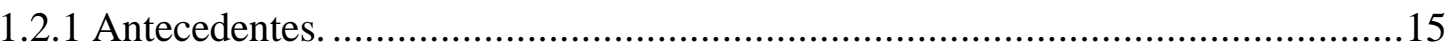

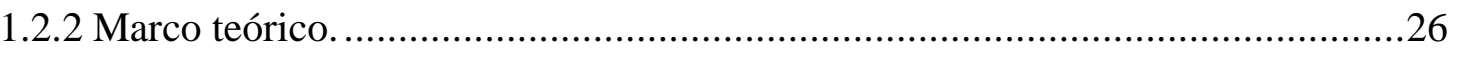

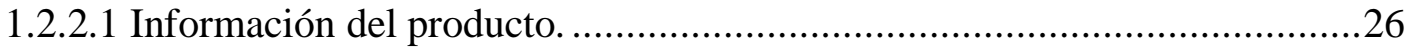

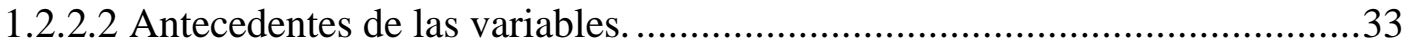

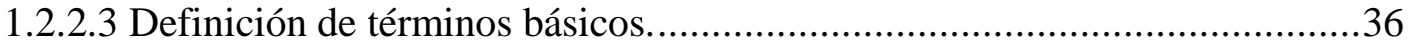

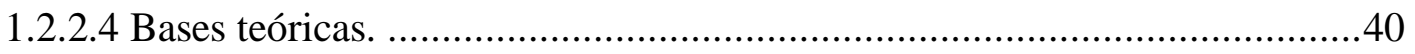

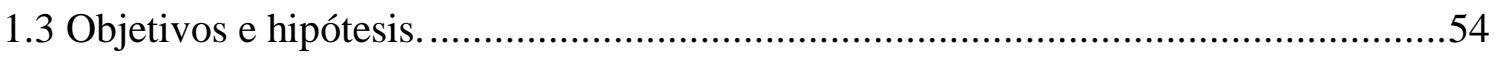

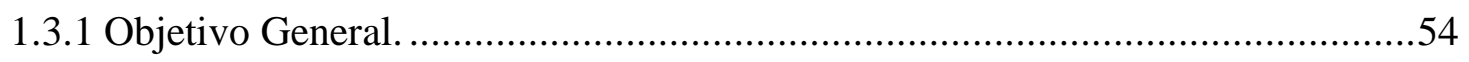

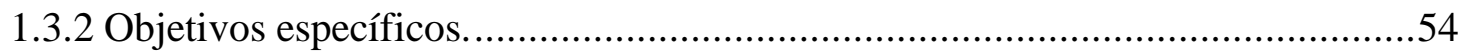

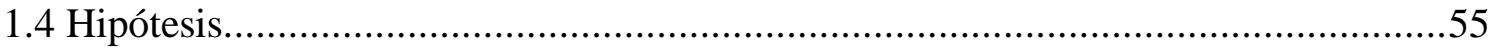

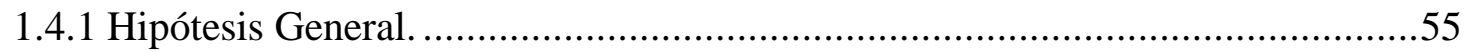

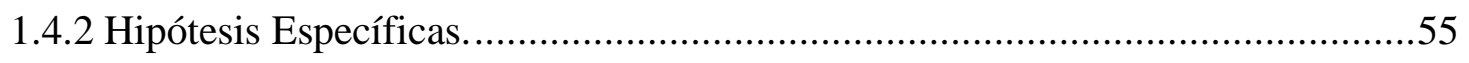

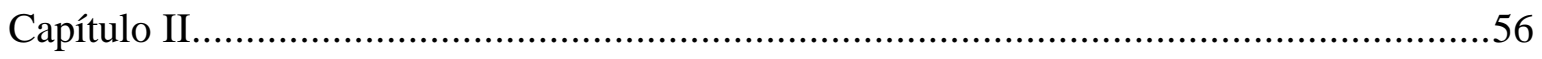

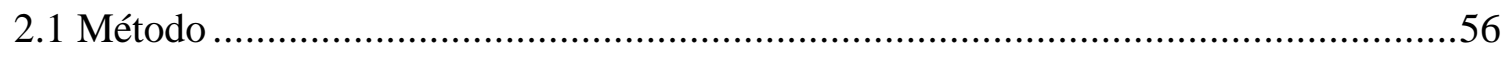

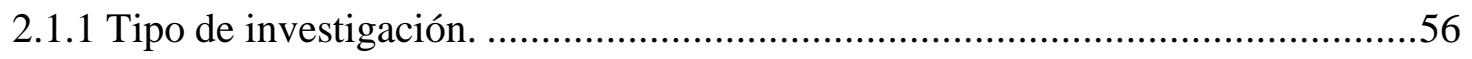

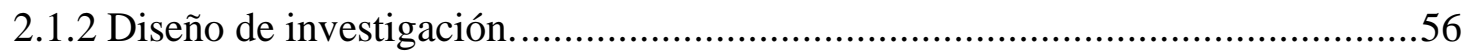

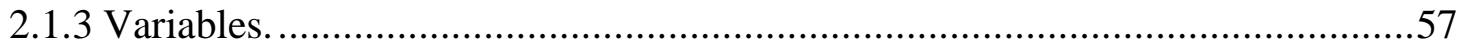

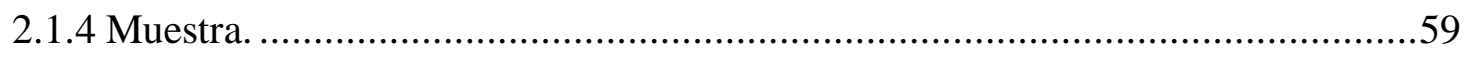

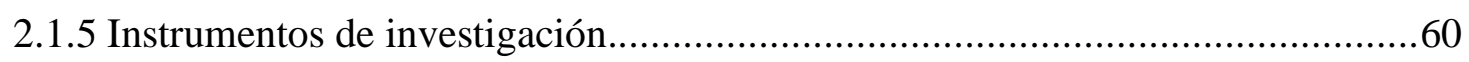


2.1.6 Procedimientos de recolección de datos....................................................61

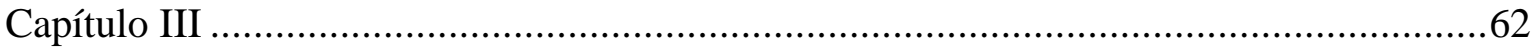

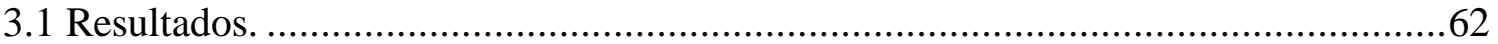

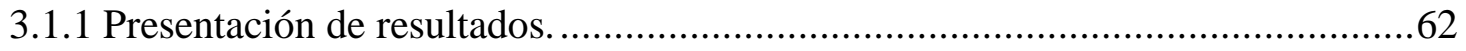

3.1.1.1 Análisis de resultados de las encuestas. ...........................................62

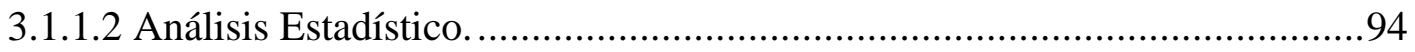

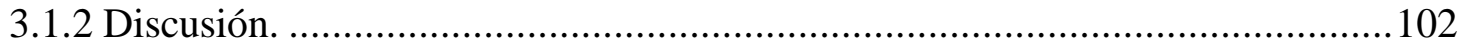

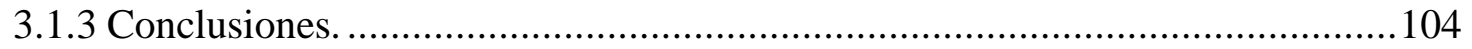

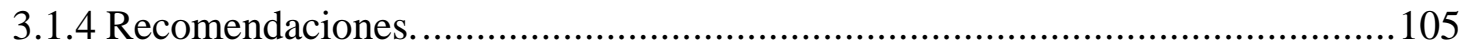

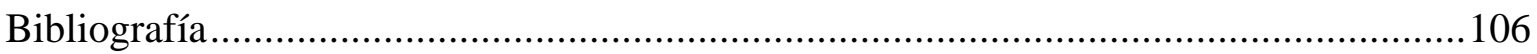

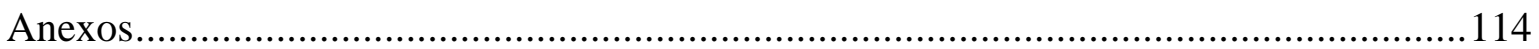




\section{Índice de Tablas}

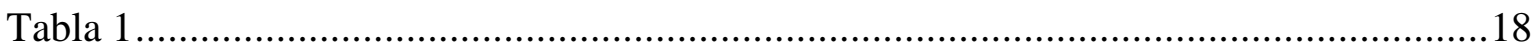

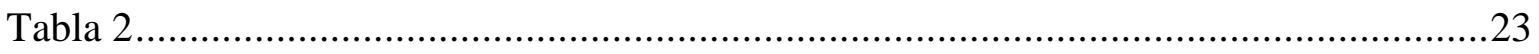

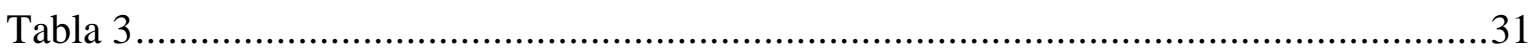

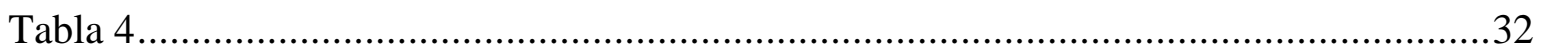

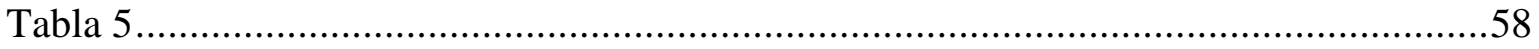

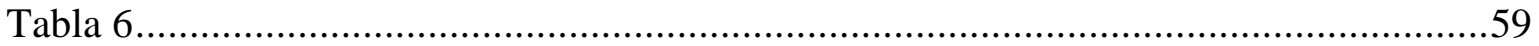

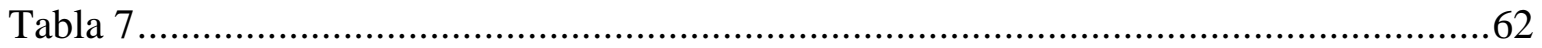

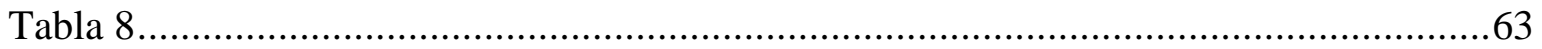

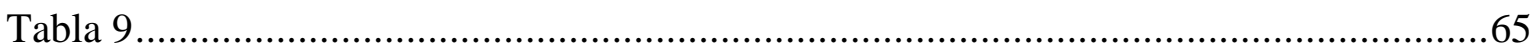

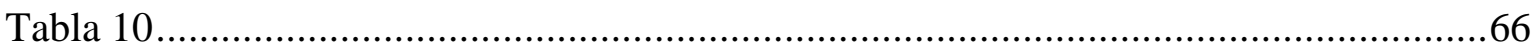

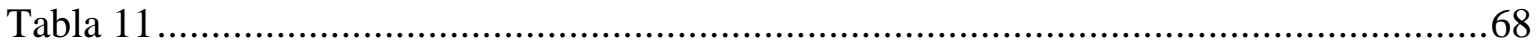

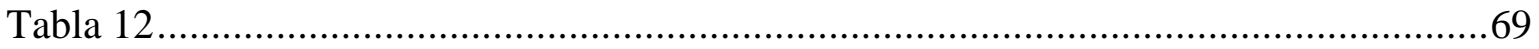

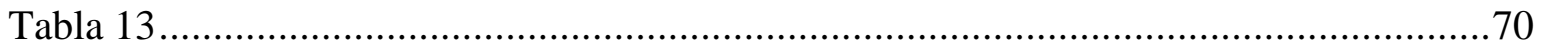

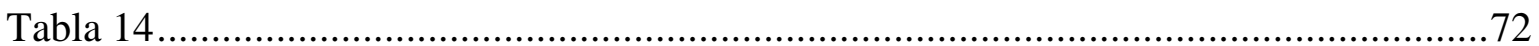

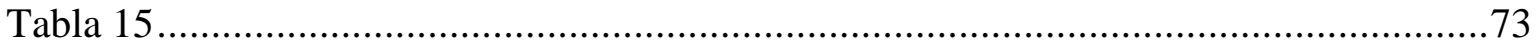

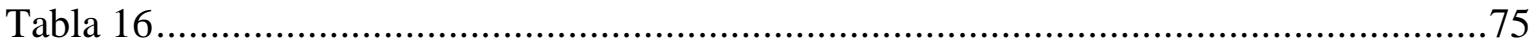

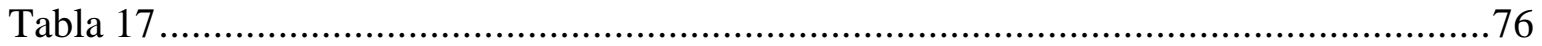

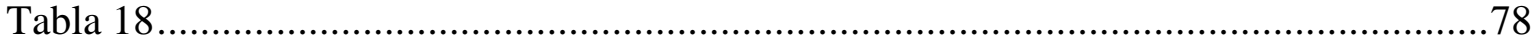

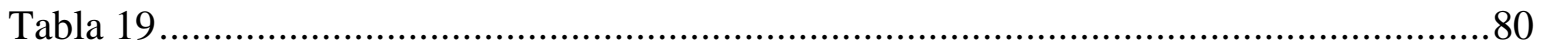

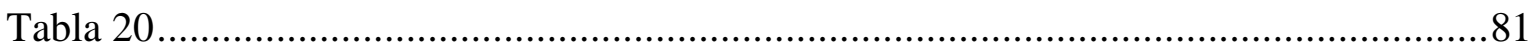

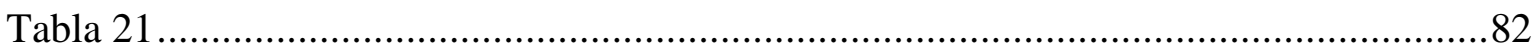

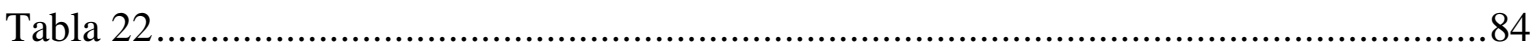

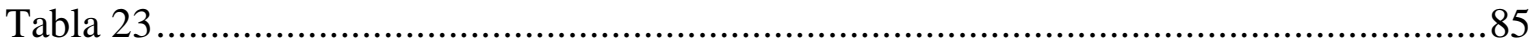

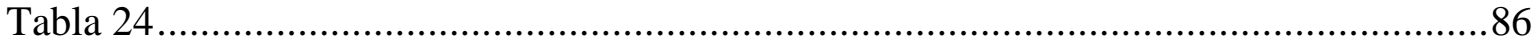

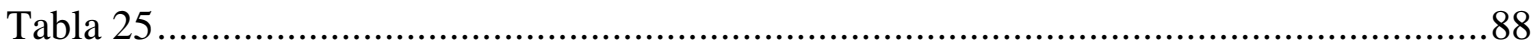

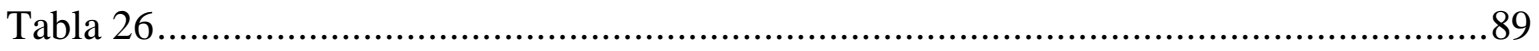

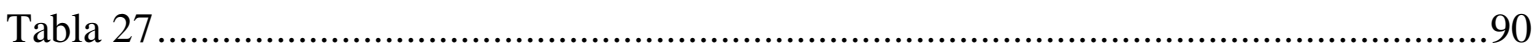

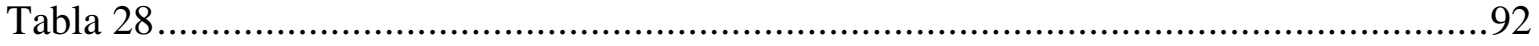

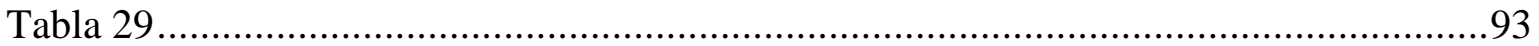

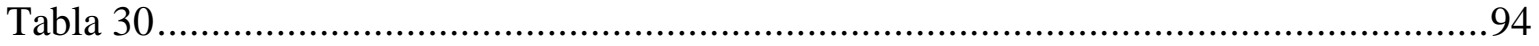

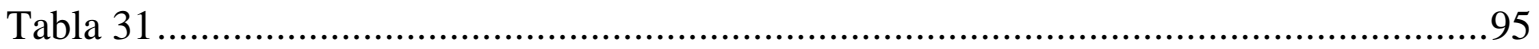




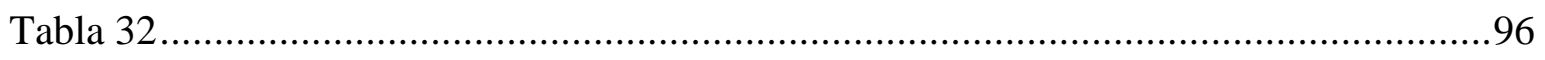

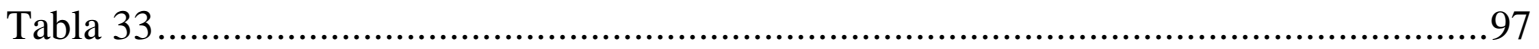

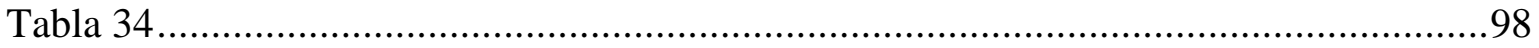

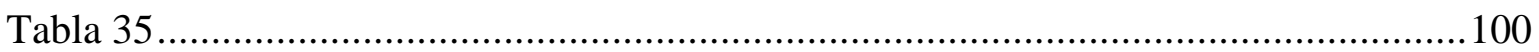

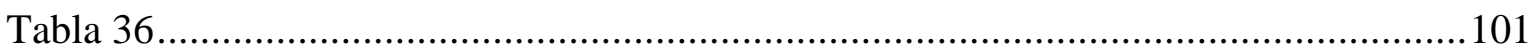




\section{Índice de Figuras}

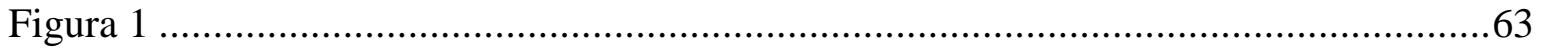

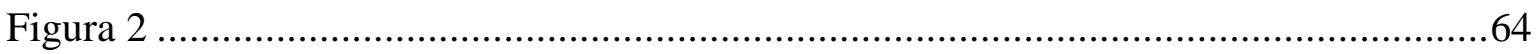

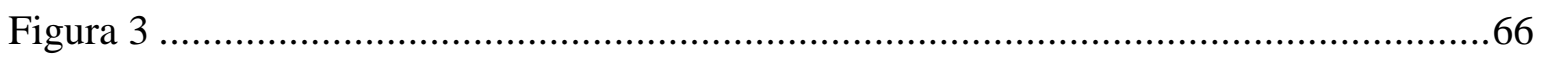

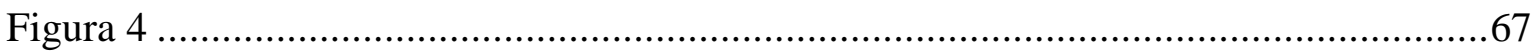

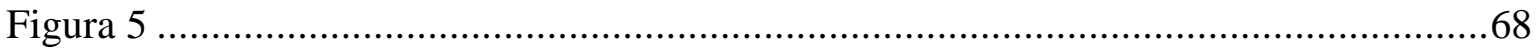

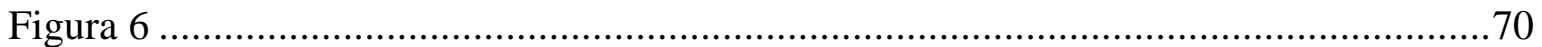

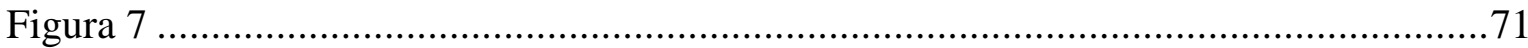

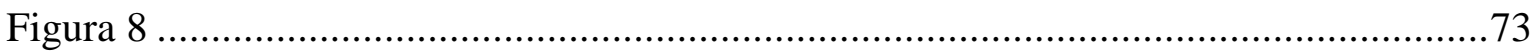

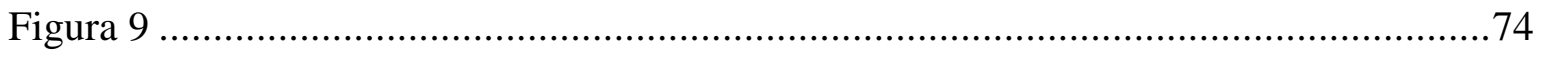

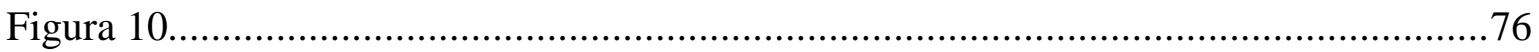

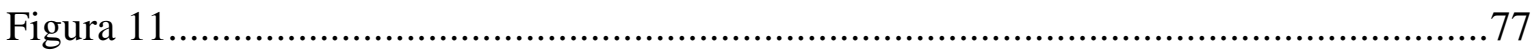

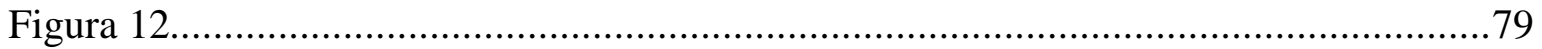

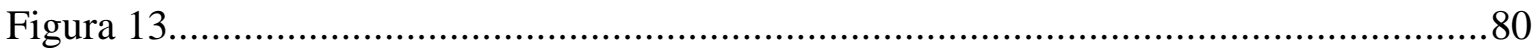

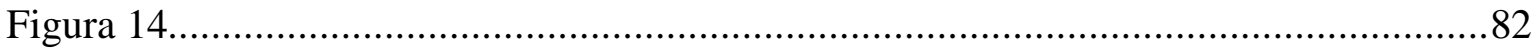

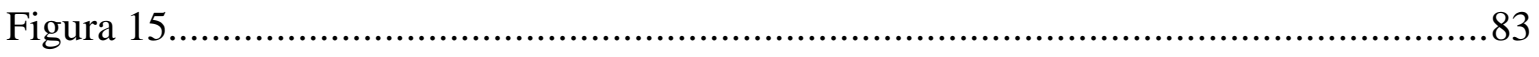

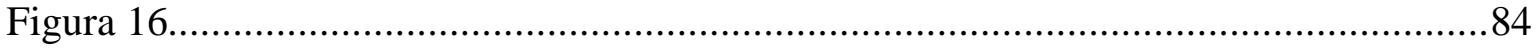

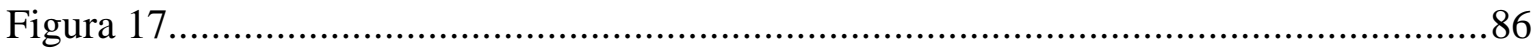

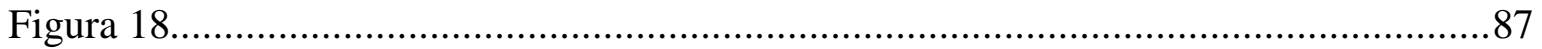

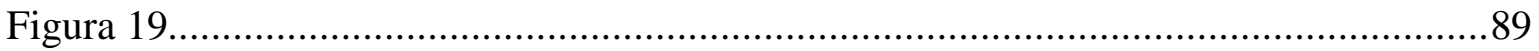

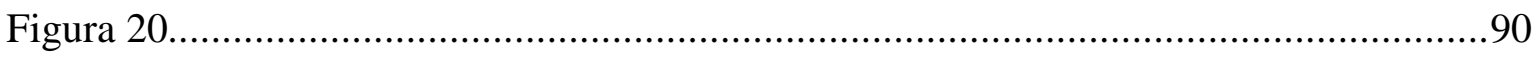

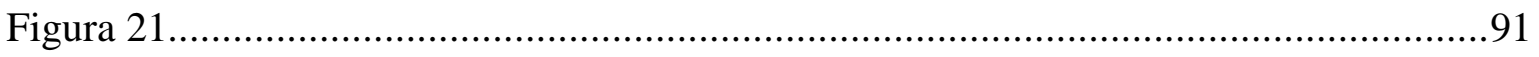

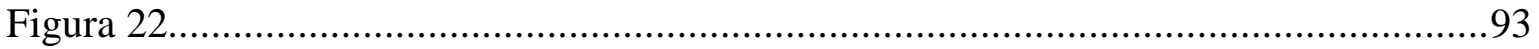

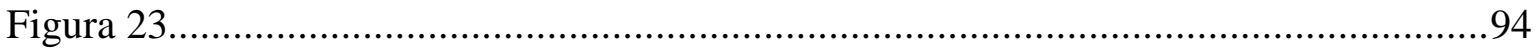

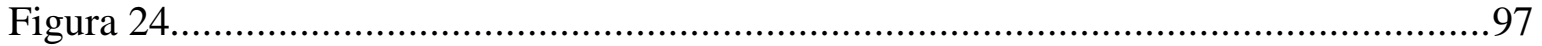

Figura 25

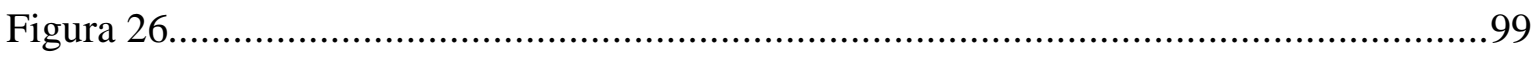

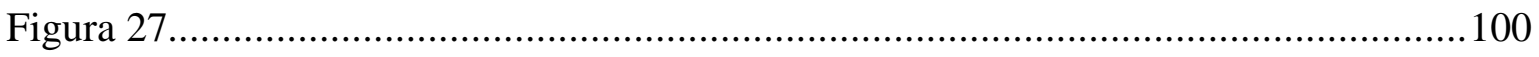




\section{Introducción \\ Capítulo I}

\subsection{Problema de investigación}

\subsubsection{Planteamiento del problema.}

- Síntomas:

Durante varios años, las exportaciones de maíz morado peruano tuvieron mucho éxito debido a diversos factores internos y externos del país. Esto sucedió debido a que existen tratados o acuerdos internacionales y nuevos regímenes que fueron establecidos por el estado peruano. Las exportaciones de maíz morado se han vuelto muy importantes tanto en los productos tradicionales de exportación, así como los que se han dado como una alternativa, por ejemplo, sus derivados, creando una gama aún más variada aumentando así el volumen y el valor de las exportaciones cada año. Es por ello que el producto se ha podido posicionar en el mercado internacional de una forma avasallante.

Se ve con gran satisfacción como la producción ha ido en aumento debido a la alta demanda del producto, creando así una forma rentable tanto para pequeños como para medianos productores, dando con ello una confianza sólida de oportunidad de negocio. Gracias a esa elevada producción de maíz morado se han expandido a nuevos clientes internacionales como lo son, los mercados de Estados Unidos de Norte América, el asiático específicamente el japonés, así como también el europeo.

\section{- Causas:}

La gran demanda que tiene el maíz morado a estos mercados se debe a las múltiples propiedades que le son atribuidas científicamente, un ejemplo de ello es que se ha 
comprobado que el maíz morado posee un alto contenido en antocianina (pigmento azul púrpura), el cual es un potente antioxidante natural que previene la degeneración de algunas células, haciéndolo muy requerido en el mercado internacional.

De igual manera otras de las virtudes que tiene el maíz morado y por la cual tiene tanta comercialización internacional es que de él se extraen colorantes naturales reemplazando de esta manera los colorantes artificiales, y como estamos en una década donde la gente se preocupa mucho por su bienestar, estos colorantes naturales se ven cada vez más requeridos por la industria alimentaria, cosmética y farmacéutica.

- Pronóstico:

Dentro de los principales mercados de exportación de colorante de maíz morado, Estados Unidos en los últimos años se ha vuelto de gran relevancia para el sector económico del país y logra una suma importante en las exportaciones, las cuales representa actualmente el $78 \%$ de participación, siendo su principal uso para la industria alimentaria. Como prueba de esto, en el 2015 se exportaron 13.939 kilos con un valor FOB entonces de US\$ 1,244,267, estos valores fluctuaron durante el periodo de manera positiva respecto de ese año, siendo para el 2019 una exportación de 13,451 kilos por un valor FOB de US\$ 869,268.

- Control de pronóstico:

Debido al creciente interés del producto, en la presente tesis se abordan los factores asociados a la comercialización de colorante de maíz morado en la industria alimentaria y su relación con las exportaciones a Estados Unidos en el periodo 2015 - 2019. 


\subsubsection{Formulación del problema.}

\subsubsection{Problema general.}

¿Cuál es la relación entre los factores de la comercialización del colorante de maíz morado en la industria alimentaria con las exportaciones a Estados Unidos durante el periodo 2015$2019 ?$

\subsubsection{Problemas Específicos.}

a. ¿Existe relación significativa entre la comercialización del colorante de maíz morado y el apoyo del gobierno peruano en fomentar las exportaciones del producto?

b. ¿Existe relación significativa entre la comercialización del colorante maíz morado y la competitividad entre empresas de productos orgánicos en EEUU?

c. ¿Existe relación significativa entre la comercialización del colorante de maíz morado y la tendencia por el consumo de productos saludables?

\subsubsection{Justificación de la investigación.}

La justificación de la presente investigación es que de acuerdo con la recopilación de datos de la comercialización de colorante de maíz morado en la industria alimentaria con respecto a las exportaciones a Estados Unidos durante el periodo 2015-2019, así como los objetivos e hipótesis planteadas, se comprobará sobre la base de los resultados ver la relación que existe entre los factores asociados a la comercialización del colorante de maíz morado y las exportaciones a Estados Unidos.

Visto desde un enfoque teórico, esta investigación servirá como fuente de información para la industria alimentaria de colorantes naturales, donde a su vez se aporta una gama de 
factores que destacan su influencia positiva en la antocianina del maíz morado en el mercado estadounidense como pigmentos empleables para la elaboración de colorantes naturales. Teniendo en consideración las propiedades anticancerígenas que se le atribuye por su alto contenido de antioxidantes, la industria alimentaria contará con un colorante que satisfaga la necesidad de color, y que a su vez añade el valor nutritivo a los productos alimenticios aplicados.

Bajo un enfoque práctico, se analizarán las exportaciones a Estados Unidos dentro del periodo señalado; ya que, de acuerdo con la competitividad entre empresas de productos orgánicos en EEUU, lo perjudicial que son los colorantes artificiales para la salud humana y el impulso del producto por parte del gobierno peruano, se obtendrá como resultado los factores que tiene la comercialización del colorante de maíz morado en dicho mercado para la industria alimentaria.

Finalmente, en un enfoque social, se espera dar a conocer el valor de este producto como recurso para la exportación, teniendo en cuenta la ventaja competitiva con que actualmente cuenta nuestro país, por ejemplo: la disponibilidad de tierras de cultivos y el clima sobre todo en lima, que es donde se produce mayormente este producto. Adicionalmente, existe una tendencia de consumo de productos saludables, surgiendo una preferencia por el uso de colorantes y pigmentos naturales, debido a la asociación de los sintéticos con problemas de salud.

Esta investigación es viable, porque permite el uso de instrumentos teóricos relacionados a las exportaciones, comercialización y competitividad. 


\subsection{Marco referencial}

\subsubsection{Antecedentes.}

- Antecedentes nacionales:

Solís (2017) en su tesis: "Comercio internacional y competitividad de colorantes de maíz morado peruano 2008 - 2016", tesis para optar al título de profesional Licenciada en negocios Internacionales, de la Universidad Cesar Vallejo, Lima. El objetivo principal de esta investigación fue determinar cómo ha sido el comercio y la competitividad de los colorantes a base de maíz morado durante los años 2008 al 2016. En esta investigación el autor trata de demostrar como en la actualidad la población se preocupa más por su bienestar en el ámbito de la salud y los colorantes a base del maíz morado es una buena opción a la hora de sustituir los artificiales. El diseño del estudio es no experimental y la investigación es de tipo descriptivo no experimental. Se concluyó que, si ha ido en aumento la producción y exportación de colorantes a base del maíz morado, pero esto no ha aumentado significativamente los ingresos a la nación.

Gallardo (2016) en su investigación: "Exportación de maíz morado al mercado de Estados Unidos 2008-2014", tesis para obtener el título profesional de licenciado en negocios internacionales, de la Universidad Cesar Vallejo, Lima. Su tesis tuvo como objetivo principal determinar la evolución de exportación del maíz morado al mercado de Estados Unidos 2008-2014 así como el estudio a todas las empresas peruanas exportadoras de maíz morado a los Estados Unidos durante el periodo del 2008 al 2014, para el análisis del estudio se utilizó la estadística, en lo cual se organizó en cuadros los datos. El autor expone como en los últimos años se ha venido aumentando la exportación de este rubro y se ve como las empresas tienen un gran interés en explotar este mercado lo cual es muy interesante y hay 
que aprovecharlo. Como conclusión se tiene que la tendencia de exportación es positiva, y que se ha dado un auge en la exportación de maíz morado.

Palaco (2018) en su investigación presentada en la Universidad Católica San Pablo, teniendo como objetivo general propuesto determinar la viabilidad técnica, económica y comercial para la instalación de una planta de procesamiento de antocianinas de maíz morado para exportación, como una forma de añadir valor agregado al maíz morado y aportar al desarrollo económico y social del Perú. Mediante un focus group se validó la información obtenida de la bibliografía y luego se proyectó la producción para los años 2018 al 2027. La presentación básica del producto será en cajas de $25 \mathrm{~kg}$, conteniendo 5 bolsas de $5 \mathrm{~kg}$ de polvo granulado, el precio por caja será de S/ 9,943. Para establecer el tamaño de la planta se analizó el tamaño del mercado de antocianinas en Estados Unidos, la tecnología para la extracción del colorante, y la disponibilidad del maíz morado para la industria en el Perú. Según su investigación, en el primer año se procesará 534.8 Tn de maíz morado crudo, obteniéndose 6.097 Tn de antocianinas y 380.35 Tn de harina de maíz como subproducto.

Salas y Tovalino (2018) en su investigación: "Obtención de antocianinas de papa nativa "Yawar Wayku" (Solanum stenotomum) para la elaboración de un colorante natural aplicable a alimentos", tesis para obtener el título de profesional de ingeniero agroindustrial y agronegocios, de la universidad San Ignacio de Loyola. Su tesis tuvo como objetivo principal determinar las condiciones óptimas de extracción de antocianinas a partir de papa nativa y evaluar su uso potencial como colorante natural en yogur, para el análisis del estudio se utilizó el método experimental cuantitativo mediante el uso de herramientas estadísticas, presentando los resultados mediante tablas. Como conclusión de la investigación, se 
determinó que, debido a las características en el colorante obtenido, este puede ser utilizado como sustituto para los colorantes artificiales.

Rojas y Vergara (2018) en su investigación presentada en la Universidad Señor de Sipan, teniendo como objetivo general propuesto determinar que "el plan negocio permite la exportación de la antocianina de maíz morado que produce la empresa Industria y comercio Lambayeque (INCOLAM) al mercado Nutracéutico del país de Estados Unidos”. Mediante una investigación de tipo descriptivo simple no experimental y un enfoque cuantitativo, considerando tres principales empresas como posibles compradores, se pudo concluir que existe una demanda actual del producto en el mercado norteamericano, la cual puede ser cubierta por empresas peruanas ya que estas si cumplen con las características y estándares solicitados por el mercado. 
Tabla 1

Antecedentes nacionales vinculados al estudio.

\begin{tabular}{|c|c|c|c|c|c|c|c|}
\hline Título & Variable & $\begin{array}{c}\text { Tipo de } \\
\text { Documento }\end{array}$ & Autor & $\begin{array}{l}\text { Universidad/ } \\
\text { Entidad }\end{array}$ & Diseño & Fuente & Aporte de Tesis \\
\hline $\begin{array}{l}\text { Comercio internacional y } \\
\text { competitividad de colorantes } \\
\text { de maíz morado peruano } \\
2008-2016\end{array}$ & 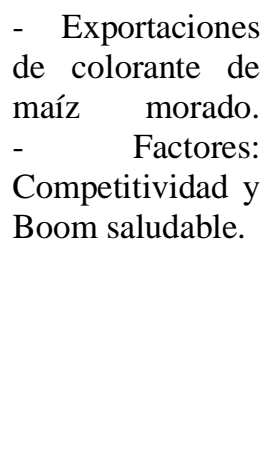 & $\begin{array}{l}\text { Tesis } \\
\text { Pregrado }\end{array}$ & $\begin{array}{l}\text { Susan } \\
\text { Solís } \\
(2017)\end{array}$ & $\begin{array}{l}\text { Universidad } \\
\text { Cesar Vallejo }\end{array}$ & Cuantitativa & $\begin{array}{l}\text { Repositorio } \\
\text { UCV }\end{array}$ & $\begin{array}{l}\text { Dicha tesis demuestra como en la } \\
\text { actualidad la población se preocupa } \\
\text { más por su salud, debido a ello el } \\
\text { colorante de maíz morado ha } \\
\text { ganado una ventaja competitiva } \\
\text { sobre los colorantes artificiales. } \\
\text { Además, muestra como la } \\
\text { exportación ha ido en aumento en } \\
\text { los años analizados; sin embargo, } \\
\text { no significaron una cantidad } \\
\text { importante de ingresos. }\end{array}$ \\
\hline $\begin{array}{l}\text { Exportación de maíz morado } \\
\text { al mercado de Estados } \\
\text { Unidos } 2008-2014\end{array}$ & $\begin{array}{l}\text { - Exportaciones } \\
\text { de colorante de } \\
\text { maíz morado. }\end{array}$ & $\begin{array}{l}\text { Tesis } \\
\text { Pregrado }\end{array}$ & $\begin{array}{l}\text { Waldir } \\
\text { Gallardo } \\
(2016)\end{array}$ & $\begin{array}{l}\text { Universidad } \\
\text { Cesar Vallejo }\end{array}$ & Cuantitativa & $\begin{array}{l}\text { Repositorio } \\
\text { UCV }\end{array}$ & $\begin{array}{l}\text { El autor expone estadísticamente la } \\
\text { tendencia de exportación positiva } \\
\text { del colorante de maíz morado a } \\
\text { Estados Unidos. Esta tesis } \\
\text { contribuirá con la presente } \\
\text { investigación, ya que es importante } \\
\text { considerar distintos aspectos del } \\
\text { crecimiento de las exportaciones } \\
\text { del producto al país de } \\
\text { investigación. }\end{array}$ \\
\hline $\begin{array}{l}\text { Proyecto para la instalación } \\
\text { de una planta de } \\
\text { procesamiento de maíz } \\
\text { morado de la variedad } \\
\text { Morado Canteño para la }\end{array}$ & 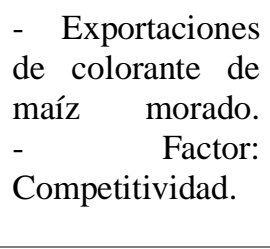 & $\begin{array}{ll}\text { Tesis } & \text { de } \\
\text { Pregrado } & \end{array}$ & $\begin{array}{l}\text { Williams } \\
\text { Palaco } \\
(2018)\end{array}$ & $\begin{array}{l}\text { Universidad } \\
\text { Católica San } \\
\text { Pablo }\end{array}$ & Mixta & $\begin{array}{l}\text { Repositorio } \\
\text { UCSP }\end{array}$ & $\begin{array}{l}\text { Esta tesis a pesar de ser un modelo } \\
\text { de negocio considera variables } \\
\text { como competitividad y una } \\
\text { tendencia futura de crecimiento } \\
\text { para las exportaciones de colorante } \\
\text { de maíz morado. Asimismo, }\end{array}$ \\
\hline
\end{tabular}


obtención y exportación de

antocianinas 2018. expone el tamaño del mercado de antocianinas en Estados Unidos, la tecnología para la extracción del colorante y la disponibilidad del maíz morado para la industria en el Perú.

\begin{tabular}{|c|c|c|c|c|c|c|}
\hline $\begin{array}{l}\text { Obtención de antocianinas } \\
\text { de papa nativa "Yawar } \\
\text { Wayku" (Solanum } \\
\text { stenotomum) para la } \\
\text { elaboración de un colorante } \\
\text { natural aplicable a alimentos }\end{array}$ & $\begin{array}{l}\text { - Colorante de } \\
\text { maíz morado. } \\
\text { - Factor: Boom } \\
\text { saludable. }\end{array}$ & $\begin{array}{ll}\text { Tesis } & \text { de } \\
\text { Pregrado } & \end{array}$ & $\begin{array}{l}\text { Diana } \\
\text { Salas y } \\
\text { Stephanie } \\
\text { Tovalino } \\
(2018)\end{array}$ & $\begin{array}{l}\text { Universidad } \\
\text { San Ignacio } \\
\text { de Loyola }\end{array}$ & Cuantitativa & $\begin{array}{l}\text { Repositorio } \\
\text { USIL }\end{array}$ \\
\hline
\end{tabular}

La presente tesis analiza sobre un colorante natural extraído de una papa nativa oriunda de Perú y su potencial como colorante natural en yogur. Además de realizar una investigación cualitativa sobre la tendencia de alimentos orgánicos y saludables. Las autoras concluyen que las condiciones del colorante son favorables para sustituir los colorantes artificiales.

\begin{tabular}{|c|c|c|c|c|c|c|c|c|}
\hline \begin{tabular}{lrrr} 
Plan de & Negocio & de \\
Exportación & \multicolumn{2}{c}{ de } & la \\
Antocianina & de & Maíz \\
Morado de & la & Empresa \\
Industria y & & Comercio \\
Lambayeque & & (INCOLAM) \\
para el & & Mercado \\
Nutraceútico & de & Estados \\
Unidos 2016 & &
\end{tabular} & $\begin{array}{ll}\text { - } & \text { Exportaciones } \\
\text { de colorante de } \\
\text { maíz morado. } \\
\text { - Factor: Apoyo } \\
\text { del } & \text { Estado } \\
\text { peruano. } & \end{array}$ & $\begin{array}{l}\text { Tesis } \\
\text { Pregrado }\end{array}$ & de & $\begin{array}{l}\text { Fátima de } \\
\text { Rocío } \\
\text { Rojas y } \\
\text { Bárbara } \\
\text { Vergara } \\
(2018)\end{array}$ & $\begin{array}{l}\text { Universidad } \\
\text { Señor de } \\
\text { Sipán }\end{array}$ & Mixta & $\begin{array}{l}\text { Repositorio } \\
\text { USP }\end{array}$ & $\begin{array}{l}\text { Este proyecto de tesis exhibe los } \\
\text { pasos a seguir para que una } \\
\text { empresa tenga éxito con la venta de } \\
\text { antocianinas en el mercado } \\
\text { estadounidense. Finalmente } \\
\text { concluye que, si se desea aplicar } \\
\text { para otro mercado, se debe realizar } \\
\text { una nueva investigación. Esta tesis } \\
\text { contribuirá a la presente } \\
\text { investigación debido a que expone } \\
\text { indicadores significativos a } \\
\text { considerar con respecto a la ayuda } \\
\text { que brinda el estado peruano a los } \\
\text { exportadores. }\end{array}$ \\
\hline
\end{tabular}

Nota: Se ha elaborado una tabla de antecedentes nacionales relacionados al tema de investigación de la presente tesis. Elaboración propia. 
- Antecedentes internacionales:

Lizano (2012) en su investigación: "Efecto del proceso de fritura en el contenido de antocianinas en empanadas elaboradas con mezclas de harina de trigo - maíz morado", Tesis de grado presentada como requisito para la obtención del título de Ingeniería de Alimentos, de la Universidad San Francisco de Quito, Ecuador. Dicha investigación tuvo como objetivo principal evaluar el efecto del proceso de fritura en el contenido de antocianinas en empanadas elaboradas con mezclas de harina de trigo- maíz morado. Este autor explica que esta variedad de maíz es producida en la sierra del Ecuador, pero en los últimos años se ha visto mermada su producción siendo lamentable por su alto contenido alimenticio, explica que esta disminución se da por el poco consumo que se observa a nivel nacional, pero hace una observación de que se pudiera exportar a grandes mercados como lo es el asiático específicamente en el Japón que es muy comercializado el maíz morado por su pigmentación. Esta investigación se realizó bajo un análisis experimental y estadístico así también se realizó un estudio sensorial. Expone que el Estado desde el año 2006 ha venido creando políticas para lograr aumentar o por lo menos mantener la producción de tan importante producto.

Garzón (2008) en su artículo: "Las antocianinas como colorantes naturales y compuestos bioactivos: Revisión", publicada en la Acta Biológica Colombiana volumen 13 de la Universidad Nacional de Colombia Sede Bogotá. Esta publicación tuvo como objetivo principal detallar un esquema actualizado de las propiedades químicas y bioactivas de las antocianinas además de su alto potencial como colorante natural. De esta manera, demuestra como la demanda por colorantes naturales ha aumentado frente a la toxicidad de los colorantes sintéticos. El autor sugiere que el interés por estos pigmentos naturales nace de 
los posibles efectos terapéuticos y benéficos, tales como: la reducción de la enfermedad coronaria, los efectos anticancerígenos, antitumorales, antinflamatorio y antidiabéticos; añadiendo el mejoramiento de la agudeza visual y del comportamiento cognitivo. Es con ello que abre una nueva perspectiva, gracias a las propiedades bioactivas de las antocianinas, para obtener productos de color con valor agregado para el consumo humano. Finalmente, a través de su composición química, reafirma como la antocianina es un gran reemplazo competitivo para los colorantes sintéticos; sin embargo, es importante conocer sus aspectos bioquímicos como: estabilidad en matrices específicas y relación entre su estructura, la actividad biológica de los metabolitos bioactivos, los efectos sinergísticos y las dosis efectivas, los cuales deben ser estudiados a más profundidad.

Aguirre (2018) en su tesis: "Desarrollo de un colorante natural desde el fruto del saúco negro para uso en la industria alimentaria", investigación para obtener el título profesional de Ingeniero Agroindustrial y de Alimentos, de la Universidad de Las Américas, Quito. Este estudio tuvo como objetivo general determinar las posibilidades de desarrollar un colorante natural a base de saúco negro dentro de la industria de alimentos. El diseño del estudio es experimental, a través de diferentes muestras durante las encuestas para determinar la aceptación del colorante en cuanto a sabor y color. Además, un breve análisis del potencial del producto en distintos mercados internacionales. Se concluyó que el colorante de saúco negro en base de agua es elegido por su sabor, en cuanto a su presentación en base de etanol es elegida por su color. Como recomendación final el autor invita a realizar su modelo de negocio y promueve la investigación de colorantes naturales dentro de la industria alimentaria, especialmente en el sector confitería. 
Mendoza et al. (2017) en el artículo: “Antocianinas totales y parámetros de color en líneas de maíz morado", publicada en la Revista Fitotecnia Mexicana volumen 40 de la Sociedad Mexicana de Fitogenética, México. La finalidad de esta investigación experimental fue de identificar el potencial de las antocianinas caracterizadas por sus parámetros de color, también determinar que grano y líneas de cultivo del maíz morado sean de mayor élite para su uso en el programa de mejoramiento genético. Dentro de la escala de colores que el grano de maíz morado puede proporcionar son 5: azul oscuro, rojo, morado azuloso, morado rojizo y morado intenso, cada uno proveniente de una línea de cultivo diferente. Entre las conclusiones más resaltantes hay tres. Primero, que los granos con mayor frecuencia de cada categoría de color son morado intenso y morado rojizo. Segundo, existe una línea de color que va desde el rojo al amarillo, de baja saturación, baja intensidad, apagados y oscuros. Tercero, dependiendo de la intensidad del color en el grano se encontraron altos rendimientos de antocianina; por ende, existe una correlación positiva.

Bonilla y Guamán (2019) en su investigación: “Comparación del mercado de carmín de cochinilla entre Ecuador y Perú y su potencial de comercialización hacia la Unión Europea”, tesis para obtener el título de Ingenieros en Comercio Exterior y Negociación Internacional, de la Universidad de las Fuerzas Armadas - ESPE, Sangolquí. El objetivo principal de esta tesis es identificar las buenas prácticas que aplica Perú en la producción y exportación de carmín de cochinilla y los requerimientos que Ecuador debe cumplir para consolidar su oferta exportable del producto, además de investigar los factores que potencien su participación en el mercado europeo. Estadísticamente, Perú supera a Ecuador en las exportaciones de carmín de cochinilla de manera exuberante. Según los datos recabados de Trade Map del 2013 al 2017 Ecuador exportó 4, 392 miles de dólares valor FOB, frente a 
Perú cuyo valor fue de 127, 870 miles de dólares. Esta investigación es no experimental de tipo descriptivo. La conclusión de esta investigación es que Perú tiene la infraestructura y tecnología necesaria para poder procesar la materia prima y hacer industria; y no solo ello, sino que Ecuador no llega a cubrir los estándares de calidad ni posee las características que tiene el carmín de cochinilla peruano.

Tabla 2

Antecedentes internacionales vinculados al estudio (continuación). 


\begin{tabular}{|c|c|c|c|c|c|c|c|}
\hline Título & Variable & $\begin{array}{c}\text { Tipo de } \\
\text { Documento }\end{array}$ & Autor & $\begin{array}{c}\text { Universidad } \\
\text { /Entidad }\end{array}$ & Diseño & Fuente & Aporte de Tesis \\
\hline $\begin{array}{l}\text { Efecto del proceso de } \\
\text { fritura en el contenido } \\
\text { de antocianinas en } \\
\text { empanadas } \\
\text { elaboradas con } \\
\text { mezclas de harina de } \\
\text { trigo - maíz morado }\end{array}$ & $\begin{array}{l}\text { - Exportaciones } \\
\text { de colorante de } \\
\text { maíz morado. } \\
\text { - Factor: Boom } \\
\text { saludable. }\end{array}$ & $\begin{array}{l}\text { Tesis de } \\
\text { Pregrado }\end{array}$ & $\begin{array}{l}\text { Ana Lizano } \\
(2012)\end{array}$ & $\begin{array}{l}\text { Universidad } \\
\text { San } \\
\text { Francisco de } \\
\text { Quito }\end{array}$ & Mixta & $\begin{array}{l}\text { Repositorio } \\
\text { USFQ }\end{array}$ & $\begin{array}{l}\text { La autora en su tesis hace mención de los } \\
\text { altos valores nutricionales que contiene } \\
\text { el maíz morado y el potencial que tiene } \\
\text { para ser utilizado como colorante debido } \\
\text { a su alto nivel de antioxidantes. El valor } \\
\text { agregado que aporta este producto } \\
\text { despierta el interés en la industria de } \\
\text { alimentos. Asimismo, una de las } \\
\text { conclusiones de su investigación es el } \\
\text { nivel favorable de aceptación que tiene } \\
\text { el consumidor con respecto al producto. }\end{array}$ \\
\hline $\begin{array}{l}\text { Las antocianinas } \\
\text { como colorantes } \\
\text { naturales } \\
\text { compuestos } \\
\text { bioactivos: Revisión }\end{array}$ & $\begin{array}{l}\text { - Colorante de } \\
\text { maíz morado. } \\
\text { - Factor: Boom } \\
\text { saludable. }\end{array}$ & $\begin{array}{l}\text { Artículo de } \\
\text { investigación }\end{array}$ & $\begin{array}{l}\text { Gloria } \\
\text { Garzón } \\
(2008)\end{array}$ & $\begin{array}{l}\text { Universidad } \\
\text { Nacional de } \\
\text { Colombia }\end{array}$ & Cuantitativa & $\begin{array}{l}\text { Acta } \\
\text { Biológica } \\
\text { Colombiana }\end{array}$ & $\begin{array}{l}\text { El articulo hace referencia al aumento de } \\
\text { la demanda por los colorantes naturales } \\
\text { provenientes de frutas, vegetales y } \\
\text { cereales, esto debido a estudio que } \\
\text { corroboran lo perjudicial que pueden } \\
\text { llegar a ser los colorantes artificiales } \\
\text { para la salud, así como también los } \\
\text { beneficios que presentan los colorantes } \\
\text { naturales para ciertas enfermedades. }\end{array}$ \\
\hline $\begin{array}{l}\text { Desarrollo de un } \\
\text { colorante natural } \\
\text { desde el fruto del } \\
\text { saúco negro para uso } \\
\text { en la industria } \\
\text { alimentaria }\end{array}$ & $\begin{array}{l}\text { - Colorante de } \\
\text { maíz morado. } \\
\text { - } \quad \text { Factores: } \\
\text { Competitividad } \\
\text { y } \quad \text { Boom } \\
\text { Saludable. }\end{array}$ & $\begin{array}{ll}\text { Tesis de } \\
\text { Pregrado }\end{array}$ & $\begin{array}{l}\text { Nicolás } \\
\text { Aguirre } \\
(2018)\end{array}$ & $\begin{array}{l}\text { Universidad } \\
\text { de Las } \\
\text { Américas }\end{array}$ & Cuantitativa & $\begin{array}{l}\text { Repositorio } \\
\text { UDLA }\end{array}$ & $\begin{array}{l}\text { La presente tesis investiga sobre un } \\
\text { colorante natural extraído del sauco } \\
\text { debido a los beneficios de los colorantes } \\
\text { naturales y las consecuencias que trae } \\
\text { para la salud el consumo de colorantes } \\
\text { artificiales. Adicionalmente, hace } \\
\text { mención del gran nivel de aceptación } \\
\text { que tendría el producto en distintos } \\
\text { mercados internacionales. }\end{array}$ \\
\hline
\end{tabular}




\begin{tabular}{|c|c|c|c|c|c|c|c|}
\hline $\begin{array}{l}\text { Antocianinas totales } \\
\text { y parámetros de color } \\
\text { en líneas de maíz } \\
\text { morado }\end{array}$ & $\begin{array}{l}\text { - Colorante de } \\
\text { maíz morado. }\end{array}$ & $\begin{array}{l}\text { Artículo de } \\
\text { investigación }\end{array}$ & $\begin{array}{l}\text { Gabriela } \\
\text { Mendoza, } \\
\text { María del } \\
\text { Carmen } \\
\text { Mendoza, } \\
\text { Adriana } \\
\text { Delgado, } \\
\text { Fernando } \\
\text { Castillo, et. } \\
\text { al. (2017) }\end{array}$ & $\begin{array}{l}\text { Sociedad } \\
\text { Mexicana de } \\
\text { Fitogenética }\end{array}$ & Cuantitativa & $\begin{array}{l}\text { Revista } \\
\text { Fitotecnia } \\
\text { Mexicana }\end{array}$ & $\begin{array}{l}\text { El articulo explica sobre el maíz morado, } \\
\text { la cantidad de antocianina que se puede } \\
\text { extraer del maíz morado, la variedad de } \\
\text { colores que se pueden obtener de este al } \\
\text { transformar la antocianina en colorante. } \\
\text { Así como también, las variedades de } \\
\text { maíz morado de los cuales se puede } \\
\text { obtener un colorante de mayor elite. }\end{array}$ \\
\hline $\begin{array}{l}\text { Comparación del } \\
\text { mercado de carmín de } \\
\text { cochinilla entre } \\
\text { Ecuador y Perú y su } \\
\text { potencial de } \\
\text { comercialización } \\
\text { hacia la Unión } \\
\text { Europea }\end{array}$ & 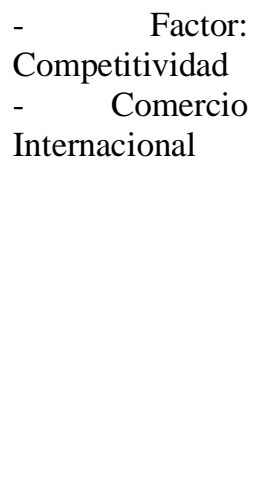 & $\begin{array}{ll}\text { Tesis de } \\
\text { Pregrado }\end{array}$ & $\begin{array}{l}\text { Victor } \\
\text { Bonilla y } \\
\text { Jessica } \\
\text { Guamán } \\
(2019)\end{array}$ & $\begin{array}{l}\text { Universidad } \\
\text { de las } \\
\text { Fuerzas } \\
\text { Armadas - } \\
\text { ESPE }\end{array}$ & Cuantitativa & $\begin{array}{l}\text { Repositorio } \\
\text { Dspace }\end{array}$ & $\begin{array}{l}\text { Los autores en su tesis hacen la } \\
\text { comparación entre Ecuador y Perú con } \\
\text { respecto al potencial que tiene Perú en } \\
\text { infraestructura y tecnología para } \\
\text { procesar la materia prima y crear } \\
\text { industria en el rubro de los colorantes } \\
\text { como el de cochinilla y exportarlo a } \\
\text { diferentes países. Asimismo, hace } \\
\text { mención a las buenas prácticas que } \\
\text { aplica Perú para que el producto pueda } \\
\text { cumplir con los estándares del mercado } \\
\text { internacional. }\end{array}$ \\
\hline
\end{tabular}

Nota: Se ha elaborado una tabla de antecedentes internacionales relacionados al tema de investigación de la presente tesis. Elaboración propia. 


\subsubsection{Marco teórico.}

\subsubsection{Información del producto.}

\subsection{Origen y distribución del maíz morado.}

El maíz morado es un conjunto de variedades de Zea mays L. que tienen una fruta morada (infrutescencia). Crecen en los Andes de Perú, Bolivia y Argentina, dispersos y cultivados también en las costas del territorio peruano mucho antes que los incas (Sevilla y Valdez 1985). Desde la época precolombina, es el cereal más importante como alimento básico, como originario de las Américas. En Perú, el maíz morado se desarrolla entre 1.200 y más de 4.000 metros sobre el nivel del mar con muchos contrastes debido a los variados microclimas que ocurren en los Andes (Sevilla y Valdez 1985).

\subsection{Beneficios del maíz morado gracias a la antocianina.}

El consumo de maíz morado está indirectamente asociado con beneficios para la salud, debido a la presencia de compuestos antioxidantes, que retrasan el daño causado por los radicales libres con actividad anticancerígena, anti neurodegenerativa y antiinflamatoria (Kraft 2008).

Estudios médicos han demostrado que pacientes con arteroesclerosis presentan contenidos bajos de antioxidantes al compararlos con individuos sanos (Durak et al. 2001), (Ching et al. 2002) encontraron que, al incrementar los niveles de antioxidantes en la sangre, los riesgos de presentar cáncer de mama se ven disminuidos, (Olsson et al. 2004) evaluaron el efecto de antocianinas, como la cianidina-3-O-glucósido, la proliferación de células de cáncer de colon y de mama, encontrando actividad anticancerígena (Joseph et al. 2003) encontraron que el consumo de suplementos antioxidantes revierte los efectos degenerativos 
del envejecimiento. Una gran variedad de fotoquímicos es responsable de estos beneficios del maíz morado, entre ellos los compuestos fenólicos. Un equipo de investigación de la universidad japonesa Doshisha, Kyoto, comprobó que el extracto de maíz morado incrementa la actividad de un gen que regula la función de las células grasas el cual previene las enfermedades cardiacas, obesidad y diabetes. Asimismo, según la revista Nutraceuticals World, es un protector de la retina y estimulador de la circulación sanguínea (Risco 2007).

\subsection{Derivados del maíz morado.}

Según los datos recopilados por varios historiadores, se sabe que el maíz morado se usó en los alimentos como bebidas, con lo que se hizo la "chicha" que se convierte en una bebida fermentada. El uso de su extracto sufrió un cambio a lo largo del tiempo, así es como en la colonia, debido a la influencia de los pasteles españoles y al ingenio de las amas de casa criollas, apareció la "mazamorra" y la "chicha morada" sabores más exquisitos (Fernández 1995).

Actualmente, además de los productos anteriormente mencionados, se puede obtener harina, lo que da pie a una amplia variedad de productos que se pueden elaborar reemplazando la harina de trigo por la harina de maíz morado, por ejemplo: panteón, brownies, pan, kekes, alfajores, galletas, entre otros. Por otro lado, el maíz morado contiene antocianina, que es un tipo de flavonoide complejo, es un pigmento procesado y purificado que se obtiene de granos, polvo y principalmente de la corona. (Araujo 1995). Asimismo, la antocianina es utilizada para hacer yogur y como colorante natural para distintos alimentos (Salinas et al. 2005). 
En la industria de la moda, la antocianina del maíz morado es utilizada para obtener distintos tonos de color que sirven como colorante para tejidos. Finalmente, debido a la gran variedad de beneficios que posee para la salud, esta también puede ser utilizada en el rubro farmacéutico en la elaboración de píldoras, complementos y suplementos naturales nutricionales.

\subsection{Colorante de maíz morado.}

El maíz morado contiene seis importantes antocianinas: pelargonidina-3-O- $\beta$ Dglucósido, peonidina-3-O- $\beta$-D-glucósido, cianidina-3-O- $\beta$-D-(6- malonilglucósido), pelargonidina-3-O- $\beta$-D-(6- malonilglucósido) y peonidina-3-O- $\beta$-D-(6- malonilglucósido) las que dan el color característico a esta especie vegetal (Aoki et al. 2002). Siendo la cianidina la que se encuentra en mayor proporción y la que es un importante antioxidante (Rafael, 2017).

Su composición incluye antocianinas, un pigmento natural muy necesario en la industria alimentaria, que en los últimos años ha generado un gran interés, especialmente en los países desarrollados, donde el uso de colorantes artificiales o sintéticos está restringido (Sevilla y Valdez 1985).

a. Propiedades: Se ha demostrado, que la antocianina del Maíz morado tiene muchas propiedades medicinales que son muy beneficiosas para el ser humano, por ejemplo: favorecer la regeneración de tejidos, prever enfermedades cardiovasculares, retardar los 38 procesos degenerativos en general, posee acción antiarrugas, incrementa el flujo sanguíneo y estimula la acción diurética (Justiniano, 2010). 
Asimismo, a las antocianinas también se les atribuye las siguientes actividades antioxidantes: reducción de la enfermedad coronaria, efectos anticancerígenos, antitumorales, antiinflamatorios y antidiabéticos; además del mejoramiento de la agudeza visual y del comportamiento cognitivo (Aguilera et al, 2011).

b. Potencial: Según Rafael (2017) podemos rescatar el gran potencial que posee el colorante de maíz morado, ya que, reporta que la cáscara del maíz morado contiene aproximadamente 10 veces más antocianinas que otras plantas, siendo más frecuentes encontrarlas en flores y frutos, estas estructuras son las que contribuyen a los brillantes colores rojos, azules y morados de estos tejidos vegetales. Asimismo, otro factor que contribuye al potencial industrial del colorante de maíz morado es que la cáscara del maíz morado contiene $10 \%$ de antocianinas.

El maíz morado se utiliza como alimento y colorante desde tiempos ancestrales, y se caracteriza por presentar dentro de su estructura química de las semillas y las corontas, antocianinas del tipo cianidina-3- $\beta$-glucósido, pelargonidina-3-glucósido, y peonidina-3-Oglucósido a nivel de coronta con bajos contenidos de sólidos solubles, lo que facilita su uso a nivel industrial (Rafael, 2017).

Finalmente, estos pigmentos representan una opción para el reemplazo competitivo de colorantes sintéticos en alimentos, productos farmacéuticos y cosméticos, y para la obtención de productos con valor agregado dirigidos al consumo humano. El colorante de maíz morado es reconocido por la Unión Europea con el Código E-163 y, también, con el mismo Código, por la Legislación Japonesa (MINAGRI, 2017). 
c. Demanda: El aumento de la demanda de este producto con el paso de los años se debe básicamente a los consumidores, ya que se ha mostrado un aumento progresivo en el consumo de productos que contengan colorantes naturales en lugar de colorantes sintéticos. La tendencia al consumo de lo natural es cada vez más fuerte y el uso de ellos es considerado un atributo de calidad del producto (Carmona, 2013).

Gracias a un estudio realizado por la Universidad de Southampton que fue solicitado por la FSA del Reino Unido (Food Standards Agency), el cual tuvo como objetivo verificar el efecto de la mezcla de seis colorantes sintéticos con benzoato sódico, usado frecuentemente como preservante en bebidas refrescantes y en otros productos consumidos por niños, la decisión de los fabricantes de aditivos de producir colorantes naturales para la industria alimentaria se vio acelerada pues el resultado concluyó que la hiperactividad infantil se podría ver aumentada por el uso de la mezcla anteriormente mencionada. Analistas confirman que este estudio ha acelerado la tendencia hacia el uso de colorantes naturales en Europa y otros mercados, ya que la demanda de los consumidores por formulaciones más naturales aumenta y los principales productores y distribuidores minoristas buscan eliminar gradualmente los ingredientes sintéticos (Carmona, 2013).

Siguiendo con lo que detalla Carmona en su reporte científico "De colorantes sintéticos a naturales en la industria alimentaria" (2013), los principales compradores de colorantes naturales son países europeos, EE.UU. y Japón. Se estima que la demanda por los colorantes naturales crezca anualmente en un $4.3 \%$ y que este aumento esté dado por el aumento del consumo de alimentos procesados y congelados, especialmente en Asia Pacífico y América Latina. Así como también, su uso en nuevas aplicaciones como alimentos horneados, dulces, cervezas y otras bebidas alcohólicas ayudaría a dicho aumento. 
d. Empresas: Debido a la creciente demanda por los colorantes naturales, con el paso de los años las empresas productoras y exportadoras de colorante de maíz morado han ido en aumento. Las principales empresas que se dedican a la exportación de colorantes para la elaboración de productos alimenticios, entre ellos el de maíz morado, en el 2019 son: Sensient Natural Colors Peru S.A.C., PRONEX S.A.

\subsection{Comercialización de colorante de maíz morado en Estados Unidos: evolución y principales empresas exportadoras.}

En los últimos años se ha visto cómo la comercialización del colorante de maíz morado ha evolucionado de manera positiva tanto en valor FOB como en peso, ello se puede observar en la tabla $\mathrm{N}^{\circ} 1$.

Tabla 3

Exportaciones de colorante de maíz morado desde el 2015 al 2019.

\begin{tabular}{llllll}
\hline & 2015 & 2016 & 2017 & 2018 & 2019 \\
\hline PESO & & & & & \\
NETO Total & 13,939 & 13,996 & 10,128 & 21,616 & 13,451 \\
\hline
\end{tabular}

FOB Total \$1,244,267 \$1,746,078 \$1,192,675 \$1,608,395 ;869,268

Fuente: Sunat.

En la tabla $\mathrm{N}^{\circ} 2$ se puede observar la variedad de empresas exportadoras de colorante de maíz morado que han entrado al mercado entre el 2015 y 2019, existen empresas que se mantienen durante el periodo, como también existen nuevas empresas que ingresan debido a la oportunidad de mercado que ha comenzado a ofrecer este producto. 
Tabla 4

Empresas que exportan colorante de maíz morado a Estados Unidos periodo 2015 -2019.

\begin{tabular}{lcccccc}
\hline $\begin{array}{c}\text { Empresas que exportan a Estados } \\
\text { Unidos }\end{array}$ & $\mathbf{2 0 1 5}$ & $\mathbf{2 0 1 6}$ & $\mathbf{2 0 1 7}$ & $\mathbf{2 0 1 8}$ & $\mathbf{2 0 1 9}$ & TOTAL \\
\hline $\begin{array}{l}\text { PRODUCTOS NATURALES DE } \\
\text { EXPORTACION S.A. - PRONEX }\end{array}$ & 774,438 & 728,500 & 347,200 & 341,000 & 409,200 & $\mathbf{2 , 6 0 0 , 3 3 8}$ \\
S.A. & & & & & & \\
$\quad$ GLOBENATURAL & 436,000 & 629,830 & 575,000 & 198,000 & - & $\mathbf{1 , 8 3 8 , 8 3 0}$ \\
INTERNACIONAL S.A. & & - & - & 652,000 & 269,000 & $\mathbf{9 2 1 , 0 0 0}$ \\
$\quad$ SENSIENT NATURAL COLORS & - & - & - & - & - & $\mathbf{2 9 , 7 1 4}$ \\
PERU S.A.C. & - & - & 29,714 & - & - & $\mathbf{1 1 , 6 0 9}$ \\
$\quad$ INVERSIONES 2A S.A.C. & 11,609 & - & - & - & - & $\mathbf{6 , 9 6 0}$ \\
$\quad$ INSPECTION \& QUALITY & - & - & - & 6,960 & - & $\mathbf{1 , 8 1 9}$ \\
TOTAL SERVICES S.A.C. & 526 & - & 900 & 33 & 360 & $\mathbf{1 , 6 0 0}$ \\
$\quad$ FRUTEX PERU S.A.C & - & - & - & 1,600 & - & $\mathbf{1 , 4 5 0}$ \\
$\quad$ MEGABUSINESS PERU S.A.C. & - & - & 540 & 540 & 370 & \\
$\quad$ FRUTAROM PERU S.A. & & & & &
\end{tabular}

Fuente: Sunat.

\subsection{PENX: Plan Estratégico Nacional Exportador.}

Los esfuerzos del gobierno peruano por impulsar a las empresas para realizar actividades de comercio exterior reflejado en sus pilares y objetivos, permite presumir que un factor que ayudó al incremento de empresas exportadoras de colorante de maíz morado entre los años 2015 y 2019, es el apoyo que se le brinda a las empresas peruanas por internacionalizarse.

\subsection{PDM: Estados Unidos.}

Dentro del PDM a Estados Unidos no incluye el sector del colorante de maíz morado específicamente o de colorantes en general, lo que existe es un apartado que menciona a los alimentos orgánicos que va dirigido al producto en materia prima y no a los aditivos naturales que otorgan valor agregado a los alimentos. Por tanto, se deduce que no existe un esfuerzo por parte del gobierno peruano por impulsar la comercialización de colorante de maíz morado a Estados Unidos. 


\subsubsection{Antecedentes de las variables.}

\subsection{Historia del comercio exterior en Perú.}

El Perú comenzó su apertura comercial en los años 90 la cual se ha consolidado como una política de estado que ha permitido aprovechar los recursos naturales del país e ir fortaleciendo otros bienes y servicios producidos en el país para colocarlos en el extranjero (MINCETUR, 2019).

El comercio exterior en el Perú ha ido mejorando con el paso de los años. Si bien es cierto en los años 90 el Perú comienza a consolidarse en el mercado extranjero, todo comenzó en 1973 cuando se creó la fundación ADEX, que hasta los años ochenta se consolidó como fundación enfocada al comercio exterior, creando así también el instituto ADEX. Luego en los años 90, se formó una zona de libre comercio entre los países miembros de la CAN, adicionalmente, Perú se integró al APEC (El Comercio, 2019).

Desde ese entonces, el Perú se ha enfocado en fomentar el comercio exterior, como, por ejemplo: promulgando la ley de promoción agraria y con nuevos tratados como el TLC con Estados Unidos, China y Unión Europea. Estas estrategias han funcionado de tal manera que en el 2018 se registró un récord de exportaciones de US\$ 47 mil 956 millones 398 (El Comercio, 2019).

\subsection{PENX: Plan Estratégico Nacional Exportador.}

El PENX por sus siglas en español significa "Plan Estratégico Nacional Exportador", este plan comprende una serie de esfuerzos y objetivos y se considera un horizonte de 10 años. La anterior versión comprendía del 2003-2013 y su objetivo principal era "desarrollar agresivamente el comercio exterior en base al esfuerzo conjunto del Estado y al sector 
privado, para incrementar y diversificar nuestra oferta exportable y lograr una inserción competitiva en los mercados internacionales"; es decir, un enfoque más a una planificación conjunta entre el sector público y privado en el Perú (MINCETUR, 2015).

No obstante, la nueva versión PENX 2025, tiene como foco principal el sector comercio exterior, específicamente las empresas debido a que estás son las que generan empleo, producen y exportan. Es por ello que sus objetivos estratégicos se pueden definir como: (i) profundizar la internacionalización de empresas; (ii) incrementar de manera sostenible y diversificada las exportaciones de bienes y servicios con valor agregado; y (iii) mejorar la competitividad del sector exportador (MINCETUR, n.d).

Asimismo, enlazado con los objetivos, el PENX 2025 establece cuatro pilares estratégicos que sirven como marco de referencia para el gobierno peruano de tomar acción, estos pilares son:

- Pilar I: Internacionalización de la empresa y diversificación de mercados, motivar a las empresas peruanas de participar en las economías de otros países para la diversificación de mercados y productos con el fin de tomar mayor ventaja de las mejores condiciones de oferta.

- Pilar II: Oferta exportable diversificada, competitiva y sostenible, consolida las exportaciones peruanas, especialmente las exportaciones no tradicionales y de servicios.

- Pilar III: Facilitación del comercio exterior y eficiencia de la cadena logística internacional, el objetivo es poder reducir los costos de transacción asociados a las operaciones de comercio exterior, incluyendo aspectos normativos y procedimentales, así como también logísticos y financieros. 
- Pilar IV: Generación de capacidades para la internacionalización y consolidación de una cultura exportadora, se espera que fortalezca las capacidades empresariales exportadoras que consoliden nuevos mercados, productos y/o servicios diversificados.

\subsection{PDM: Estados Unidos.}

Los Planes de Desarrollo de Mercados o PDM son herramientas que comprenden información relevante del mercado internacional a desarrollar. Sus objetivos son los de ampliar, diversificar y consolidar la presencia de los bienes y servicios peruanos. De igual manera, el PDM promueve la internacionalización en los principales mercados del exterior, especialmente para aprovechar la apertura comercial, en el marco de la implementación del Plan Estratégico Nacional Exportador, PENX 2025 (Suárez, 2018).

El PDM relevante para esta investigación es al de Estados Unidos, en dicho plan se abarcan temas como: (i) información general de Estados Unidos; (ii) indicadores macroeconómicos; (iii) cultura de negocios; (iv) intercambio comercial Perú - Estados Unidos; (v) acuerdos comerciales y regulaciones de importaciones; (vi) distribución y transporte de mercancías; (vii) canales de comercialización; (viii) tendencias del consumidor y características del mercado; (ix) priorización de productos; (x) oportunidades comerciales para productos peruanos; (xi) plan de acción; y (xii) principales ferias (MINCETUR, 2015).

Dentro del PDM a Estados Unidos no incluye el sector del colorante de maíz morado específicamente o de colorantes en general, lo que existe es un apartado que menciona a los alimentos orgánicos que va dirigido al producto en materia prima y no a los aditivos naturales que otorgan valor agregado a los alimentos. 


\subsection{Historia de la FDA en Estados Unidos.}

La Administración de Alimentos y Medicamentos es la agencia de protección al consumidor más antigua del gobierno federal de Estados Unidos. Las regulaciones del gobierno comenzaron en 1848; sin embargo, en 1930 es que se comenzó a conocer a la agencia con su nombre actual. Dicho esto, las primeras regulaciones en 1906 se enfocaron en el comercio interestatal, comenzando por la prohibición del comercio de alimentos y droga adulterada y mal etiquetadas. Desde entonces la FDA ha ido cambiando y adaptándose junto con los cambios sociales, políticos y legales por los que ha pasado Estados Unidos a lo largo del tiempo (FDA, 2018).

Un ejemplo de los cambios en las regulaciones fueron las que se implementaron luego del atentado del 11 de setiembre del 2001. A manera de prevención de un posible ataque bioterrorista, la FDA aumentó la rigurosidad en los alimentos tanto como los que se producían como los que ingresaban al país. Se modificó la legislación como barrera paraarancelaria y como medida para vigilar las importaciones, así como también se aplicaron medidas para controlar a los empleados, los suministros y la cadena de distribución de los alimentos y medicamentos para descartar la presencia de ántrax y toxinas botulínicas (Secilio, 2005).

\subsubsection{Definición de términos básicos.}

\subsection{Maíz morado y Antocianina.}

Según la revista PURPLE CORN FACT SHEET (2017), el maíz morado, es el maíz de tipo amiláceo que tiene pigmentos de antocianina distribuidos en la planta. Se caracteriza por presentar mazorcas con coronta o marlo fuertemente pigmentadas de color morado tanto externamente como en su interior y sus granos tienen el pericarpio de color morado (p.2). 
La antocianina del maíz morado es un tipo de flavonoide complejo. Es un pigmento procesado y purificado que se obtiene de granos, polvo y principalmente de la corona. (Araujo 1995).

\subsection{Valor Agregado.}

La manera más simple de enunciar el concepto de valor agregado se obtiene al señalar que se trata de aquel que se añade a un producto, bien o servicio, en el proceso, cada vez que se produce (Daniels et al, 2018).

\subsection{Colorantes.}

La FDA (2004) define un colorante como cualquier tinte, pigmento o sustancia que, cuando se agrega o aplica a un alimento, medicamento o cosmético, o al cuerpo humano, es capaz (solo o mediante reacciones con otras sustancias) de impartir color. Dependiendo de su procedencia estos pueden ser naturales o artificiales.

\subsection{Factores.}

Según la RAE se definen estas palabras de la siguiente manera:

- Factor: Elemento o causa que actúan junto con otros.

Asimismo, factores de éxito, según Lopez, C. desde el punto de vista administrativo, significa:

"Los factores claves de éxito son los elementos que le permiten al empresario alcanzar los objetivos que se ha trazado y distinguen a la empresa de la competencia haciéndola única" (Lopez, 2002) 


\subsection{Competitividad.}

Si se recurre a la Real Academia Española, competitividad se puede definir como la capacidad de un país para competir eficazmente con la oferta extranjera de bienes y servicios en los mercados domésticos y extranjero.

De igual manera, según Urrutia este término se define como la capacidad de responder ventajosamente en los mercados internacionales, de acuerdo con esto se entiende la importancia de obtener ventajas competitivas para ingresar a mercados externos que permitan desarrollar la productividad del país, sectores y empresa.

\subsection{Comercialización.}

Según la RAE, la palabra comercialización se define como: "Acción y efecto de comercializar". Asimismo, comercializar significa: "dar a un producto condiciones y vías de distribución para su venta." (RAE, 2014).

\subsection{Comercio Exterior.}

El comercio exterior consiste en un intercambio ordinario, generalmente de productos a cambio de dinero, con la característica diferencial de que para poder realizar el intercambio se ha de atravesar una "frontera" (límite geográfico que delimita el área de cada país). Cada estado puede controlar su comercio exterior facilitando mediante la reducción o exoneración de aranceles gracias a los tratados de libre comercio, como también pueden obstaculizarlo mediante el pago de impuestos, controles sanitarios estrictos, distintas legislaciones fiscales, entre otros (Bustillo, 2000). 


\subsection{Exportación.}

La palabra exportar tiene origen etimológico en el latín como exportāre, cuya definición según la Real Academia Española (RAE) es vender géneros a otro país. Por ende, exportación se puede definir como el acto y efecto de exportar.

Como actividad del comercio internacional, la exportación es la venta servicios o bienes producidos por una empresa en un país a clientes que residen en un país diferente al de origen (Daniels et al, 2018).

Por último, desde punto de vista Aduanero, la exportación es un régimen aduanero por el cual, se permite la salida del territorio aduanero de las mercancías nacionales o nacionalizadas para su uso o consumo definitivo en el exterior. Para ello la transferencia de bienes debe efectuarse a un cliente domiciliado en el extranjero (SUNAT, 2008).

\subsection{FDA: Food and Drug Administration.}

La Administración de Alimentos y Medicamentos es una agencia que pertenece al departamento de salud y servicios humanos. Esta agencia tiene como misión proteger la salud pública garantizando la seguridad y eficacia de los medicamentos humanos y veterinarios, productos biológicos y dispositivos médicos; y garantizando la seguridad del suministro de alimentos, cosméticos y productos que emiten radiación en Estados Unidos. Así como también, regular los productos que contienen tabaco, apoyar en acelerar las innovaciones en los productos médicos para mejorar la salud pública; y de garantizar el suministro de alimentos a la población y fomentar el desarrollo de productos médicos ante cualquier evento terrorista (FDA, 2018). 


\subsubsection{Bases teóricas.}

\subsection{Enfoques de la competitividad.}

Ibañéz y Troncoso (2001) detallan en su libro Algunas teorías e instrumentos para el análisis de la competitividad que existen distintas perspectivas de como analizar la competitividad, actualmente se evalúan en tres niveles que son macro, meso y micro.

En el enfoque Macro se encuentran todos los factores conceptualizados para estudiar la competitividad de un país, región o economía nacional y se pueden analizar tres enfoques o teorías de distintos autores como el Diamante de Porter en donde plantea cuatro atributos genéricos que forman parte del entorno como son las condiciones de los factores, condiciones de la demanda, sectores afines y de apoyo, estrategia, estructura y rivalidad de las empresas.
a. Condiciones de los factores
b. Condiciones de la demanda
c. Sectores conexos y relacionados
d. Estrategia estructura

Bajo este mismo enfoque, se tiene el modelo del Informe Mundial de Competitividad (IMC), basándose en ocho factores que se miden en función a 378 indicadores, estos son:
a. El vigor de la economía
b. La Internacionalización
c. Gobierno
d. Finanzas
e. Gestión empresarial 
f. Ciencia y tecnología

g. Recursos humanos

Asimismo, otro enfoque es el evolucionista de la OCDE, en donde los factores de la competitividad pueden basarse en factores básicos, avanzados y especializados.

a. Factores básicos

b. Factores Avanzados

c. Factores especializados

Por otro lado, dentro del nivel intermedio (Meso), los autores consideran el modelo de las cinco fuerzas de Michael Porter, en donde realiza una investigación en el Enfoque de planificación de la estrategia corporativa planteado en 1980 en su libro Competitive Strategy: Techniques for Analyzing Industries and Competitors, en el que se explican las cinco fuerzas que establecen las consecuencias de rentabilidad a largo plazo de un mercado o de algún segmento de éste. Además, precisó que el modelo comprendía:

a. El poder de negociación de los proveedores

b. El poder de negociación de los compradores

c. La amenaza de productos sustitutos

d. La amenaza de entrada de nuevos competidores

e. La rivalidad de los competidores 


\subsection{Teorías de libre comercio.}

- Teoría de base exportadora:

Según Amstrong (1978), la base exportadora es una de las teorías que brinda más herramientas que generan un diseño de estrategias y de políticas de desarrollo regional, es de las más aceptadas por los investigadores abocados al análisis de la economía regional. En otras palabras, constituye el argumento algebraico de la teoría de la exportación principal, cuyo propósito central fue de determinar el impulso para el desarrollo de una región al exterior, y de su capacidad interna para reaccionar a él (p. 35).

La lógica del argumento en su momento fue el interés que para muchos gobiernos tuvo el desarrollo de una cesta exportable de algodón, trigo, pieles, tomate, petróleo, etc, que les hizo diseñar un conjunto de estrategias para producir esos bienes en áreas determinadas, y que tomaron la forma de patrones de asentamientos, urbanización e infraestructura que en conjunto facilitarían el proceso de producción y su movilización hacia los lugares donde sería exportado.

La economía regional se organizó en torno a un conjunto de empresas ligadas a la exportación, a las que se denominó básicas y otras correlacionadas tanto a ellas como al

mercado interno, llamadas domésticas. Así, en el producto interno bruto (PIB) regional influirían dos grandes estructuras de producción, cuya síntesis es la siguiente:

$$
\mathrm{PBI}=\mathrm{BE}+\mathrm{BD}
$$

PBI: Producto Bruto interno

BE: Base Exportadora (exportaciones) 
BD: Base Domestica (economía interna o importaciones)

La expresión anterior, si bien a grosso modo indica la manera en que se estructura el PIB regional y lo importante de los ingresos por exportación, no dice nada sobre su influencia en el desarrollo regional. Para ello, la base exportadora como punto de partida toma el multiplicador de Keynes, cuya expresión algebraica, es la siguiente:

(Nowlan, 2006, pág. 1-6)

\section{$\mathrm{Y}=\mathrm{C}+\mathrm{I}+\mathrm{G}-\mathrm{T}+\mathrm{X}-\mathrm{M}$}

Donde $\mathrm{Y}$ es el ingreso regional, $\mathrm{C}$ el consumo, I la inversión, G el gasto del gobierno central en la región, $\mathrm{T}$ los impuestos que recaba el gobierno central, $\mathrm{X}$ las exportaciones y M las importaciones. En la ecuación anterior, las variables que en un momento determinado representarían las fugas para la región serían los saldos que resulten de G-T y X-M.

Si en ambos son positivos ( $\mathrm{G}>\mathrm{T}$ y $\mathrm{X}>\mathrm{M})$, esto significa que: $\mathrm{G}$ siendo el gasto público, sea mayor a los impuestos de gobierno habrá mayores ingresos - lo mismo si las exportaciones son mayores que las importaciones. Al cumplirse este enunciado, la región estaría recibiendo más recursos del resto del mundo que viceversa.

Ahora bien, si en muchas regiones sus sistemas de información son insuficientes para medir la magnitud de las fugas, una forma indirecta de hacerlo sería a través del coeficiente de especialización. Éste compara el porcentaje de empleo en una actividad i, en la región j, con el del empleo en esa actividad i en el país, y asume que para satisfacer las necesidades locales se requiere un movimiento económico industrial proporcional al nacional. Así, en las industrias cuyo valor del coeficiente sea $>1$ se consideran superavitarias y cuando sean $<1$, deficitarias. Las primeras constituyen las fortalezas y no deben descuidarse; en tanto que las 
segundas muestran las debilidades y, por tanto, deben atenderse para reducir las fugas de importación. Si más de la mitad de los sectores de una región tiene valores superiores a 1, su estructura económica se considerará diversificada, de lo contrario será mono dependiente.

Una vez aplicado el coeficiente de especialización a todos los sectores, se podrá evaluar su desempeño económico, que de antemano estará en función de los que tengan coeficientes con valores superiores a 1, a lo que Rodrik (2006, 10-23) añadiría que al interior de ellos el coeficiente de Gini muestre un valor que tienda a 0 , y en lo posible, que el nivel medio de ingresos de la cesta de productos exportables corresponda al de una región con percepciones superiores.

Como toda teoría, la base exportadora tiene debilidades, una de ellas es supeditar el crecimiento regional a los factores externos o, como diría Tamayo (2000, 2-4), no considerar las limitantes que le podría imponer al crecimiento la escasez de insumos fundamentales o la competitividad necesaria que requiere del sector doméstico, e incluso que en un momento determinado el mercado interno puede ser más importante que el mero énfasis en las exportaciones. Sin embargo, ello no debe minimizar la lógica del argumento ni subestimar las fugas, como tampoco la importancia de una estructura de diversificación, cuya cesta de productos esté orientada hacia los mercados de ingresos altos.

\section{- Nueva teoría del comercio:}

Hill en su libro "Negocios Internacionales" (2015) menciona dentro del capítulo de Teorías del Comercio Internacional a "La nueva teoría del comercio", esta se consideró en la década de 1970 cuando varios economistas señalaron que la capacidad de las empresas de alcanzar economías de escala tendría implicaciones importantes para el comercio 
internacional. En primer lugar, se debe definir las economías de escala, estas son reducciones a los costos unitarios que se obtienen con grandes volúmenes de producción; proceden de varias fuentes, como de la capacidad de distribuir los costos fijos en un volumen cuantioso o la de los grandes productores de recurrir a trabajadores y equipo especializados más productivos que los empleados y equipos menos especializados. Es por ello que las economías de escala son una causa importante en la reducción de costos de muchos sectores, desde productos del sector farmacéutico hasta el sector aeroespacial o desde lo orgánico a lo sintético en el sector alimentario.

- Modelo de innovación:

La teoría de Modelo de Innovación se refiere a que existe una relación directa entre la innovación y la internacionalización, esta consiste en asumir la decisión de una organización de aumentar su compromiso internacional a la de desarrollar innovaciones con un sentido amplio. Las decisiones para la internacionalización e innovación son determinaciones creativas y deliberadas que se desarrollan dentro de los límites impuestos por las capacidades internas del negocio y el mercado, estas son tomadas bajo condiciones de incertidumbre, por ello a los directivos que toman las decisiones se les asigna un papel protagónico en la promoción del proceso (Alonso y Donoso, 1998).

Para Cavusgil (1980) la internacionalización es un proceso de innovación empresarial que es básico para lograr la internacionalización de medianas y pequeñas empresas. Para este modelo se destaca el carácter acumulativo de las decisiones tomadas tanto en el proceso de expansión como en el de innovación, estas decisiones se encuentran condicionadas por las que se tomaron en el pasado y a su vez condiciona las que se tomarán en el futuro. 
En general, el modelo propone las siguientes etapas de desarrollo de la actividad internacional de una empresa:

1. Mercado doméstico.

2. Pre exportadora.

3. Exportadora experimental.

4. Exportadora activa.

5. Exportadora comprometida.

- Teoría de ventajas comparativas:

Para entender esta teoría se debe tener en cuenta la "Teoría de Ventaja Absoluta", la cual contrasta con la "Teoría de Ventajas Comparativas". La teoría de Smith analizó lo que sucedería si un país tuviera una ventaja absoluta en la producción de todos los bienes, el resultado es que no obtendría ventaja del comercio internacional. En su libro de 1817 Principios de política económica, David Ricardo mostró que eso no ocurriría. De acuerdo con su teoría de la ventaja comparativa, es conveniente que un país se especialice en los bienes que produce con mayor eficiencia y compre a otros lo que produce menos eficientemente, aunque ello implique comprar a otras naciones bienes que él mismo podría generar con más eficiencia (Hill, 2015).

- Modelo de economía abierta:

Una economía abierta es aquella que posee relaciones con el resto del mundo, lo cual implica la existencia de una demanda tanto por exportaciones como por importaciones. Los países son cada vez más interdependientes en temas de relaciones económicas, lo cual se 
refleja en las cifras del intercambio de bienes y servicios, y también de activos financieros entre las economías. El análisis de estas relaciones es dividido en dos áreas: el comercio y las finanzas internacionales. Primero, se hablará del intercambio comercial (exportaciones e importaciones) y las razones que sustentan este intercambio, para luego analizar la parte financiera (balanza de pagos, tipos de cambio).

Según Carrasco (2002), el comercio internacional significa una fuente de aumento en el bienestar del país. En otras palabras, es posible abarcar más allá de la frontera de posibilidades máximas de producción, permite la cooperación entre países y poder obtener con la misma cantidad de recursos y tecnología una canasta de consumo mayor. Se puede reasignar recursos de manera más eficiente, lo cual implica que los países tienden a la especialización.

Se especializan en la producción de aquellos bienes que permiten mejorar la asignación de recursos con respecto a la situación cuando no había comercio internacional, esto incentiva aún más el comercio, como consecuencia cada país desarrolla una actividad económica más rentable.

Conforme los países se especializan se da una división del trabajo en el país. Esta división internacional del trabajo implica a su vez que se profundice la especialización, y que se concentren los procesos productivos en fabricar ciertos bienes con el fin de intercambiarlos, y de ese modo todos los países tengan una mayor cantidad de bienes. Esta tendencia la podemos observar alrededor del mundo, ya que por ejemplo existen países desarrollados que producen bienes manufacturados o industriales, los cuales emplean relativamente poca mano 
de obra, también podemos observar otras economías que tienen procesos productivos que son intensivos en el uso del trabajo, tal es el caso de las economías de América Latina.

De esa manera, el comercio internacional, a través del aumento en las exportaciones e importaciones, genera un incremento en el nivel de producción del ingreso y de ese modo promueve el desarrollo económico, dando como resultado el bienestar de la población.

El comercio internacional impulsa el desarrollo económico cuando el país reasigna recursos de manera más eficiente, es decir busca los procesos productivos que permiten producir los bienes a menor costo, y cuando los países producen a precios más bajos se dice que explotan sus ventajas comparativas.

La ventaja comparativa se da cuando se puede producir un bien con un costo menor comparado con el resto del mundo. Si los países producen los bienes con meta comparativa entonces el mantenimiento de estas ventajas facilita un mayor desarrollo económico.

- Principales razones que justifican la existencia del comercio internacional como teoría:

El comercio internacional hace referencia a una interacción entre mercados que están separados, y este tipo de relaciones no están integradas en otras ramas de la economía. En un país existe un gran número de mercados que interactúan simultáneamente para determinar la cantidad a producir y los precios. Aun así, los mercados pueden estar separados, por distintos motivos, ya sea geográficos, monetarios, culturales, entre otros.

Para efectos de la teoría del comercio internacional se delimita el concepto de mercado por la movilidad de los factores de producción, principalmente del factor trabajo. Se colocan 
límites a la movilidad de los factores, pues no pueden ir libremente de un lugar a otro, pero no a la movilidad de los bienes los cuales sí pueden ser trasladados de un sitio a otro.

Las principales razones para la existencia del comercio internacional como una teoría parte de las siguientes:

a. La diferencia que se da entre la movilidad de recursos entre los países y la alta movilidad que tienen los factores dentro del mismo país.

b. El ambiente sociopolítico difiere en gran medida de un país a otro, mientras que en el mismo país tiende a ser más uniforme. Esto se da como consecuencia de que en un país se comparten las mismas costumbres, leyes, etc.

c. Los mercados están separados.

d. Los problemas que analiza la teoría del comercio internacional son diferentes a los que señalan otras teorías. En comercio internacional se requiere del análisis del equilibrio general y no parcial.

\subsection{Requisitos FDA para entrada de colorantes a Estados Unidos.}

El colorante de maíz morado si bien es cierto encaja con la descripción de la categoría "Colorantes exentos de certificación", debido a que estos colorantes se obtienen principalmente de una fuente vegetal. En realidad, se debe considerar como "Colorante sujeto a certificación" porque el producto no se encuentra en la lista estipulada en el reglamento título 21 CFR parte 73.1 (FDA, 2019).

La categoría colorante sujeto a certificación cuentan con un orden para su nombre oficial en la FDA. Por lo general, tienen nombres de tres partes: un prefijo como FD\&C (alimentos, 
medicamentos y cosméticos) dependiendo de su uso en distintos sectores, un color y un número (FDA, 2019). Del maíz morado se puede extraer distinta gama de colores siendo el más común el Rojo No. 40; es por ello que se define este producto como aditivo de color (Mendoza et al., 2017).

Según el Código Electrónico de Regulaciones Federales de la FDA (2020), los requisitos necesarios para los aditivos de color son:

a. Identidad: Este se debe detallar minuciosamente qué es, cuáles son sus componentes naturales y/o químicos, y proceso de extracción del colorante. De igual manera, se debe mencionar en qué casos es adecuado diluir el colorante cuyo listado se encuentra nuevamente en la parte 73 del título 21 del reglamento de la FDA.

b. Especificaciones: En caso del colorante de maíz morado debe cumplir con ciertas especificaciones y debe estar libre de impurezas que no sean las mencionadas en las reglamentaciones promulgadas en virtud de la sección 408 de la Ley Federal de Alimentos, Medicamentos y Cosméticos.

c. Usos y restricciones: El colorante en cuestión puede ser utilizado para tintar alimentos, incluidos los suplementos para diabéticos, en cantidades consistentes con las buenas prácticas de fabricación. Evidentemente tiene ciertas restricciones especificadas en la sección 401 de la ley.

d. Etiquetado: Las normas de etiquetado para los aditivos de color se encuentran en la $\$ 70.25$ de la parte 73 título 21 , las cuales son: 
- El nombre del color directo o el nombre de cada ingrediente que comprende el colorante si se trata de una mezcla.

- Una declaración que indique las limitaciones generales para el uso del aditivo de color, por ejemplo "solo para uso alimentario".

- Cuando las regulaciones emitidas imponen limitaciones cuantitativas para un uso general o específico de un color liso, la cantidad de cada color liso en términos de peso por unidad / volumen o porcentaje en peso.

- Una fecha de vencimiento.

e. Certificación: Todo el proceso para la certificación de la FDA el cual se especifica paso a paso en la parte 80 título $21:$

- Solicitud de Certificación.

- Muestras para acompañar las solicitudes.

- Certificación, el comisionario determinará si cumple con los requisitos necesarios y también realizar las investigaciones que considere pertinentes.

- Limitaciones del certificado.

- Autoridad para rechazar el servicio de certificación.

- Mezclas de aditivos de color; certificación y exención de certificación.

- Tratamiento de lote pendiente de certificación.

- Tratamiento del lote después de la certificación.

- Registros de distribución.

\subsection{Ley de la Oferta y la Demanda.}

La oferta y la demanda son de las fuerzas que hacen que el mercado funcione, estas determinan la cantidad que se produce cada bien y el precio al que se vende. Todo ello es 
posible debido a que ambas fuerzas interactúan en los mercados; para aclarar, se entiende por mercado a toda institución social en la que los bienes y servicios se intercambian (Burneo \& Larios, 2015).

Compradores y vendedores se ponen de acuerdo sobre el precio de un bien o servicio, de manera que coordinan las decisiones de los productores y consumidores en el mercado. A grandes rasgos se puede decir que cuando hay precios bajos, se estimula el consumo pero desaniman la producción; por el contrario, cuando los precios son altos desanima el consumo y estimulan la producción (Alfaro, González \& Pina, 2013).

La demanda está relacionada con lo que los consumidores desean adquirir, en otras palabras, refleja la intención de comprar y la compra es la acción. Por otro lado, la oferta se relaciona con los términos en los que las empresas desean producir y vender sus productos; es decir, recoge las intenciones de venta de los productos y vender es realmente hacerlo (Alfaro, González \& Pina, 2013).

Cuando se menciona la "Ley de la Oferta y la Demanda" existen tres términos importantes a definir: la ley de la demanda, la ley de la oferta y el equilibrio del mercado. En primer lugar, la ley de la demanda se refiere a la relación inversa que existe entre precio y cantidad, en el sentido que, cuando se reduce el precio, aumenta la cantidad demandada, mientras que, cuando el precio aumenta, la cantidad demandada disminuye. En segundo lugar, la ley de la oferta expresa la relación directa que existe entre precio y cantidad ofrecida, cuando el precio aumenta, la cantidad ofrecida también se incrementa, y viceversa (Burneo \& Larios, 2015). Por último, el equilibrio del mercado es, como el nombre lo indica, encontrar un equilibrio entre los planes de consumo del consumidor y los de producción de los productores. Un 
precio arbitrario no logra que los planes de demanda y oferta coincidan, es por ello que se busca un punto de corte entre las curvas de la oferta y demanda donde un precio y cantidad pueda propiciar un pleno acuerdo entre productores y consumidores, más conocido como el "punto de equilibrio" o en palabras comunes "el punto donde no se gana ni se pierde" (Alfaro, González \& Pina, 2013).

\subsection{Tendencia "Estilo de Vida Saludable".}

Según un estudio de Google (2016), se ha podido demostrar que actualmente existe una nueva tendencia en el consumidor por llevar un estilo de vida saludable. Prueba de esto es que entre el 2013 y el 2015 se duplicó el número de búsquedas para "comida saludable".

Yendo más allá de la comida, se puede notar que existe un cambio en los hábitos de consumo de las personas, por ejemplo: el "quiero saber", en el que buscan diversas alternativas de comida saludable, y de cómo llevar un estilo de vida fitness. Luego tenemos el "quiero ir", en el que buscan alternativas de lugares que promuevan una atmósfera saludable como lo son los hoteles ecológicos y los restaurantes orgánicos. Después se encuentra el momento "quiero hacer", momento que es aprovechado por distintas marcas y los ahora conocidos como "creadores de contenido" quienes aprovechan esta oportunidad publicando tutoriales de recetas o rutinas de ejercicio. Finalmente está el momento más importante al que llega el consumidor que es el "quiero comprar" (Google, 2016).

Según las consultoras Nielsen y Kantar se puede confirmar el auge de este fenómeno debido a que, en América Latina, el 17\% de la canasta familiar corresponde a productos saludables, con países como Brasil, Chile y México creciendo a una tasa superior al 8\% anual en esa categoría. En Argentina, 7 de cada 10 personas reconocen un "alto nivel de 
preocupación" por su salud y bienestar, con un 31\% poniendo especial énfasis en la alimentación. Asimismo, según Renata Segovia, Solutions Manager de Kantar Worldpanel, se trata de una tendencia global con impacto en toda la región que involucra "modificar hábitos alimenticios", con familias de ingresos elevados y medios, así como parejas con pocos hijos y alto nivel educativo encabezando la tendencia (Google, 2016). Con respecto al mercado peruano, según una encuesta de Datum, el 68\% de los encuestados asocia el llevar una vida saludable con comer sano y un $58 \%$ con hacer deporte; sin embargo, la mayoría aún piensa que mantener un estilo de vida saludable es difícil (Villanueva y Yrala, 2018).

Actualmente, distintas marcas internacionales como Nestlé y Unilever están aprovechando esta tendencia complementándose con los recursos tecnológicos para generar contenido y ofrecer al consumidor productos que vayan acorde al nuevo estilo de vida que están adoptando.

\subsection{Objetivos e hipótesis.}

\subsubsection{Objetivo General.}

Determinar la relación de los factores asociados a la comercialización del colorante de maíz morado en la industria alimentaria y las exportaciones a Estados Unidos durante el periodo $2015-2019$.

\subsubsection{Objetivos específicos.}

a. Analizar la relación significativa entre la comercialización del colorante de maíz morado y el apoyo del gobierno peruano en fomentar las exportaciones del producto.

b. Analizar la relación significativa entre la comercialización del colorante maíz morado y la competitividad entre empresas de productos orgánicos en EEUU. 
c. Analizar la relación significativa entre la comercialización del colorante de maíz morado y la tendencia por el consumo de productos saludables.

\subsection{Hipótesis.}

\subsubsection{Hipótesis General.}

Los factores asociados a la comercialización del colorante de maíz morado y las exportaciones a Estados Unidos tienen una relación significativa durante el periodo 20152019.

\subsubsection{Hipótesis Específicas.}

a. La comercialización del colorante de maíz morado tiene relación significativa con el apoyo del gobierno peruano en fomentar las exportaciones del producto.

b. La comercialización del colorante de maíz morado tiene relación significativa con la competitividad entre empresas de productos orgánicos en EE.UU.

c. La comercialización del colorante de maíz morado tiene relación significativa con la tendencia por el consumo de productos saludables. 


\section{Capítulo II}

\subsection{Método}

\subsubsection{Tipo de investigación.}

La presente investigación será de tipo cuantitativa. Segun Sarduy (2007), la investigación cuantitativa se dedica a recoger, procesar y analizar datos cuantitativos o numéricos sobre variables previamente determinadas. Este tipo de investigación va más allá de un simple listado de resultados ya que estos se presentan en un informe final el cual va acorde a las variables establecidas al principio y mostrando como resultados una realidad específica a la cual están sujetas estas variables. Dicho esto, se aplicará un cuestionario compuesto de 23 preguntas dirigido a gerentes generales, del área de exportaciones, operaciones y/o logística, siendo en total de 30 encuestados. Las respuestas de las encuestas serán procesadas con el software SPSS para determinar si las hipótesis son aceptadas o no.

\subsubsection{Diseño de investigación.}

Para probar las hipótesis planteadas en esta investigación se utilizará un diseño no experimental, enfoque transversal y alcance descriptivo y correlacional. Para analizar ello, se realizarán encuestas a los funcionarios pertinentes de las empresas que exporten colorante de maíz morado en la industria alimentaria a Estados Unidos del 2015 al 2019. A continuación, la definición del método seleccionado:

Diseño: no experimental cuantitativa y transversal: Según Arbaiza (2014) “en los diseños no experimentales no se realiza un control de las variables para estudiar un comportamiento específico, pues la premisa es que las variables independientes ya se presentaron y, por tanto, sus efectos ya ocurrieron", este diseño aplica a esta investigación donde se analizarán los 
factores asociados a la comercialización de colorante de maíz morado y las exportaciones a Estado Unidos, hechos que ya ocurrieron. Añadiendo a ello, es una investigación con un enfoque transversal porque la información es recabada en un tiempo único (Hernández et al., 2014); en caso de esta tesis el periodo donde se medirán las dimensiones de exportaciones es del 2015 al 2019.

Alcance: descriptivo y correlacional: De acuerdo con Bernal (2010), mencionado por Arbaiza en 2014, es un estudio de nivel descriptivo porque se "expone las características, las propiedades y los rasgos determinantes y particulares de una situación o de un grupo mediante la observación y la reseña de sus componentes".

Asimismo, este es un estudio correlacional debido a que se genera una relación entre dos o más variables en un tiempo determinado (Hernández et al., 2014). En la presente tesis se quiere demostrar que existe una relación entre los factores asociados a la comercialización de colorante de maíz morado en la industria alimentaria y las exportaciones a Estados Unidos.

\subsubsection{Variables.}

Se considerarán las siguientes variables para la investigación cuantitativa:

- Factores asociados a la comercialización de colorante de maíz morado: apoyo del gobierno peruano a los exportadores, competitividad y tendencias saludables.

- Exportaciones a Estados Unidos periodo 2015 - 2019. 
Tabla 5

Matriz de Operacionalización.

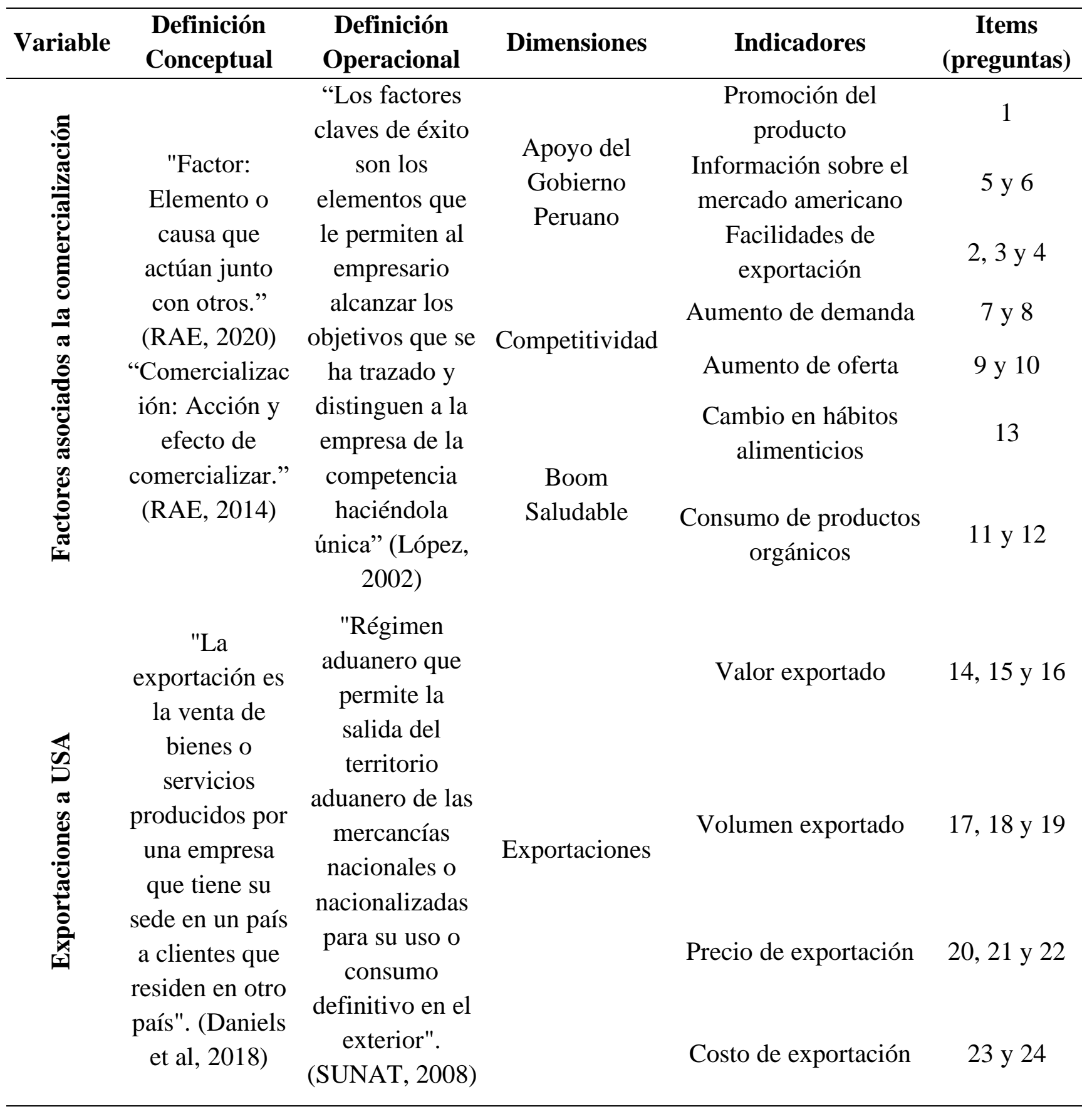

Nota: Matriz de Operacionalización de las variables de factores de éxito y exportación a Estados Unidos para el desarrollo de la guía de pautas y la encuesta. Adaptado de "Elaboración propia". 


\subsubsection{Muestra.}

McClave, Benson y Sincich (2008, referido por Robles, 2019) afirman que "una población es un conjunto de unidades usualmente personas, objetos, transacciones o eventos; en los que estamos interesados en estudiar". Para esta investigación la población está conformada por las 7 empresas que exportan colorante de maíz morado a Estados Unidos del 2015 al 2019.

Por otro lado, la muestra se define como "subconjunto de la población del cual se recolectan los datos y debe ser representativo de ésta” (Hernández et al., 2014). Para efectos de esta investigación el tipo de muestra es censal, debido a que, según Hernández citado por Castro (2003), "si la población es menor o igual a cincuenta (50) individuos, la población es igual a la muestra". Adicional a ello, Hayes (1999) afirmó que este tipo de método se utiliza cuando es necesario saber las opiniones de todos los participantes de la investigación. Es por ello, que nuestra muestra serán las 7 empresas que exportan colorante de maíz morado a Estados Unidos.

Tabla 6

Participación de mercado de las empresas exportadoras de colorante de maíz morado a Estados Unidos 2019.

\begin{tabular}{lrr}
\hline \multicolumn{1}{c}{ Empresas exportadoras a Estados Unidos 2019 } & $\begin{array}{l}\text { Valor } \\
\text { FOB }\end{array}$ & \% PART. \\
\hline PRODUCTOS NATURALES DE EXPORTACION & 409,200 & $60.27 \%$ \\
S.A. - PRONEX S.A. & & \\
SENSIENT NATURAL COLORS PERU S.A.C. & 269,000 & $39.62 \%$ \\
ZOWI PERU SOCIEDAD ANONIMA CERRADA & 370 & $0.05 \%$
\end{tabular}




Total general $\quad 678,930 \quad 100.00 \%$

Fuente: Sunat.

De igual manera, el muestreo de esta investigación es no probabilístico, lo cual significa que "la selección de los sujetos a estudio dependerá de ciertas características, criterios, etc. que el investigador considere en ese momento" (Otzen y Manterola, 2017). Para efectos de esta tesis se han seleccionado las empresas que comercializan colorantes de maíz morado al mercado estadounidense y en base a nuestro criterio eran más accesibles para obtener soporte con el llenado de cuestionarios. Asimismo, se tomará en cuenta el "Teorema central del límite" el cual determina como regla general que se puede utilizar como tamaño muestral un mínimo 30 objetos de investigación (Quintela del Rio, 2019). En consecuencia, en esta investigación la muestra estará compuesta por 30 funcionarios, quienes serán los gerentes generales, del área de exportaciones, operaciones y/o logística de cada una de las empresas referidas a la comercialización de colorante de maíz morado a Estados Unidos.

\subsubsection{Instrumentos de investigación.}

El instrumento a utilizar para la presente investigación será un cuestionario con preguntas cerradas, para el cual se empleará la escala de tipo Likert, pues esta según Hernández (2014) permite asumir que los ítems o afirmaciones miden la actitud de la persona hacia un único concepto subyacente. 


\subsubsection{Procedimientos de recolección de datos.}

Se realizarán encuestas con las empresas mencionadas con anterioridad, serán de manera virtual enviando el cuestionario por correo electrónico y LinkedIn. Los datos obtenidos se procesarán por el software estadístico SPSS, previamente mencionado. 


\section{Capítulo III}

\subsection{Resultados.}

\subsubsection{Presentación de resultados.}

\subsubsection{Análisis de resultados de las encuestas.}

- Pregunta 1: El estado peruano promociona el producto a los diversos mercados internacionales.

Tabla 7

Pregunta 1.

\begin{tabular}{lrrrr}
\hline & Frecuencia & Porcentaje & $\begin{array}{c}\text { Porcentaje } \\
\text { válido }\end{array}$ & $\begin{array}{c}\text { Porcentaje } \\
\text { acumulado }\end{array}$ \\
\hline En desacuerdo & 15 & 50,0 & 50,0 & 50,0 \\
Ni de acuerdo ni en desacuerdo & 6 & 20,0 & 20,0 & 70,0 \\
De acuerdo & 7 & 23,3 & 23,3 & 93,3 \\
Muy de acuerdo & 2 & 6,7 & 6,7 & 100,0 \\
\hline Total & 30 & 100,0 & 100,0 & \\
\hline
\end{tabular}

Nota: Resultado de la pregunta 1: El estado peruano promociona el producto a los diversos mercados internacionales. Adaptado de "Encuesta de colorante de maíz morado", por fuente propia, 2020. 


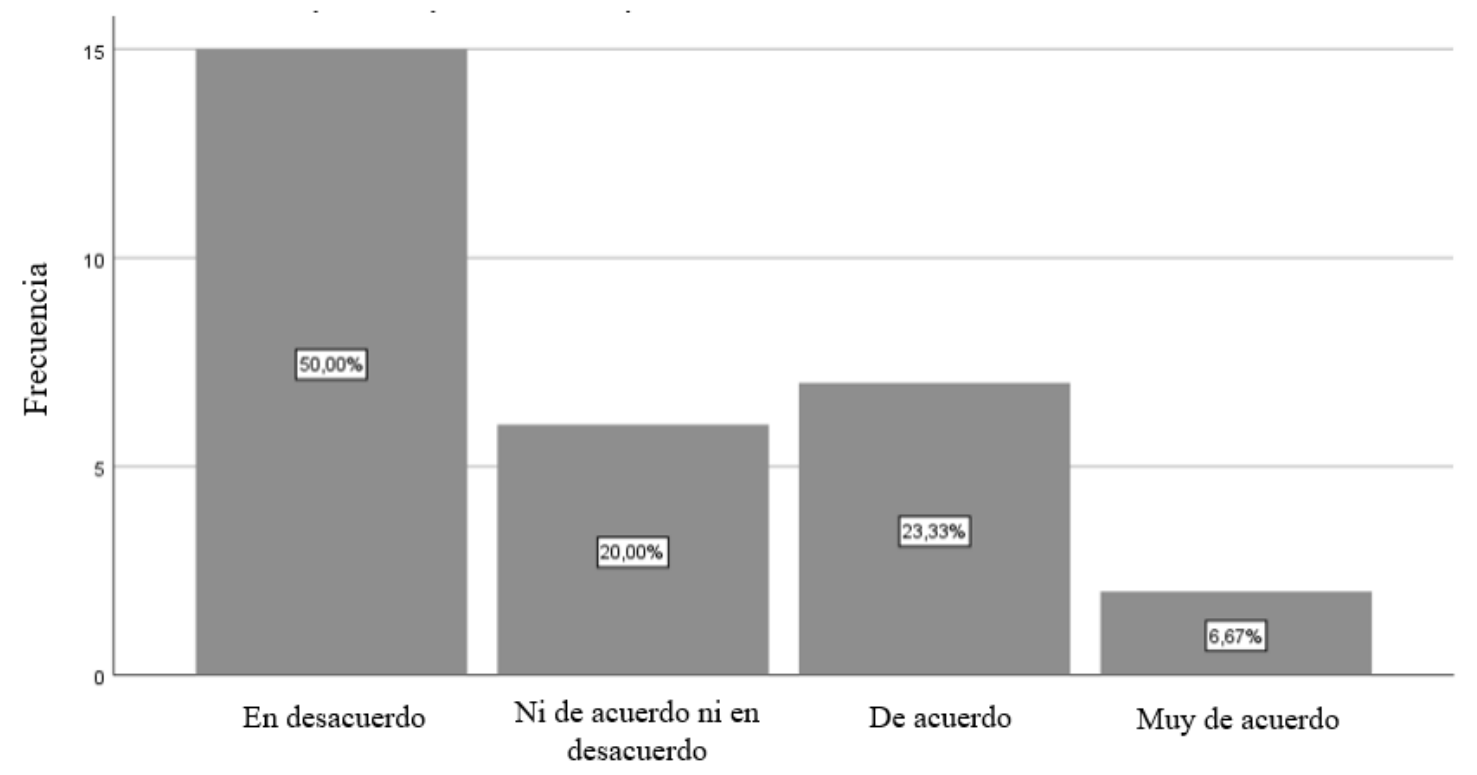

Figura 1

El estado peruano promociona el producto a los diversos mercados internacionales. Adaptado de "Encuesta de colorante de maíz morado”, por fuente propia, 2020.

Interpretación:

Se observa que la mitad de los encuestados (50\%) indicaron estar en desacuerdo con que el estado peruano promociona el colorante de maíz morado a los diversos mercados internacionales. Mientras que sólo 7 encuestados (23.3\%) están de acuerdo y 2 muy de acuerdo (6.7\%) con la afirmación.

- Pregunta 2: El estado le brinda herramientas que le faciliten la exportación del producto.

Tabla 8

Pregunta 2.

\begin{tabular}{lrrrr}
\hline & Frecuencia & Porcentaje & $\begin{array}{c}\text { Porcentaje } \\
\text { válido }\end{array}$ & $\begin{array}{r}\text { Porcentaje } \\
\text { acumulado }\end{array}$ \\
\hline Muy en desacuerdo & 2 & 6,7 & 6,7 & 6,7 \\
En desacuerdo & 17 & 56,7 & 56,7 & 63,3
\end{tabular}




\begin{tabular}{lrrrr} 
Ni de acuerdo ni en desacuerdo & 9 & 30,0 & 30,0 & 93,3 \\
De acuerdo & 2 & 6,7 & 6,7 & 100,0 \\
\hline Total & 30 & 100,0 & 100,0 & \\
\hline
\end{tabular}

Nota: Resultado de la pregunta 2: El estado le brinda herramientas que le faciliten la exportación del producto. Adaptado de "Encuesta de colorante de maíz morado", por fuente propia, 2020.

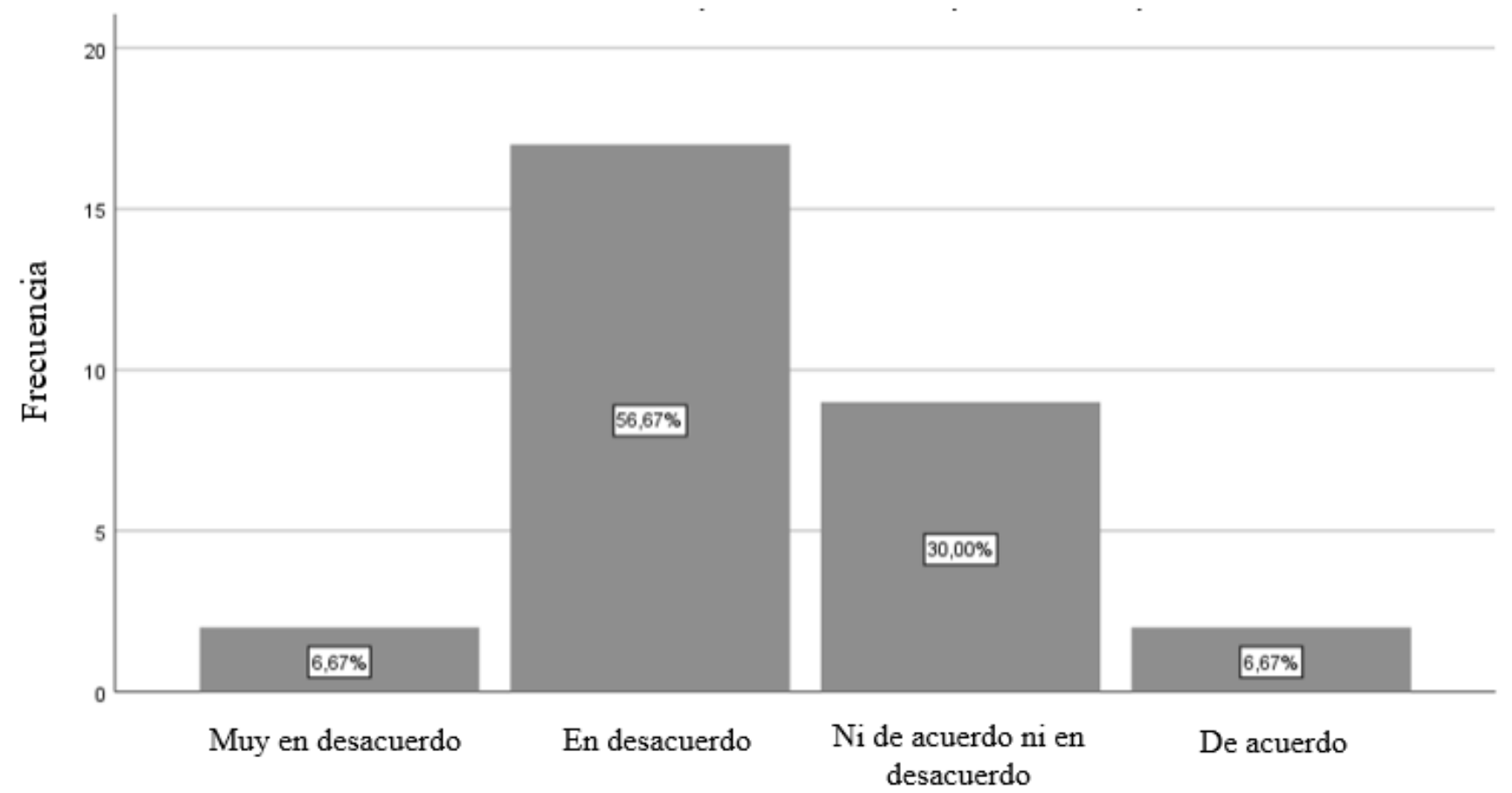

Figura 2

El estado le brinda herramientas que le faciliten la exportación del producto. Adaptado de “Encuesta de colorante de maíz morado”, por fuente propia, 2020.

Interpretación:

Con respecto a esta afirmación, la mayoría de encuestados respondieron estar muy en desacuerdo (6.7\%) o en desacuerdo (56.7\%), con lo cual nos indica que ellos no perciben que el estado les brinde herramientas que le faciliten la exportación del colorante de maíz morado. Además, un 30\% de encuestados no se encuentra ni de acuerdo ni en desacuerdo con la afirmación planteada. 
- Pregunta 3: El Plan Estratégico Nacional Exportador (PENX) no aporta positivamente al volumen exportado durante el periodo mencionado.

Tabla 9

Pregunta 3.

\begin{tabular}{lrrrr}
\hline & Frecuencia & Porcentaje & $\begin{array}{c}\text { Porcentaje } \\
\text { válido }\end{array}$ & $\begin{array}{c}\text { Porcentaje } \\
\text { acumulado }\end{array}$ \\
\hline En desacuerdo & 7 & 23,3 & 23,3 & 23,3 \\
Ni de acuerdo ni en desacuerdo & 13 & 43,3 & 43,3 & 66,7 \\
De acuerdo & 10 & 33,3 & 33,3 & 100,0 \\
\hline Total & 30 & 100,0 & 100,0 & \\
\hline
\end{tabular}

Nota: Resultado de la pregunta 3: El Plan Estratégico Nacional Exportador (PENX) no aporta positivamente al volumen exportado durante el periodo mencionado. Adaptado de "Encuesta de colorante de maíz morado", por fuente propia, 2020.

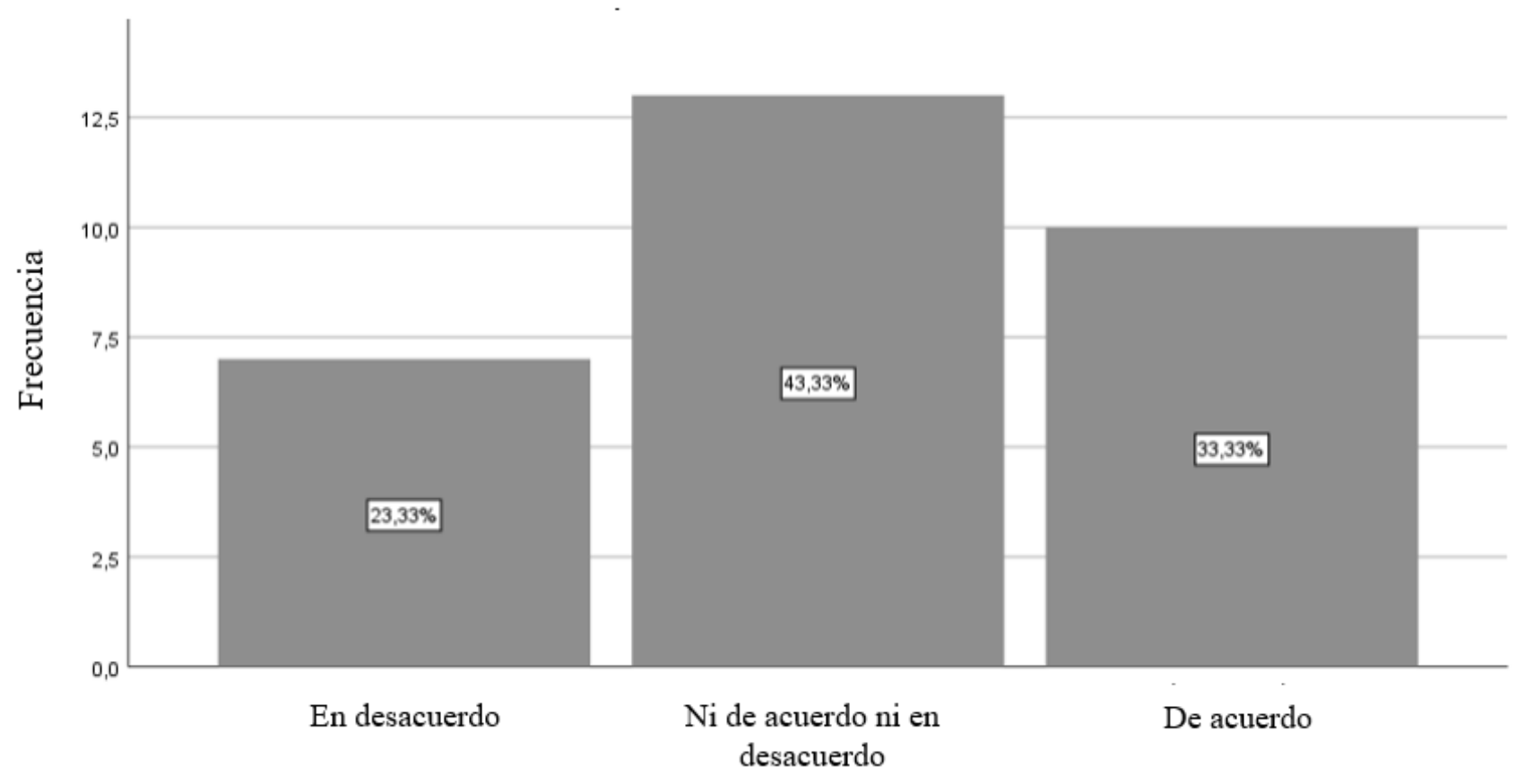


Figura 3

El Plan Estratégico Nacional Exportador (PENX) no aporta positivamente al volumen exportado durante el periodo mencionado. Adaptado de "Encuesta de colorante de maíz morado", por fuente propia, 2020.

Interpretación:

A pesar de que la mayoría de encuestados (43.3\%) respondió que no está ni de acuerdo ni en desacuerdo, el siguiente mayor porcentaje de respuesta fue que estaban de acuerdo (33.3\%). Por ende, se puede afirmar que el Plan Estratégico Nacional Exportador (PENX) no aporta positivamente al volumen exportado durante el periodo 2015 - 2019.

- Pregunta 4: Si usted importa algún insumo para la elaboración del colorante de maíz morado (materia prima, envasado y/o empaquetado), percibe algún beneficio tributario por parte del Estado peruano. Ejemplo: Acogerse bajo el régimen Drawback o de reposición de mercancías con franquicia arancelaria.

Tabla 10

Pregunta 4.

\begin{tabular}{lrrrr}
\hline & Frecuencia & Porcentaje & $\begin{array}{c}\text { Porcentaje } \\
\text { válido }\end{array}$ & $\begin{array}{c}\text { Porcentaje } \\
\text { acumulado }\end{array}$ \\
\hline Muy en desacuerdo & 9 & 30,0 & 30,0 & 30,0 \\
En desacuerdo & 13 & 43,3 & 43,3 & 73,3 \\
Ni de acuerdo ni en desacuerdo & 5 & 16,7 & 16,7 & 90,0 \\
De acuerdo & 2 & 6,7 & 6,7 & 96,7 \\
Muy de acuerdo & 1 & 3,3 & 3,3 & 100,0 \\
\hline Total & 30 & 100,0 & 100,0 & \\
\hline
\end{tabular}


Nota: Resultado de la pregunta 4: Si usted importa algún insumo para la elaboración del colorante de maíz morado (materia prima, envasado y/o empaquetado), percibe algún beneficio tributario por parte del Estado peruano. Adaptado de "Encuesta de colorante de maíz morado", por fuente propia, 2020.

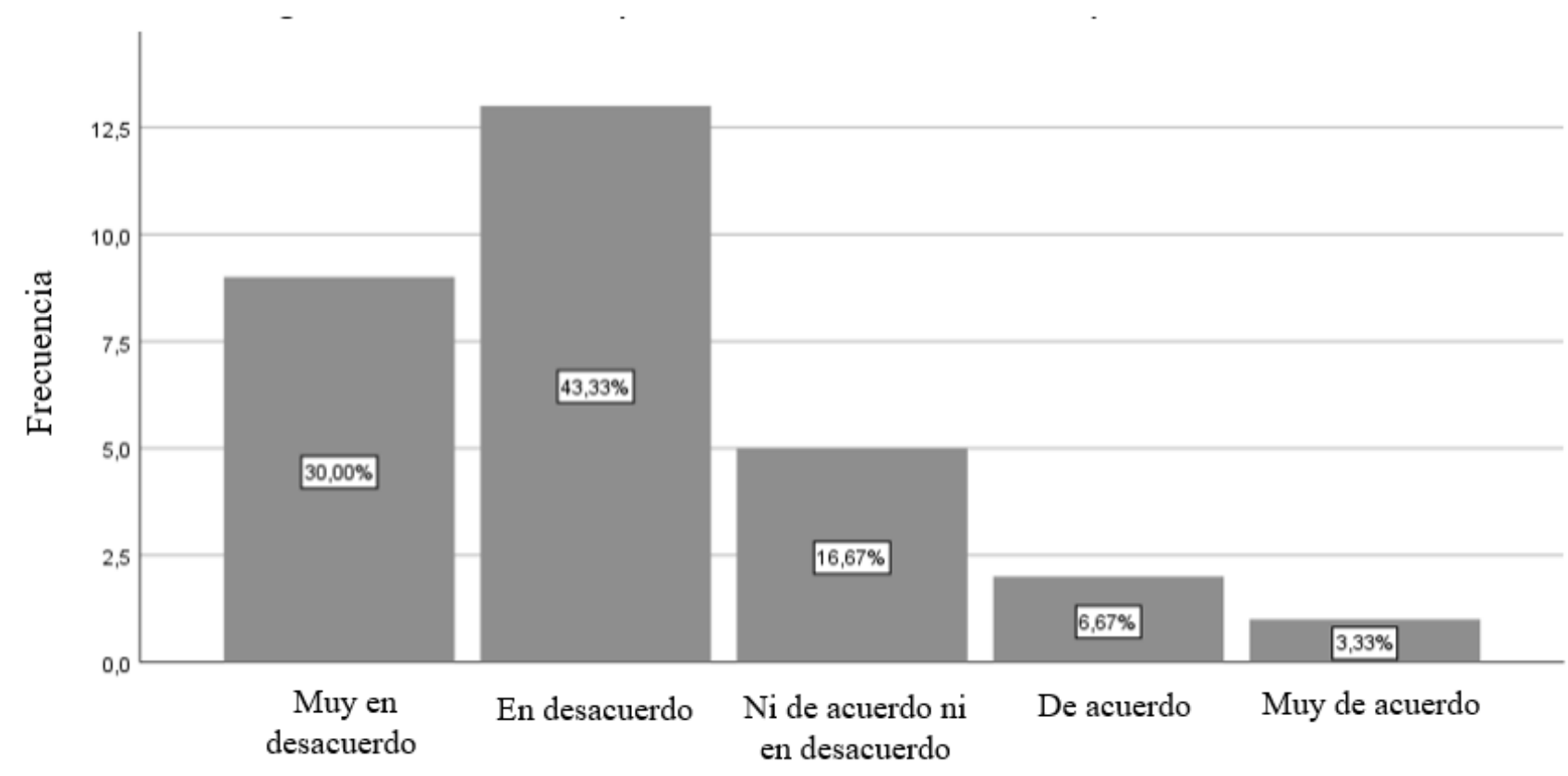

Figura 4

Si usted importa algún insumo para la elaboración del colorante de maíz morado (materia prima, envasado y/o empaquetado), percibe algún beneficio tributario por parte del Estado peruano. Ejemplo: Acogerse bajo el régimen Drawback o de reposición de mercancías con franquicia arancelaria. Adaptado de “Encuesta de colorante de maíz morado”, por fuente propia, 2020.

Interpretación:

Referente a esta afirmación, los encuestados en su mayoría se encuentran en desacuerdo (43.4\%) o muy en desacuerdo (30\%), esto indica que específicamente por la elaboración de colorante de maíz morado no percibe algún beneficio tributario por parte del estado peruano. En contraste, solo 3 encuestados respondieron afirmativamente (de acuerdo y muy de acuerdo).

- Pregunta 5: El estado peruano le brinda información sobre las tendencias y necesidades del mercado americano. 


\section{Tabla 11}

Pregunta 5.

\begin{tabular}{lrrrr}
\hline & Frecuencia & Porcentaje & $\begin{array}{c}\text { Porcentaje } \\
\text { válido }\end{array}$ & $\begin{array}{c}\text { Porcentaje } \\
\text { acumulado }\end{array}$ \\
\hline Muy en desacuerdo & 1 & 3,3 & 3,3 & 3,3 \\
En desacuerdo & 8 & 26,7 & 26,7 & 30,0 \\
Ni de acuerdo ni en desacuerdo & 5 & 16,7 & 16,7 & 46,7 \\
De acuerdo & 13 & 43,3 & 43,3 & 90,0 \\
Muy de acuerdo & 3 & 10,0 & 10,0 & 100,0 \\
\hline Total & 30 & 100,0 & 100,0 & \\
\hline
\end{tabular}

Nota: Resultado de la pregunta 5: El estado peruano le brinda información sobre las tendencias y necesidades del mercado americano. Adaptado de "Encuesta de colorante de maíz morado", por fuente propia, 2020.

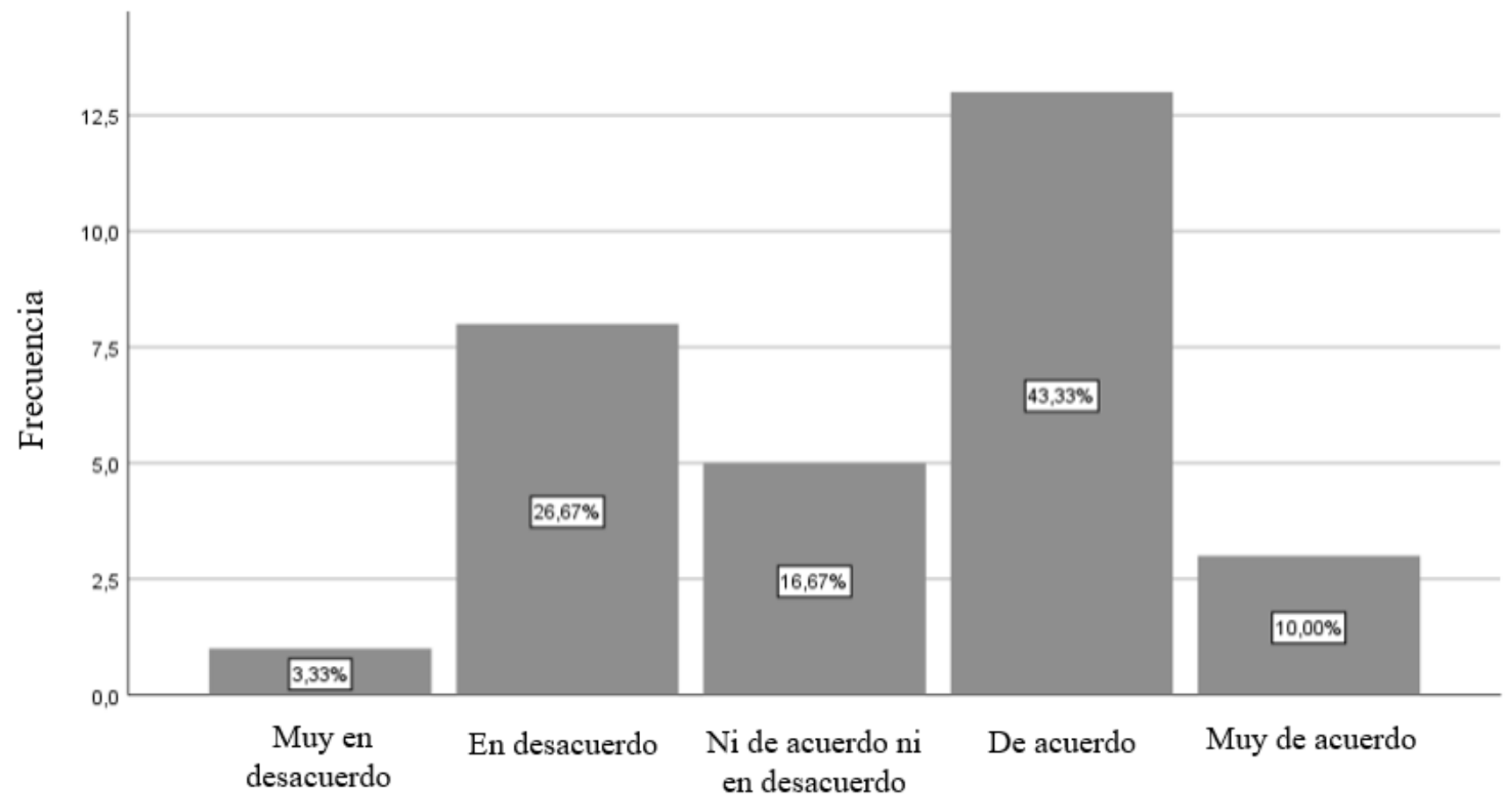

Figura 5

El estado peruano le brinda información sobre las tendencias y necesidades del mercado americano. Adaptado de "Encuesta de colorante de maíz morado", por fuente propia, 2020.

Interpretación: 
Un 43.3\% (de acuerdo) de encuestados afirman recibir información sobre las tendencias y necesidades del mercado americano por parte del estado peruano. Aunque también un $26.7 \%$ (en desacuerdo) percibe lo contrario.

- Pregunta 6: El Plan de Desarrollo de Mercado de Estados Unidos debe incluir el rubro de colorantes naturales y darle mayor importancia.

Tabla 12

Pregunta 6.

\begin{tabular}{|c|c|c|c|c|}
\hline & Frecuencia & Porcentaje & $\begin{array}{l}\text { Porcentaje } \\
\text { válido }\end{array}$ & $\begin{array}{l}\text { Porcentaje } \\
\text { acumulado }\end{array}$ \\
\hline Muy en desacuerdo & 1 & 3,3 & 3,3 & 3,3 \\
\hline Ni de acuerdo ni en desacuerdo & 7 & 23,3 & 23,3 & 26,7 \\
\hline De acuerdo & 15 & 50,0 & 50,0 & 76,7 \\
\hline Muy de acuerdo & 7 & 23,3 & 23,3 & 100,0 \\
\hline Total & 30 & 100,0 & 100,0 & \\
\hline
\end{tabular}

Nota: Resultado de la pregunta 6: El Plan de Desarrollo de Mercado de Estados Unidos debe incluir el rubro de colorantes naturales y darle mayor importancia. Adaptado de "Encuesta de colorante de maíz morado", por fuente propia, 2020. 


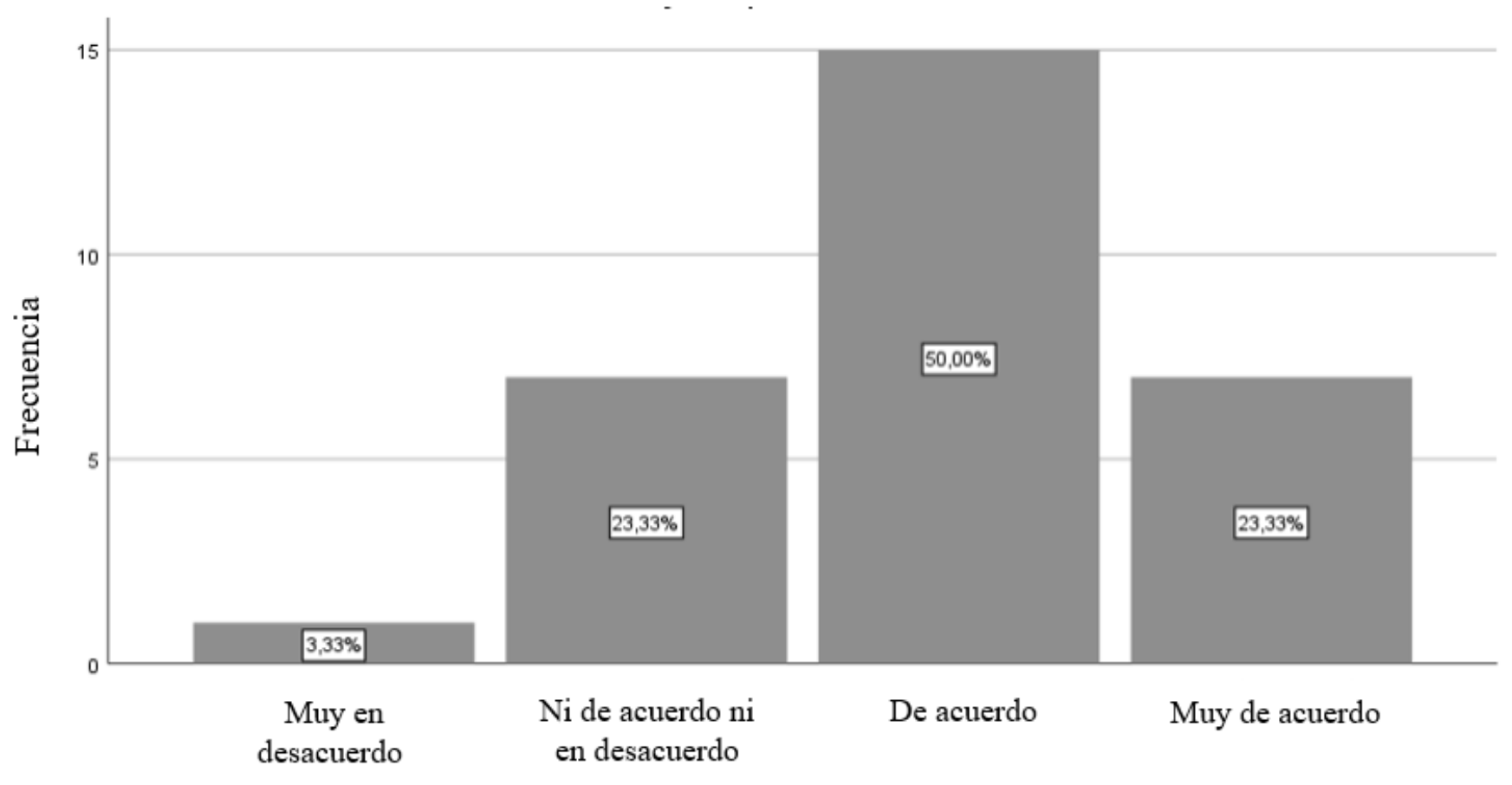

Figura 6

El Plan de Desarrollo de Mercado de Estados Unidos debe incluir el rubro de colorantes naturales y darle mayor importancia. Adaptado de "Encuesta de colorante de maíz morado", por fuente propia, 2020.

Interpretación:

De los 30 encuestados, 15 (50\%) consideran que el Plan de Desarrollo de Mercado de Estados Unidos debe incluir el rubro de colorantes naturales y darle mayor importancia; así como también, 7 encuestados (23.3\%) manifestaron estar muy de acuerdo con esta afirmación. Mientras que solo $1(3.3 \%)$ se encuentra muy en desacuerdo y la diferencia; es decir, el $23.3 \%$ se encuentra ni de acuerdo ni en desacuerdo.

- Pregunta 7: El volumen exportado ha aumentado debido al incremento de empresas de productos orgánicos o saludables en Estados Unidos.

Tabla 13 


\section{Pregunta 7.}

\begin{tabular}{lrrrr}
\hline & Frecuencia & Porcentaje & $\begin{array}{c}\text { Porcentaje } \\
\text { válido }\end{array}$ & $\begin{array}{c}\text { Porcentaje } \\
\text { acumulado }\end{array}$ \\
\hline En desacuerdo & 4 & 13,3 & 13,3 & 13,3 \\
Ni de acuerdo ni en desacuerdo & 2 & 6,7 & 6,7 & 20,0 \\
De acuerdo & 15 & 50,0 & 50,0 & 70,0 \\
Muy de acuerdo & 9 & 30,0 & 30,0 & 100,0 \\
\hline Total & 30 & 100,0 & 100,0 & \\
\hline
\end{tabular}

Nota: Resultado de la pregunta 7: El volumen exportado ha aumentado debido al incremento de empresas de productos orgánicos o saludables en Estados Unidos. Adaptado de "Encuesta de colorante de maíz morado", por fuente propia, 2020.

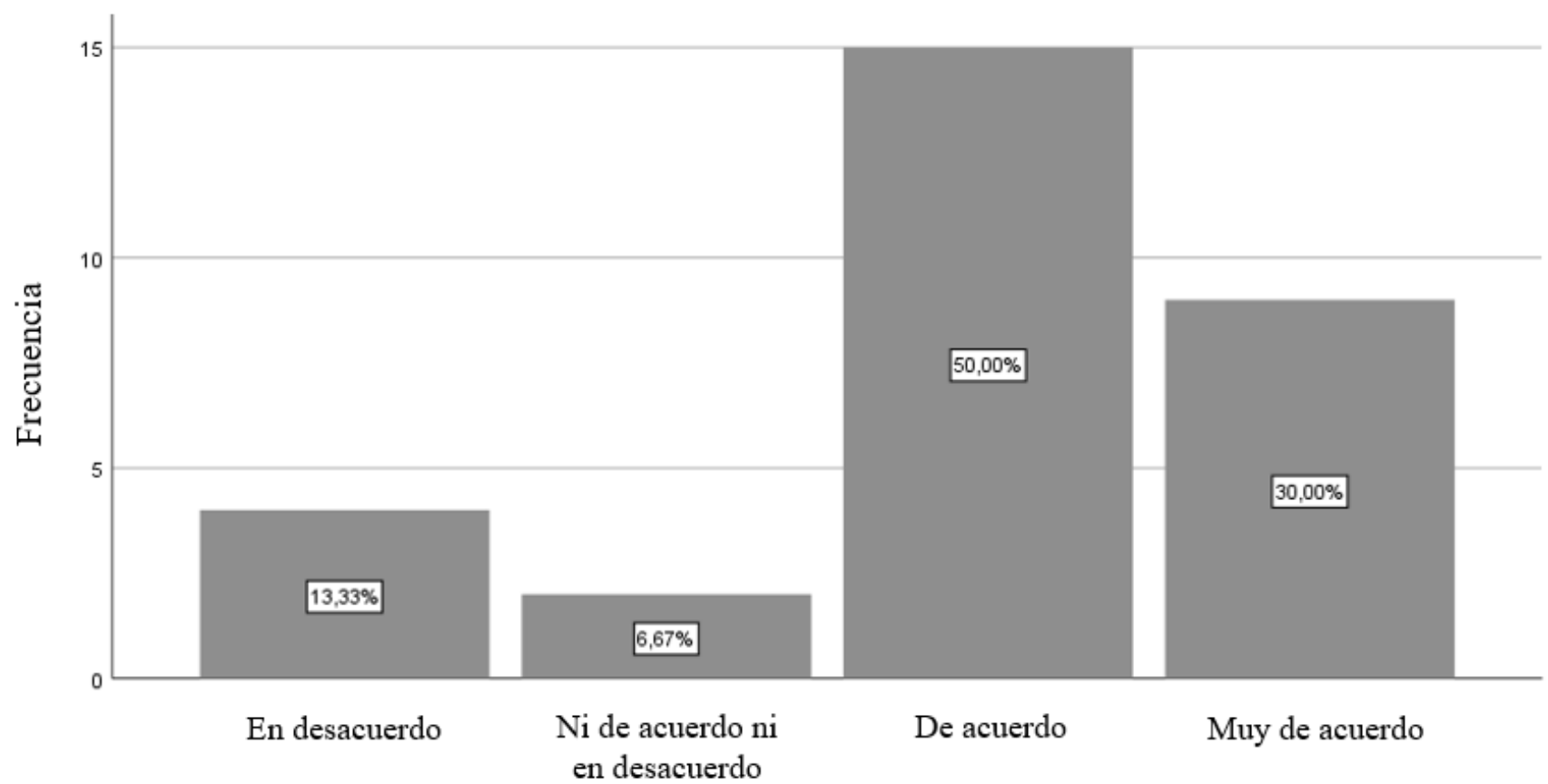

Figura 7

El volumen exportado ha aumentado debido al incremento de empresas de productos orgánicos o saludables en Estados Unidos. Adaptado de "Encuesta de colorante de maíz morado", por fuente propia, 2020.

Interpretación: 
En su mayoría; es decir el 50\% (de acuerdo) y 30\% (muy de acuerdo), consideran que el volumen exportado por ellos ha aumentado debido al incremento de empresas de productos orgánicos o saludables en Estados Unidos. Solo fueron 4 (13.3\%) los encuestados que no se encuentran de acuerdo con la afirmación.

- Pregunta 8: Uno de los factores del aumento del volumen exportado es gracias a la calidad que aportan los colorantes naturales al producto final.

Tabla 14

Pregunta 8.

\begin{tabular}{lrrrr}
\hline & Frecuencia & Porcentaje & $\begin{array}{c}\text { Porcentaje } \\
\text { válido }\end{array}$ & $\begin{array}{c}\text { Porcentaje } \\
\text { acumulado }\end{array}$ \\
\hline En desacuerdo & 5 & 16,7 & 16,7 & 16,7 \\
Ni de acuerdo ni en desacuerdo & 2 & 6,7 & 6,7 & 23,3 \\
De acuerdo & 14 & 46,7 & 46,7 & 70,0 \\
Muy de acuerdo & 9 & 30,0 & 30,0 & 100,0 \\
\hline Total & 30 & 100,0 & 100,0 & \\
\hline
\end{tabular}

Nota: Resultado de la pregunta 8: Uno de los factores del aumento del volumen exportado es gracias a la calidad que aportan los colorantes naturales al producto final. Adaptado de "Encuesta de colorante de maíz morado", por fuente propia, 2020. 


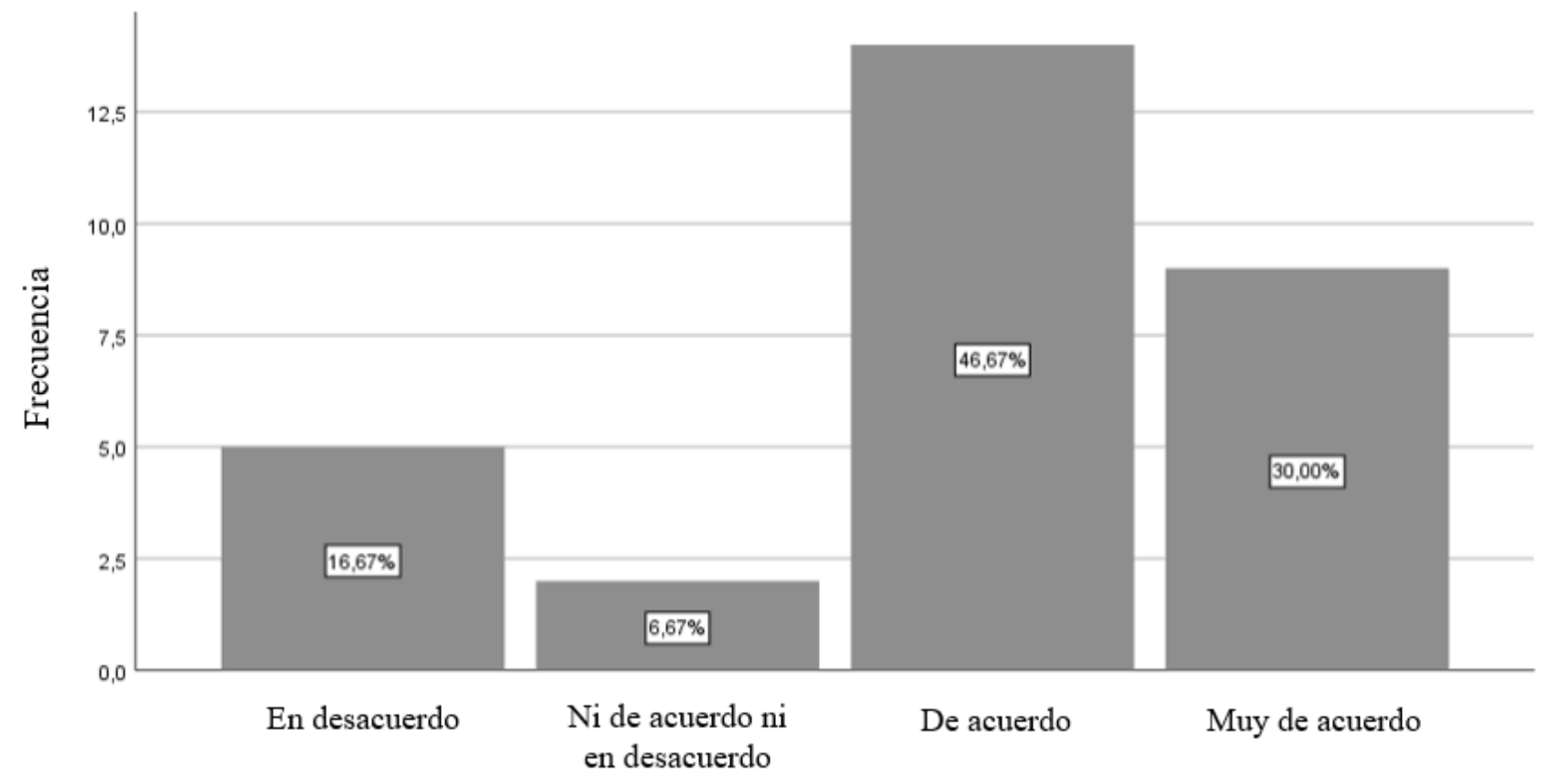

Figura 8

Uno de los factores del aumento del volumen exportado es gracias a la calidad que aportan los colorantes naturales al producto final. Adaptado de "Encuesta de colorante de maíz morado", por fuente propia, 2020.

Interpretación:

En este caso, un $46.7 \%$ se encuentra de acuerdo con que uno de los factores del aumento del volumen exportado es gracias a la calidad que aportan los colorantes naturales al producto final, siendo apoyado por un $30 \%$ de encuestados que están muy de acuerdo. Sin embargo, el 16.7\% se muestra en desacuerdo.

- Pregunta 9: El volumen exportado ha disminuido debido al aumento de empresas peruanas exportadoras de colorante de maíz morado.

Tabla 15

Pregunta 9. 


\begin{tabular}{lrrrr}
\hline & Frecuencia & Porcentaje & $\begin{array}{c}\text { Porcentaje } \\
\text { válido }\end{array}$ & $\begin{array}{c}\text { Porcentaje } \\
\text { acumulado }\end{array}$ \\
\hline Muy en desacuerdo & 1 & 3,3 & 3,3 & 3,3 \\
En desacuerdo & 7 & 23,3 & 23,3 & 26,7 \\
Ni de acuerdo ni en desacuerdo & 10 & 33,3 & 33,3 & 60,0 \\
De acuerdo & 11 & 36,7 & 36,7 & 96,7 \\
Muy de acuerdo & 1 & 3,3 & 3,3 & 100,0 \\
\hline Total & 30 & 100,0 & 100,0 & \\
\hline
\end{tabular}

Nota: Resultado de la pregunta 9: El volumen exportado ha disminuido debido al aumento de empresas peruanas exportadoras de colorante de maíz morado. Adaptado de "Encuesta de colorante de maíz morado", por fuente propia, 2020.

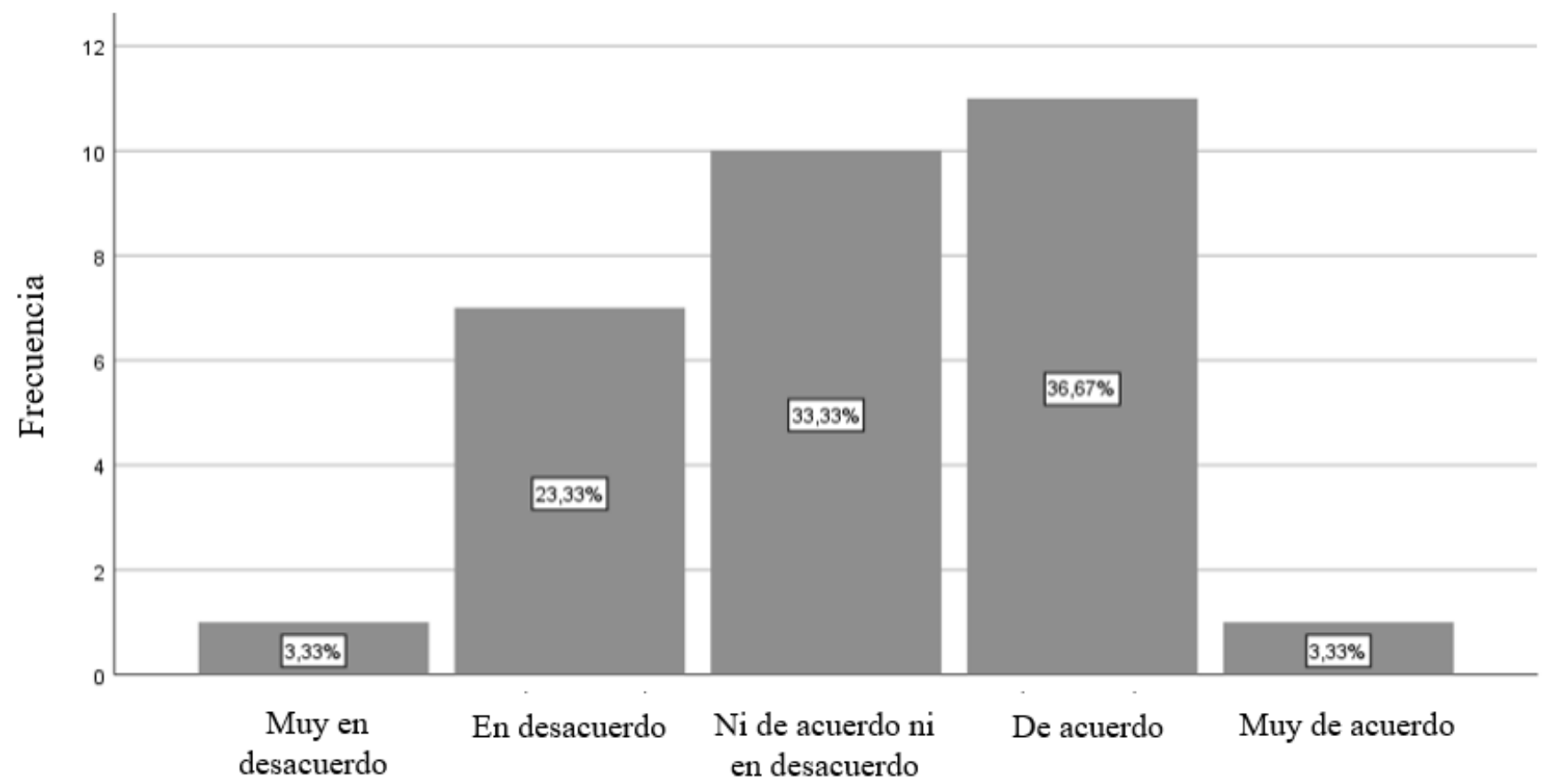

Figura 9

El volumen exportado ha disminuido debido al aumento de empresas peruanas exportadoras de colorante de maíz morado. Adaptado de "Encuesta de colorante de maíz morado", por fuente propia, 2020.

Interpretación: 
Para esta pregunta, el $36.7 \%$ se encuentra de acuerdo con que el volumen exportado ha disminuido debido al aumento de empresas peruanas exportadoras de colorante de maíz morado. Seguido por un $33.3 \%$ que no está ni de acuerdo ni en desacuerdo y un $23.3 \%$ que se encuentra en desacuerdo.

- Pregunta 10: El precio de exportación se ha visto afectado negativamente debido al incremento de empresas exportadoras de colorante de maíz morado.

Tabla 16

Pregunta 10.

\begin{tabular}{lrrrr}
\hline & Frecuencia & Porcentaje & $\begin{array}{c}\text { Porcentaje } \\
\text { válido }\end{array}$ & $\begin{array}{c}\text { Porcentaje } \\
\text { acumulado }\end{array}$ \\
\hline Muy en desacuerdo & 1 & 3,3 & 3,3 & 3,3 \\
En desacuerdo & 11 & 36,7 & 36,7 & 40,0 \\
Ni de acuerdo ni en desacuerdo & 14 & 46,7 & 46,7 & 86,7 \\
De acuerdo & 4 & 13,3 & 13,3 & 100,0 \\
\hline Total & 30 & 100,0 & 100,0 & \\
\hline
\end{tabular}

Nota: Resultado de la pregunta 10: El precio de exportación se ha visto afectado negativamente debido al incremento de empresas exportadoras de colorante de maíz morado. Adaptado de "Encuesta de colorante de maíz morado", por fuente propia, 2020. 


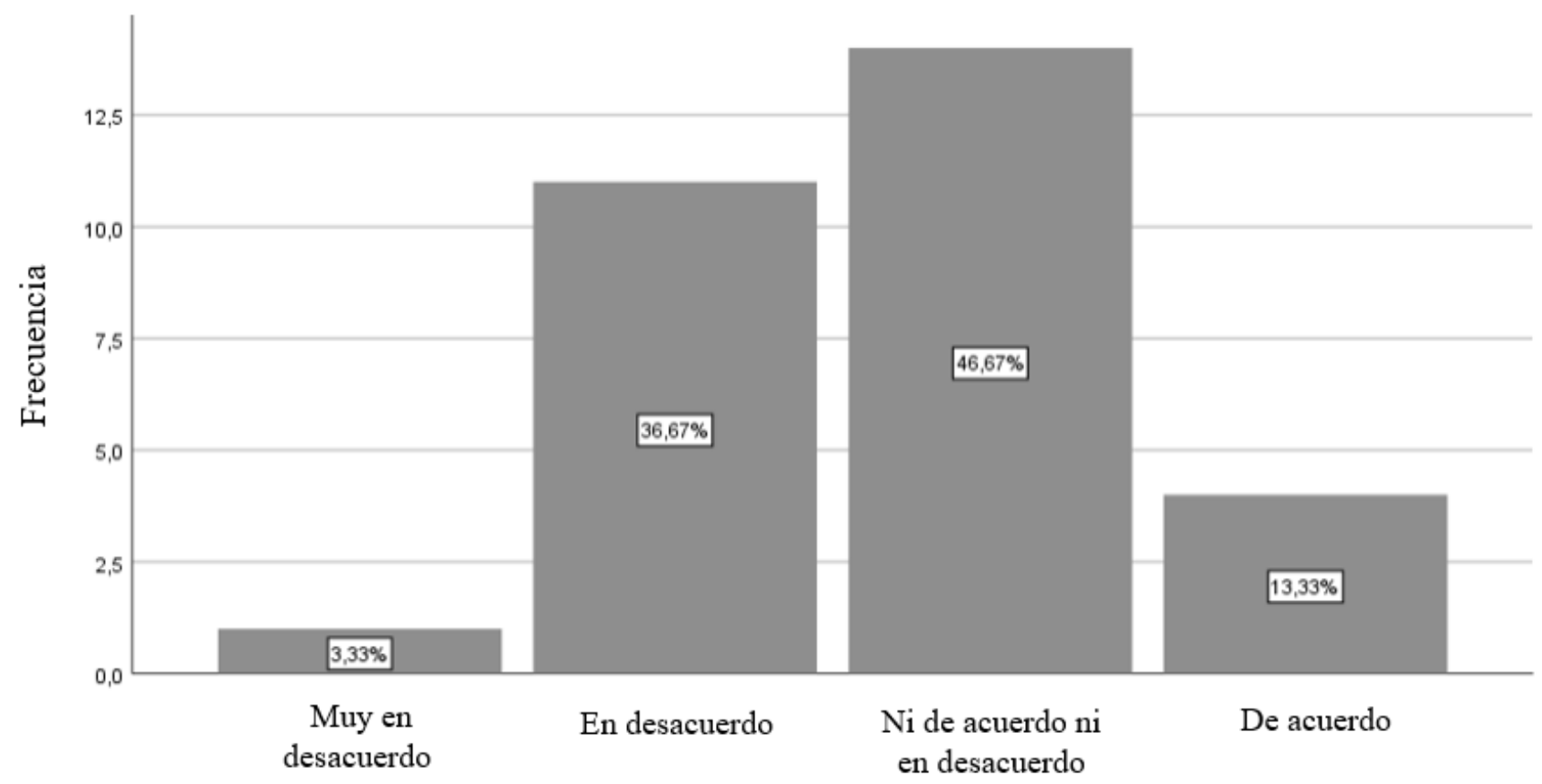

Figura 10

El precio de exportación se ha visto afectado negativamente debido al incremento de empresas exportadoras de colorante de maíz morado. Adaptado de "Encuesta de colorante de maiz morado", por fuente propia, 2020.

Interpretación:

En esta pregunta el $46.7 \%$ de encuestados respondió que no está ni de acuerdo ni en desacuerdo, esta respuesta nos indica que si hubo variaciones en el precio de exportación no fueron de gran significancia para el encuestado.

- Pregunta 11: El aumento del volumen exportado se debe a que el consumidor final actualmente se encuentra más interesado en los productos orgánicos o saludables.

Tabla 17

Pregunta 11. 


\begin{tabular}{lrrrr}
\hline & Frecuencia & Porcentaje & $\begin{array}{c}\text { Porcentaje } \\
\text { válido }\end{array}$ & $\begin{array}{c}\text { Porcentaje } \\
\text { acumulado }\end{array}$ \\
\hline En desacuerdo & 2 & 6,7 & 6,7 & 6,7 \\
Ni de acuerdo ni en desacuerdo & 1 & 3,3 & 3,3 & 10,0 \\
De acuerdo & 12 & 40,0 & 40,0 & 50,0 \\
Muy de acuerdo & 15 & 50,0 & 50,0 & 100,0 \\
\hline Total & 30 & 100,0 & 100,0 & \\
\hline
\end{tabular}

Nota: Resultado de la pregunta 11: El aumento del volumen exportado se debe a que el consumidor final actualmente se encuentra más interesado en los productos orgánicos o saludables. Adaptado de "Encuesta de colorante de maíz morado", por fuente propia, 2020.

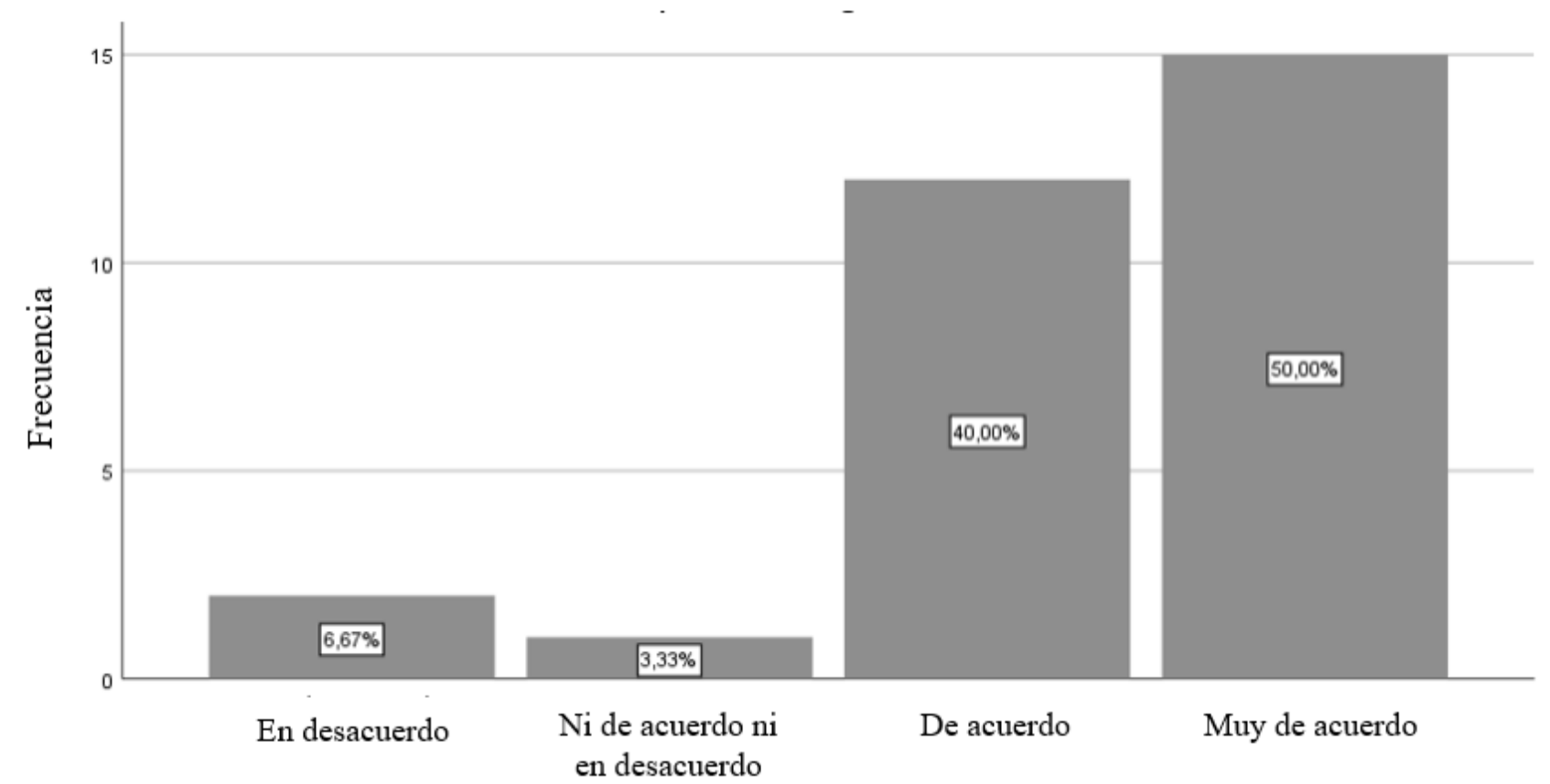

Figura 11

El aumento del volumen exportado se debe a que el consumidor final actualmente se encuentra más interesado en los productos orgánicos o saludables. Adaptado de "Encuesta de colorante de maíz morado”, por fuente propia, 2020.

Interpretación: 
El 90\% de encuestados, divididos entre de acuerdo y muy de acuerdo, considera que el aumento del volumen exportado se debe a que el consumidor final actualmente se encuentra más interesado en los productos orgánicos o saludables. Mientras que solo un $6.7 \%$ se encuentra en desacuerdo.

- Pregunta 12: El precio de exportación se ha visto beneficiado debido a que las personas consumen mayor cantidad de productos orgánicos o saludables.

Tabla 18

Pregunta 12.

\begin{tabular}{lrrrr}
\hline & Frecuencia & Porcentaje & $\begin{array}{c}\text { Porcentaje } \\
\text { válido }\end{array}$ & $\begin{array}{c}\text { Porcentaje } \\
\text { acumulado }\end{array}$ \\
\hline En desacuerdo & 3 & 10,0 & 10,0 & 10,0 \\
Ni de acuerdo ni en desacuerdo & 3 & 10,0 & 10,0 & 20,0 \\
De acuerdo & 17 & 56,7 & 56,7 & 76,7 \\
Muy de acuerdo & 7 & 23,3 & 23,3 & 100,0 \\
\hline Total & 30 & 100,0 & 100,0 & \\
\hline
\end{tabular}

Nota: Resultado de la pregunta 12: El precio de exportación se ha visto beneficiado debido a que las personas consumen mayor cantidad de productos orgánicos o saludables. Adaptado de "Encuesta de colorante de maíz morado", por fuente propia, 2020. 


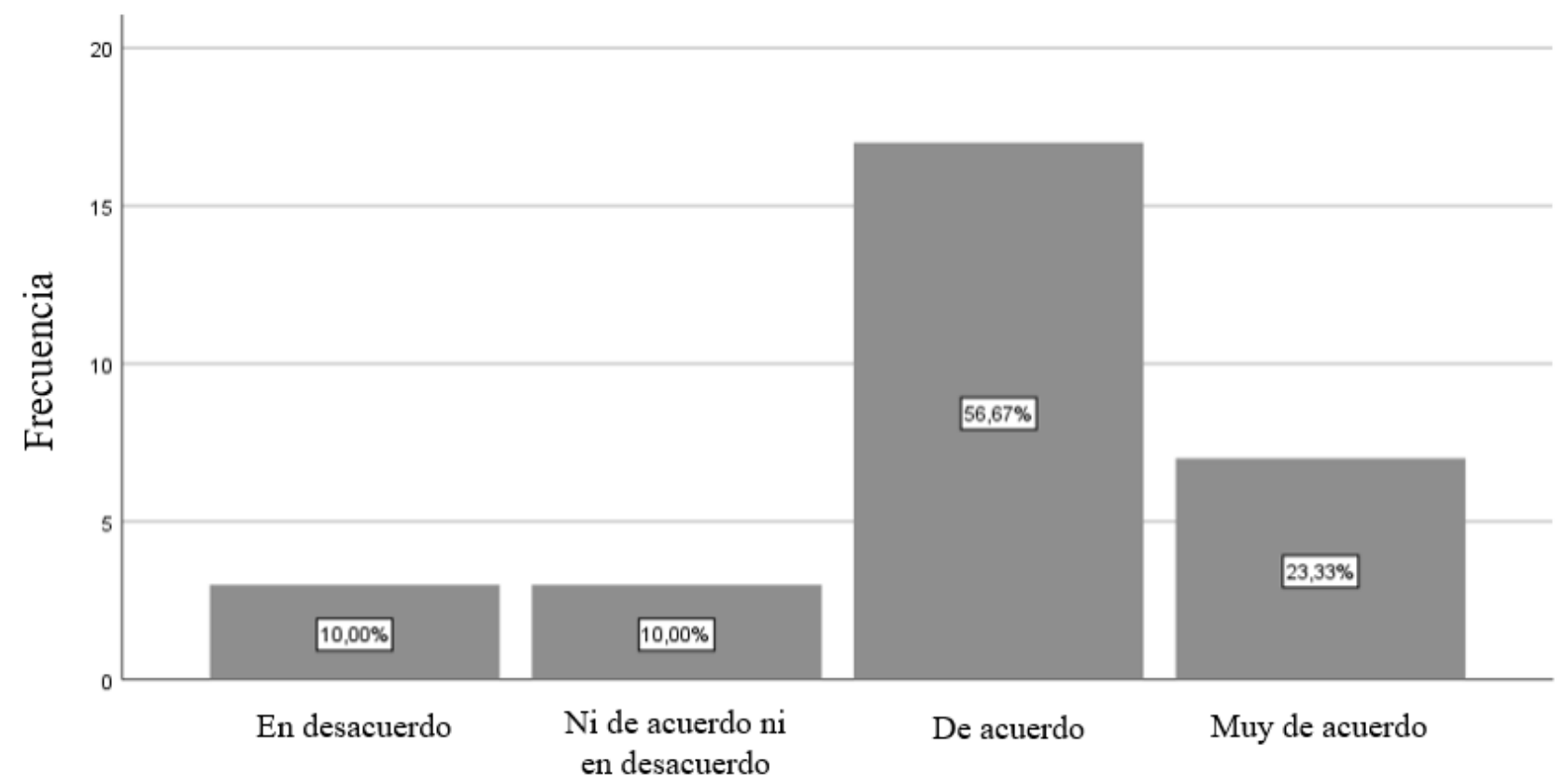

Figura 12

El precio de exportación se ha visto beneficiado debido a que las personas consumen mayor cantidad de productos orgánicos o saludables. Adaptado de "Encuesta de colorante de maíz morado", por fuente propia, 2020.

Interpretación:

Un 56.7\% de los encuestados está de acuerdo con que el precio de exportación se ha visto beneficiado debido a que las personas consumen mayor cantidad de productos orgánicos o saludables. Por otro lado, hubo un empate entre los encuestados que están en desacuerdo y ni de acuerdo ni en desacuerdo, $10 \%$ cada uno.

- Pregunta 13: Como usted sabe la obesidad es un problema que ha venido afectando a la población de Estados Unidos durante muchos años y debido a ello muchas personas están haciendo cambios en sus hábitos alimenticios. Debido a lo anteriormente mencionado, el incremento de sus ventas entre 2015 - 2019 se debe al aumento de conciencia sobre la obesidad en Estados Unidos. 
Tabla 19

Pregunta 13

\begin{tabular}{lrrrr}
\hline & Frecuencia & Porcentaje & $\begin{array}{c}\text { Porcentaje } \\
\text { válido }\end{array}$ & $\begin{array}{r}\text { Porcentaje } \\
\text { acumulado }\end{array}$ \\
\hline En desacuerdo & 2 & 6,7 & 6,7 & 6,7 \\
Ni de acuerdo ni en desacuerdo & 6 & 20,0 & 20,0 & 26,7 \\
De acuerdo & 15 & 50,0 & 50,0 & 76,7 \\
Muy de acuerdo & 7 & 23,3 & 23,3 & 100,0 \\
\hline Total & 30 & 100,0 & 100,0 & \\
\hline
\end{tabular}

Nota: Resultado de la pregunta 13: Como usted sabe la obesidad es un problema que ha venido afectando a la población de Estados Unidos durante muchos años y debido a ello muchas personas están haciendo cambios en sus hábitos alimenticios. Debido a lo anteriormente mencionado, el incremento de sus ventas entre 2015 - 2019 se debe al aumento de conciencia sobre la obesidad en Estados Unidos. Adaptado de "Encuesta de colorante de maíz morado", por fuente propia, 2020.

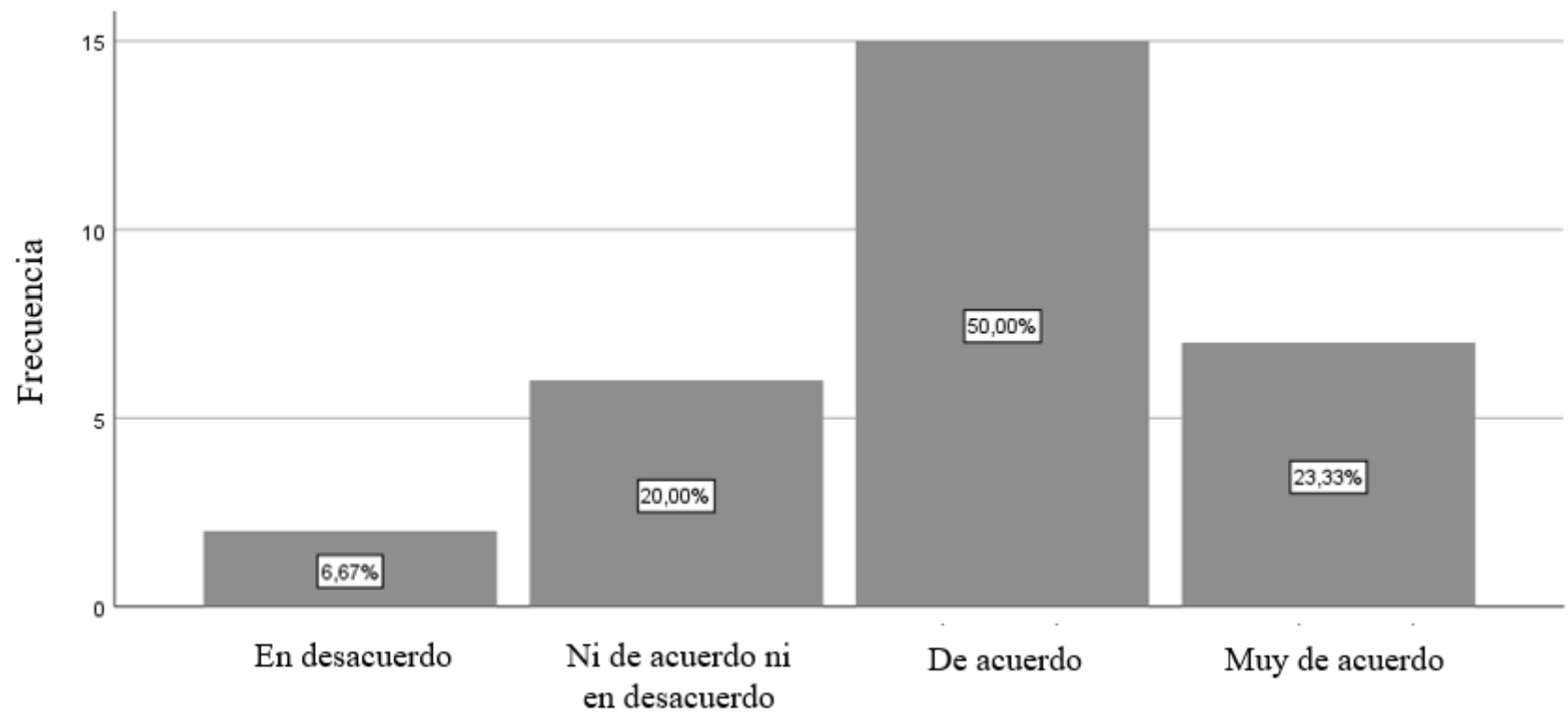

Figura 13

Como usted sabe la obesidad es un problema que ha venido afectando a la población de Estados Unidos durante muchos años y debido a ello muchas personas están haciendo cambios en sus 
hábitos alimenticios. Debido a lo anteriormente mencionado, el incremento de sus ventas entre 2015 - 2019 se debe al aumento de conciencia sobre la obesidad en Estados Unidos. Adaptado de “Encuesta de colorante de maiz morado”, por fuente propia, 2020.

Interpretación:

La mitad de encuestados; es decir un 50\%, se encuentra de acuerdo con que, debido al aumento de conciencias sobre la obesidad en Estados Unidos, sus ventas han incrementado en el periodo 2015 - 2019; adicionalmente, un 23.3\% de encuestados apoyan la afirmación estando muy de acuerdo. En contraste, solo 2 encuestados (6.7\%) se encuentran en desacuerdo.

- Pregunta 14: Los factores de: competitividad, boom saludable y apoyo del Estado peruano han influido positivamente en el valor exportado de colorantes de maíz morado.

Tabla 20

Pregunta 14.

\begin{tabular}{lrrrr}
\hline & Frecuencia & Porcentaje & $\begin{array}{c}\text { Porcentaje } \\
\text { válido }\end{array}$ & $\begin{array}{c}\text { Porcentaje } \\
\text { acumulado }\end{array}$ \\
\hline En desacuerdo & 1 & 3,3 & 3,3 & 3,3 \\
Ni de acuerdo ni en desacuerdo & 5 & 16,7 & 16,7 & 20,0 \\
De acuerdo & 18 & 60,0 & 60,0 & 80,0 \\
Muy de acuerdo & 6 & 20,0 & 20,0 & 100,0 \\
\hline Total & 30 & 100,0 & 100,0 & \\
\hline
\end{tabular}

Nota: Resultado de la pregunta 14: Los factores de: competitividad, boom saludable y apoyo del Estado peruano han influido positivamente en el valor exportado de colorantes de maíz morado. Adaptado de "Encuesta de colorante de maíz morado", por fuente propia, 2020. 


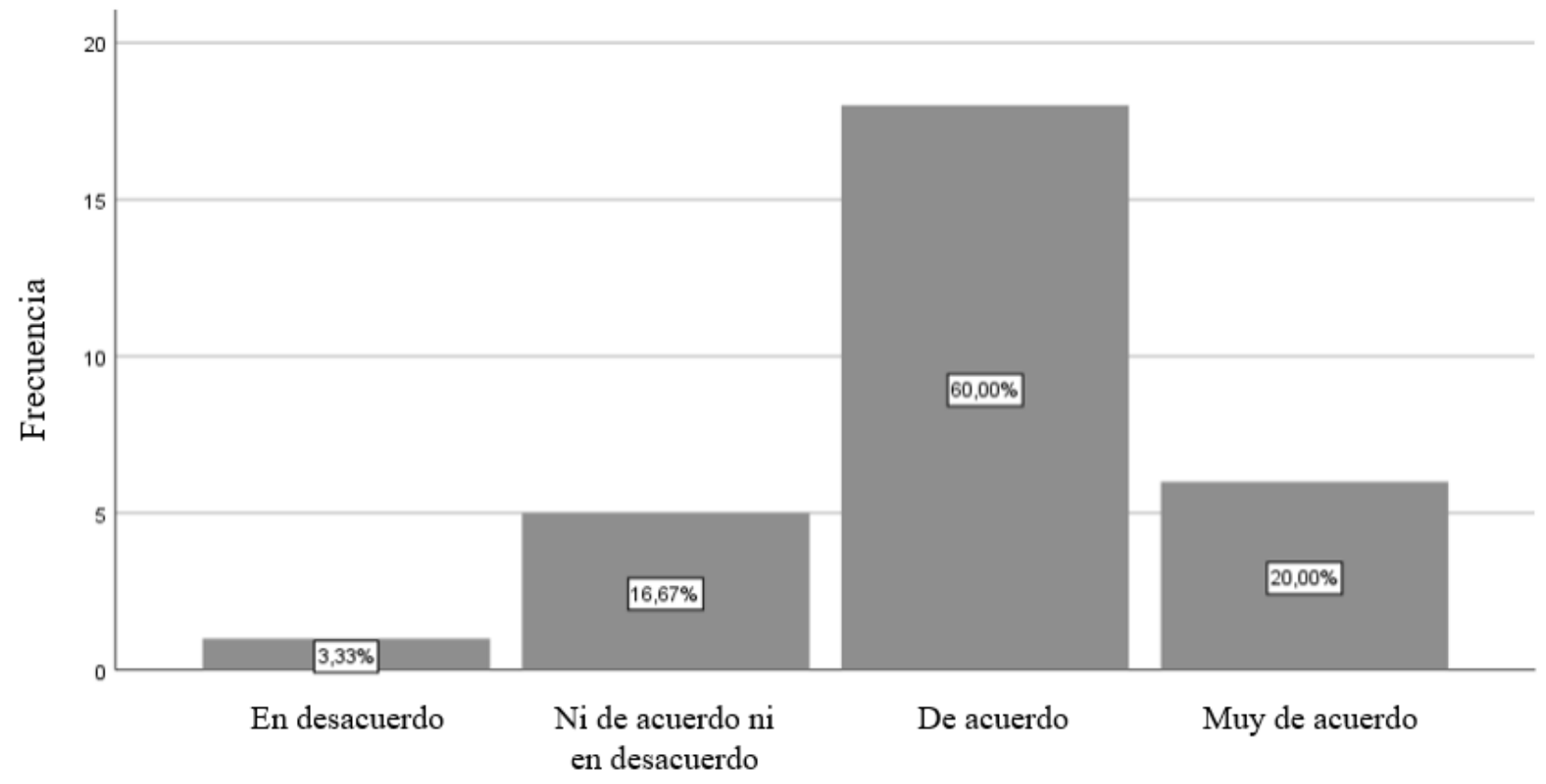

Figura 14

Los factores de: competitividad, boom saludable y apoyo del Estado peruano han influido positivamente en el valor exportado de colorantes de maíz morado. Adaptado de "Encuesta de colorante de maíz morado", por fuente propia, 2020.

Interpretación:

De los encuestados, un $60 \%$ está de acuerdo con que los factores planteados en la tesis: apoyo del estado peruano, competitividad y boom saludable, han influenciado positivamente en el valor exportado de colorantes de maíz morado.

- Pregunta 15: El valor agregado que aporta el colorante de maíz morado no es el causante del aumento de sus exportaciones.

Tabla 21

Pregunta 15. 


\begin{tabular}{lrrrr}
\hline & Frecuencia & Porcentaje & $\begin{array}{c}\text { Porcentaje } \\
\text { válido }\end{array}$ & $\begin{array}{c}\text { Porcentaje } \\
\text { acumulado }\end{array}$ \\
\hline En desacuerdo & 12 & 40,0 & 40,0 & 40,0 \\
Ni de acuerdo ni en desacuerdo & 8 & 26,7 & 26,7 & 66,7 \\
De acuerdo & 10 & 33,3 & 33,3 & 100,0 \\
\hline Total & 30 & 100,0 & 100,0 & \\
\hline
\end{tabular}

Nota: Resultado de la pregunta 15: El valor agregado que aporta el colorante de maíz morado no es el causante del aumento de sus exportaciones. Adaptado de "Encuesta de colorante de maíz morado", por fuente propia, 2020.

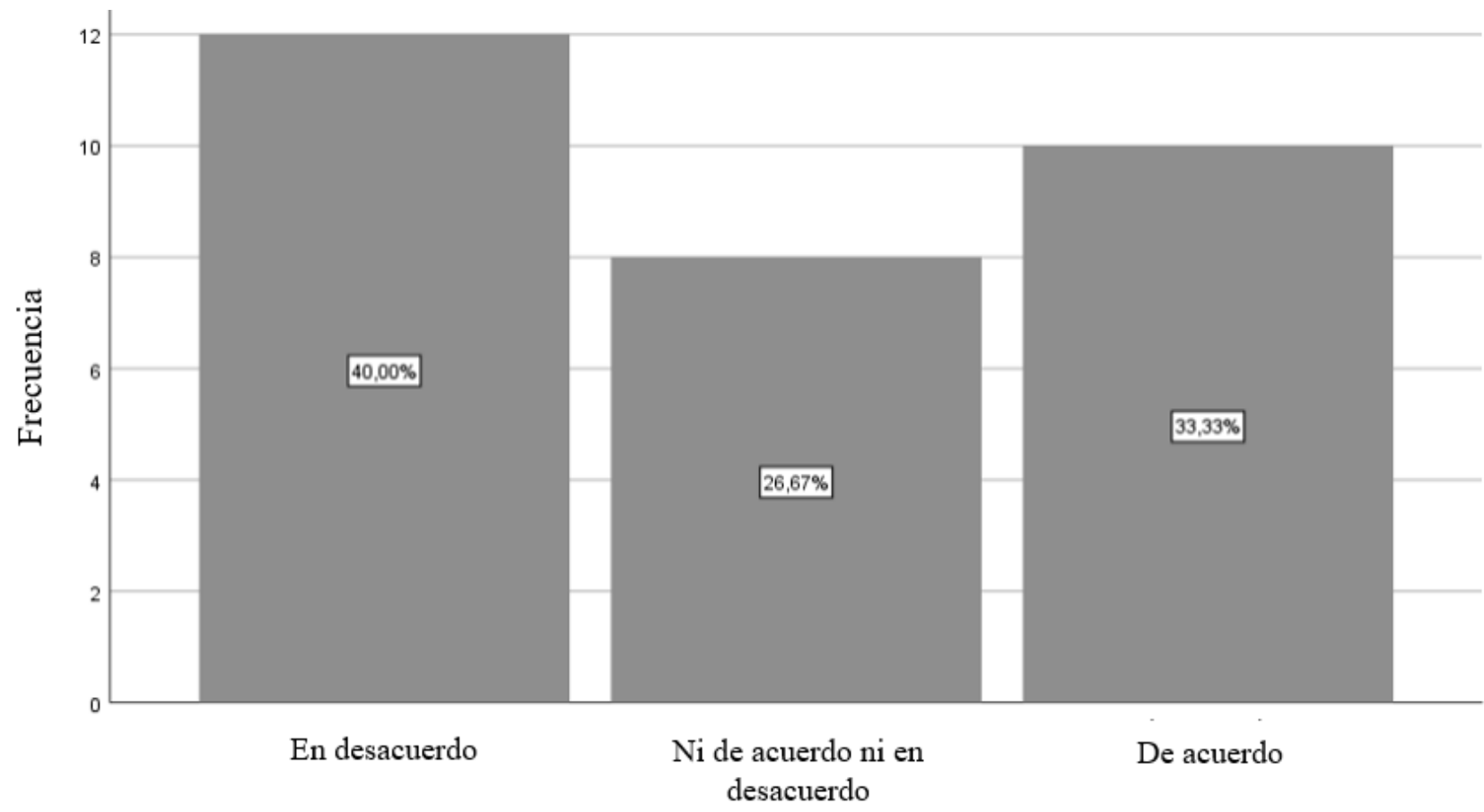

Figura 15

El valor agregado que aporta el colorante de maíz morado no es el causante del aumento de sus exportaciones. Adaptado de "Encuesta de colorante de maíz morado”, por fuente propia, 2020. Interpretación:

En esta pregunta, el $40 \%$ de encuestados considera que el valor agregado que aporta el colorante de maíz morado es el causante del aumento de sus exportaciones. Mientras que un $33.3 \%$ se encuentra en desacuerdo; es decir, que efectivamente el valor agregado que aporta el colorante de maíz morado no es el causante del aumento de sus exportaciones. 
- Pregunta 16: La cantidad de toneladas de colorante de maíz morado se ha incrementado desde la aparición de la tendencia por el consumo de productos saludables.

Tabla 22

Pregunta 16.

\begin{tabular}{lrrrr}
\hline & Frecuencia & Porcentaje & $\begin{array}{c}\text { Porcentaje } \\
\text { válido }\end{array}$ & $\begin{array}{c}\text { Porcentaje } \\
\text { acumulado }\end{array}$ \\
\hline Ni de acuerdo ni en desacuerdo & 8 & 26,7 & 26,7 & 26,7 \\
De acuerdo & 21 & 70,0 & 70,0 & 96,7 \\
Muy de acuerdo & 1 & 3,3 & 3,3 & 100,0 \\
\hline Total & 30 & 100,0 & 100,0 & \\
\hline
\end{tabular}

Nota: Resultado de la pregunta 16: La cantidad de toneladas de colorante de maíz morado se ha incrementado desde la aparición de la tendencia por el consumo de productos saludables. Adaptado de "Encuesta de colorante de maíz morado", por fuente propia, 2020.

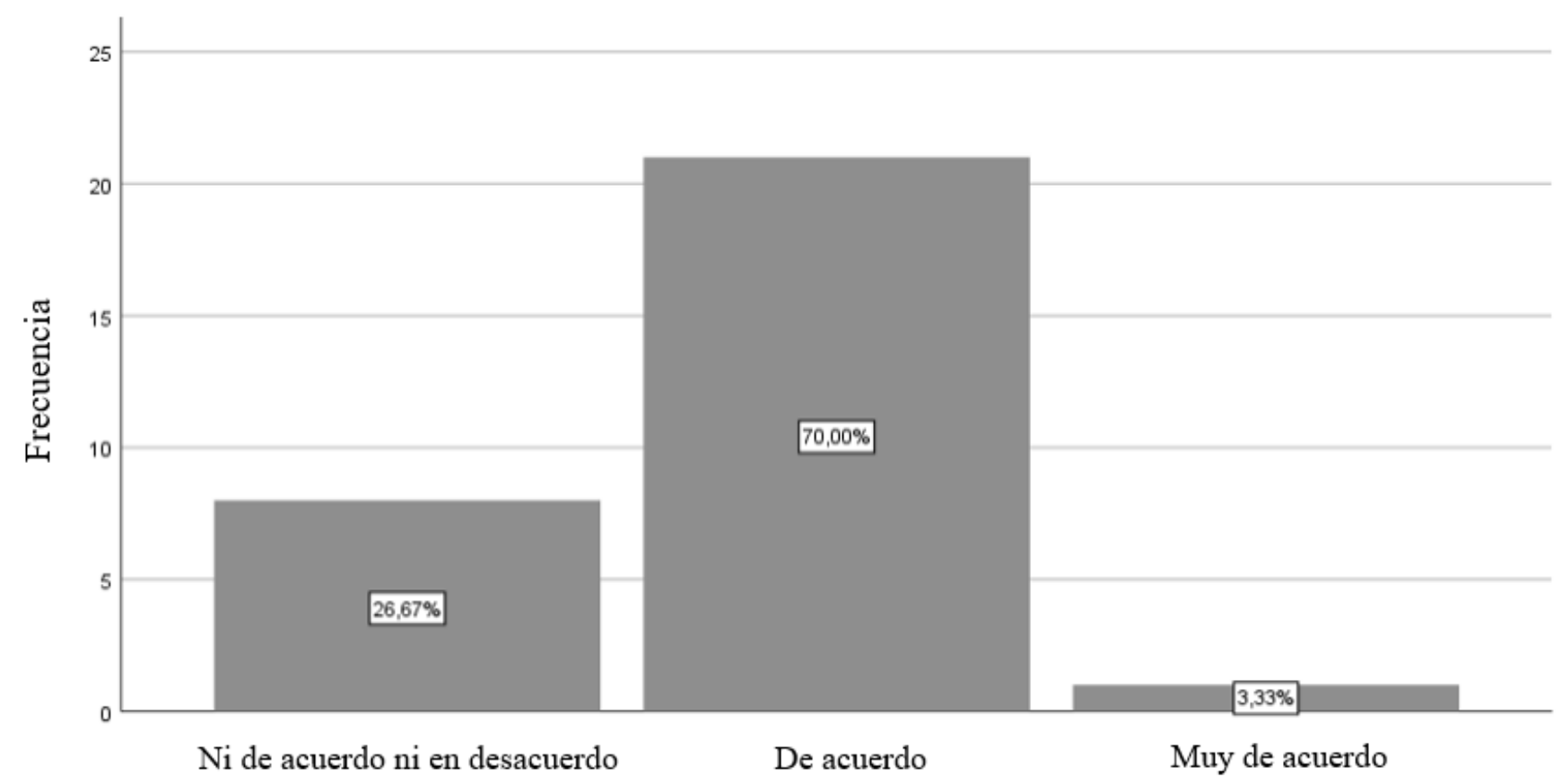

Figura 16 
La cantidad de toneladas de colorante de maíz morado se ha incrementado desde la aparición de la tendencia por el consumo de productos saludables. Adaptado de "Encuesta de colorante de maiz morado", por fuente propia, 2020.

Interpretación:

El 70\% de encuestados está de acuerdo con que la cantidad de toneladas de colorante de maíz morado se ha incrementado desde la aparición de la tendencia por el consumo de productos saludables.

- Pregunta 17: El aumento en la competitividad entre empresas de productos orgánicos o saludables en Estado Unidos ha influido positivamente en la cantidad exportada de colorante de maíz morado.

Tabla 23

Pregunta 17.

\begin{tabular}{lrrrr}
\hline & Frecuencia & Porcentaje & $\begin{array}{c}\text { Porcentaje } \\
\text { válido }\end{array}$ & $\begin{array}{c}\text { Porcentaje } \\
\text { acumulado }\end{array}$ \\
\hline En desacuerdo & 1 & 3,3 & 3,3 & 3,3 \\
Ni de acuerdo ni en desacuerdo & 4 & 13,3 & 13,3 & 16,7 \\
De acuerdo & 22 & 73,3 & 73,3 & 90,0 \\
Muy de acuerdo & 3 & 10,0 & 10,0 & 100,0 \\
\hline Total & 30 & 100,0 & 100,0 & \\
\hline
\end{tabular}

Nota: Resultado de la pregunta 17: El aumento en la competitividad entre empresas de productos orgánicos o saludables en Estado Unidos ha influido positivamente en la cantidad exportada de colorante de maíz morado. Adaptado de "Encuesta de colorante de maíz morado", por fuente propia, 2020. 


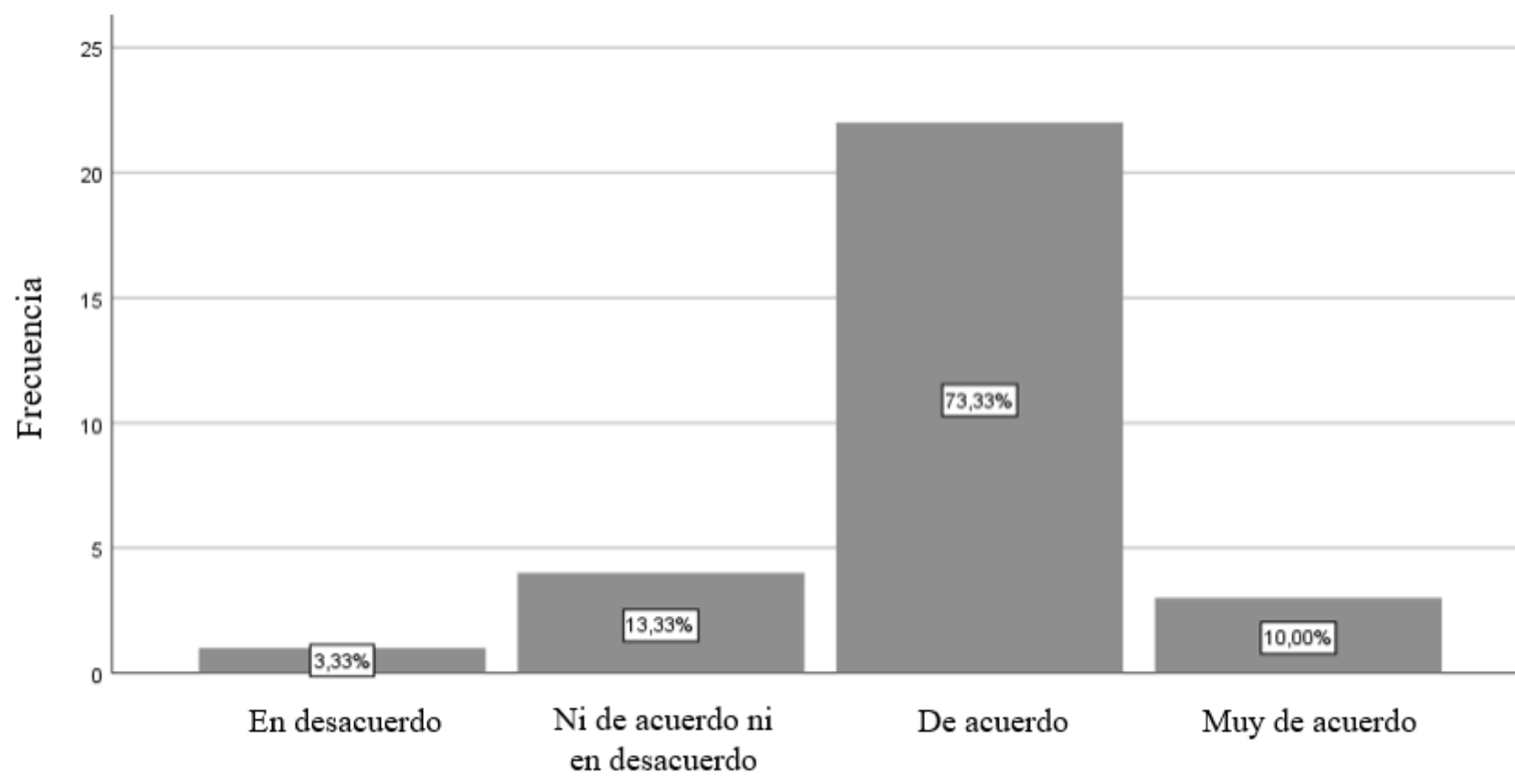

Figura 17

El aumento en la competitividad entre empresas de productos orgánicos o saludables en Estado Unidos ha influido positivamente en la cantidad exportada de colorante de maíz morado. Adaptado de "Encuesta de colorante de maíz morado", por fuente propia, 2020 Interpretación:

Unos 22 encuestados (73.3\%) están de acuerdo con que el aumento en la competitividad entre empresas de productos orgánicos o saludables en Estado Unidos ha influido positivamente en la cantidad exportada de colorante de maíz morado. Tan solo un encuestado (3.3\%) se encuentra en desacuerdo.

- Pregunta 18: Desde el cambio del nuevo Plan Estratégico Nacional Exportador (PENX) 2015-2025, el volumen exportado ha aumentado.

Tabla 24

Pregunta 18. 


\begin{tabular}{lrrrr}
\hline & Frecuencia & Porcentaje & $\begin{array}{c}\text { Porcentaje } \\
\text { válido }\end{array}$ & $\begin{array}{c}\text { Porcentaje } \\
\text { acumulado }\end{array}$ \\
\hline En desacuerdo & 1 & 3,3 & 3,3 & 3,3 \\
Ni de acuerdo ni en desacuerdo & 11 & 36,7 & 36,7 & 40,0 \\
De acuerdo & 17 & 56,7 & 56,7 & 96,7 \\
Muy de acuerdo & 1 & 3,3 & 3,3 & 100,0 \\
\hline Total & 30 & 100,0 & 100,0 & \\
\hline
\end{tabular}

Nota: Resultado de la pregunta 18: Desde el cambio del nuevo Plan Estratégico Nacional Exportador (PENX) 20152025, el volumen exportado ha aumentado. Adaptado de "Encuesta de colorante de maíz morado", por fuente propia, 2020.

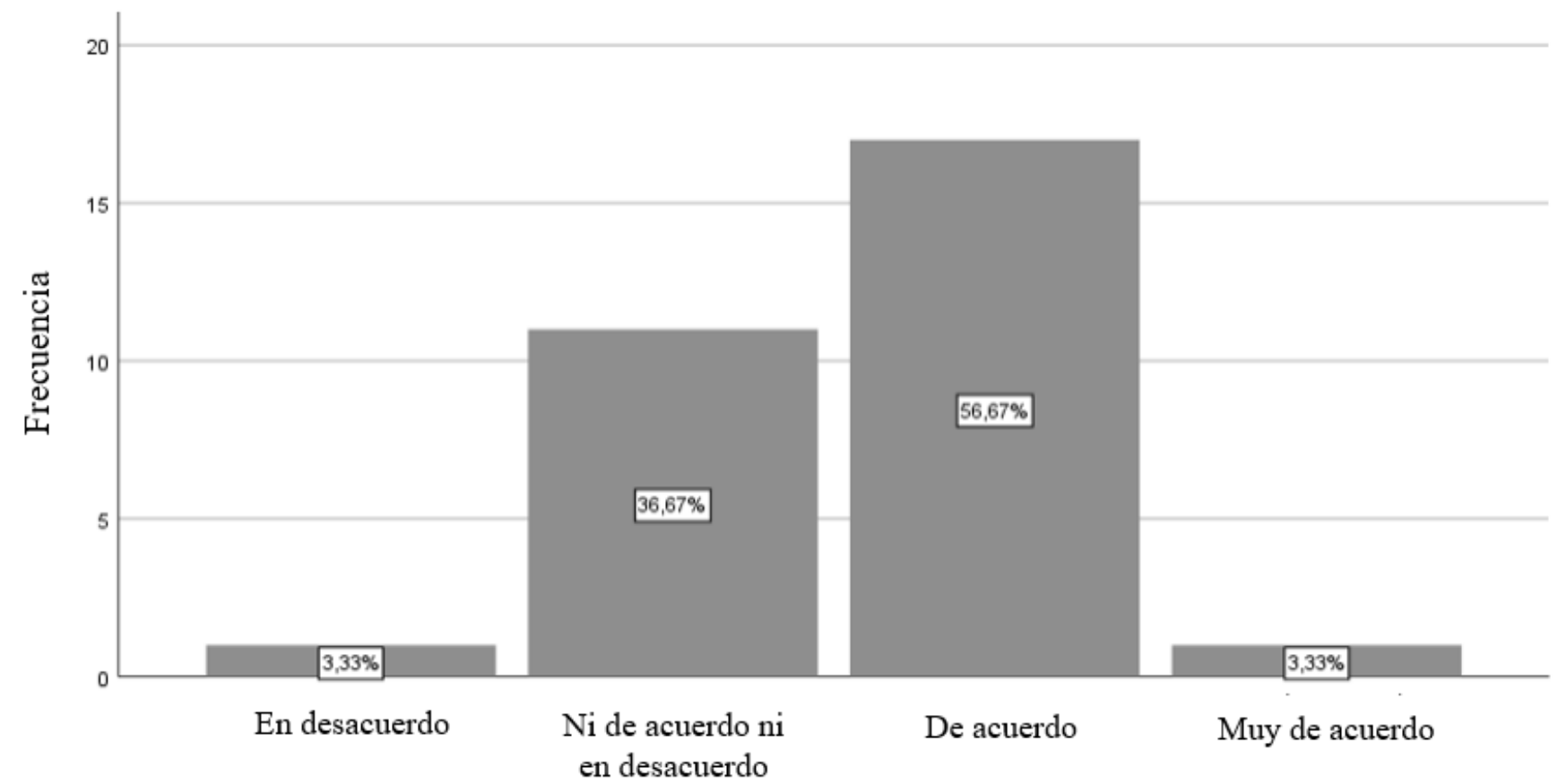

Figura 18

Desde el cambio del nuevo Plan Estratégico Nacional Exportador (PENX) 2015-2025, el volumen exportado ha aumentado. Adaptado de "Encuesta de colorante de maíz morado", por fuente propia, 2020.

Interpretación:

En esta pregunta, 17 encuestados $(56.7 \%)$ respondieron que se encuentran de acuerdo a que desde el cambio del nuevo Plan Estratégico Nacional Exportador (PENX) 2015-2025, su volumen 
exportado ha aumentado. Asimismo, un 36.7\% indicó que se encuentra ni de acuerdo ni en desacuerdo.

- Pregunta 19: El precio de venta del colorante de maíz morado ha disminuido desde el aumento de la cantidad de empresas productoras de este producto.

Tabla 25

Pregunta 19.

\begin{tabular}{lrrrr}
\hline & Frecuencia & Porcentaje & $\begin{array}{c}\text { Porcentaje } \\
\text { válido }\end{array}$ & $\begin{array}{c}\text { Porcentaje } \\
\text { acumulado }\end{array}$ \\
\hline Muy en desacuerdo & 1 & 3,3 & 3,3 & 3,3 \\
En desacuerdo & 14 & 46,7 & 46,7 & 50,0 \\
Ni de acuerdo ni en desacuerdo & 9 & 30,0 & 30,0 & 80,0 \\
De acuerdo & 6 & 20,0 & 20,0 & 100,0 \\
\hline Total & 30 & 100,0 & 100,0 & \\
\hline
\end{tabular}

Nota: Resultado de la pregunta 19: El precio de venta del colorante de maíz morado ha disminuido desde el aumento de la cantidad de empresas productoras de este producto. Adaptado de "Encuesta de colorante de maíz morado", por fuente propia, 2020.

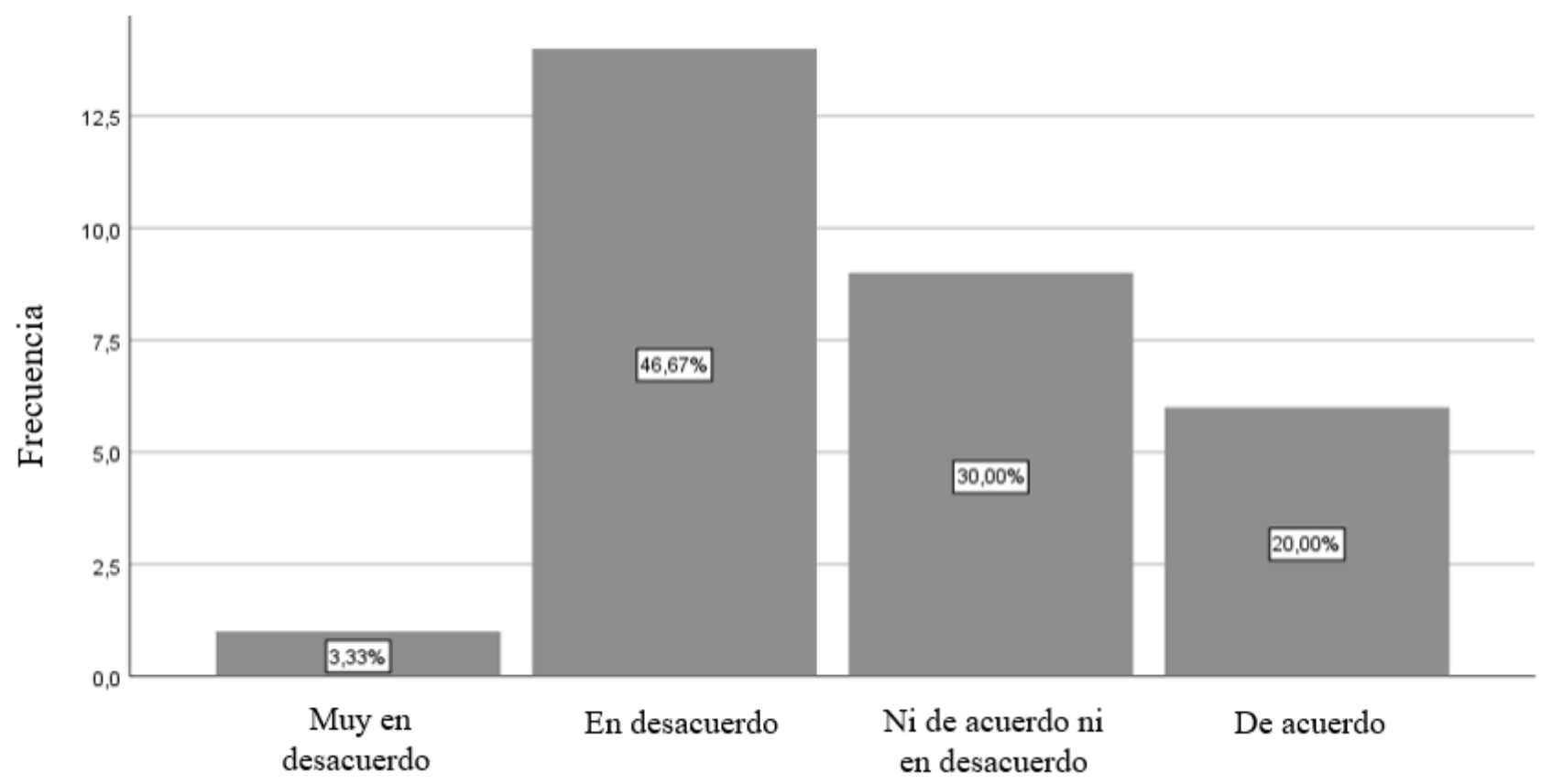


Figura 19

El precio de venta del colorante de maíz morado ha disminuido desde el aumento de la cantidad de empresas productoras de este producto. Adaptado de "Encuesta de colorante de maíz morado", por fuente propia, 2020.

Interpretación:

Se puede observar que el $46.7 \%$ de encuestados indicó que se encuentra en desacuerdo a que el precio de venta del colorante de maíz morado ha disminuido desde el aumento de la cantidad de empresas productoras de este producto, por lo que se puede entender que el precio se ha mantenido o aumentado durante el periodo 2015 - 2019.

- Pregunta 20: El precio de venta del colorante de maíz morado ha incrementado desde el aumento de la cantidad de empresas productoras de productos orgánicos y saludables en Estados Unidos.

Tabla 26

Pregunta 20.

\begin{tabular}{lrrrr}
\hline & Frecuencia & Porcentaje & $\begin{array}{c}\text { Porcentaje } \\
\text { válido }\end{array}$ & $\begin{array}{c}\text { Porcentaje } \\
\text { acumulado }\end{array}$ \\
\hline En desacuerdo & 6 & 20,0 & 20,0 & 20,0 \\
Ni de acuerdo ni en desacuerdo & 8 & 26,7 & 26,7 & 46,7 \\
De acuerdo & 15 & 50,0 & 50,0 & 96,7 \\
Muy de acuerdo & 1 & 3,3 & 3,3 & 100,0 \\
\hline Total & 30 & 100,0 & 100,0 & \\
\hline
\end{tabular}

Nota: Resultado de la pregunta 20: El precio de venta del colorante de maíz morado ha incrementado desde el aumento de la cantidad de empresas productoras de productos orgánicos y saludables en Estados Unidos. Adaptado de "Encuesta de colorante de maíz morado", por fuente propia, 2020. 


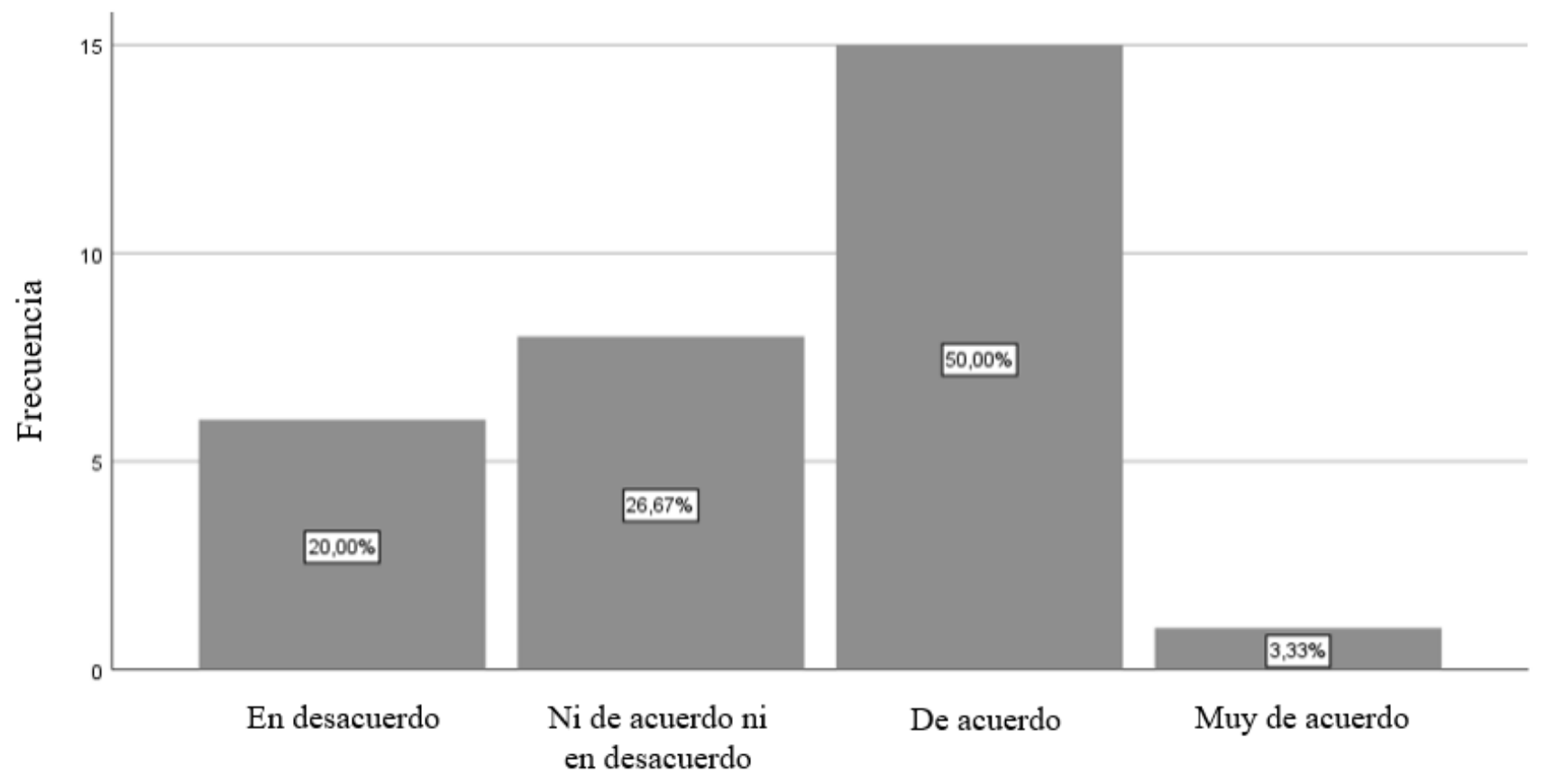

Figura 20

El precio de venta del colorante de maíz morado ha incrementado desde el aumento de la cantidad de empresas productoras de productos orgánicos y saludables en Estados Unidos. Adaptado de "Encuesta de colorante de maíz morado", por fuente propia, 2020.

Interpretación:

El 50\% de los encuestados respondió que se encuentra de acuerdo a que el precio de venta del colorante de maíz morado ha incrementado desde el aumento de la cantidad de empresas productoras de productos orgánicos y saludables en Estados Unidos. Mientras que un 20\% indicó que se encuentra en desacuerdo.

- Pregunta 21: El precio de exportación no se ha visto beneficiado debido al apoyo del estado peruano.

Tabla 27

Pregunta 21. 


\begin{tabular}{lrrrr}
\hline & Frecuencia & Porcentaje & $\begin{array}{c}\text { Porcentaje } \\
\text { válido }\end{array}$ & $\begin{array}{c}\text { Porcentaje } \\
\text { acumulado }\end{array}$ \\
\hline En desacuerdo & 1 & 3,3 & 3,3 & 3,3 \\
Ni de acuerdo ni en desacuerdo & 10 & 33,3 & 33,3 & 36,7 \\
De acuerdo & 17 & 56,7 & 56,7 & 93,3 \\
Muy de acuerdo & 2 & 6,7 & 6,7 & 100,0 \\
\hline Total & 30 & 100,0 & 100,0 & \\
\hline
\end{tabular}

Nota: Resultado de la pregunta 21: El precio de exportación no se ha visto beneficiado debido al apoyo del estado peruano. Adaptado de "Encuesta de colorante de maíz morado", por fuente propia, 2020.

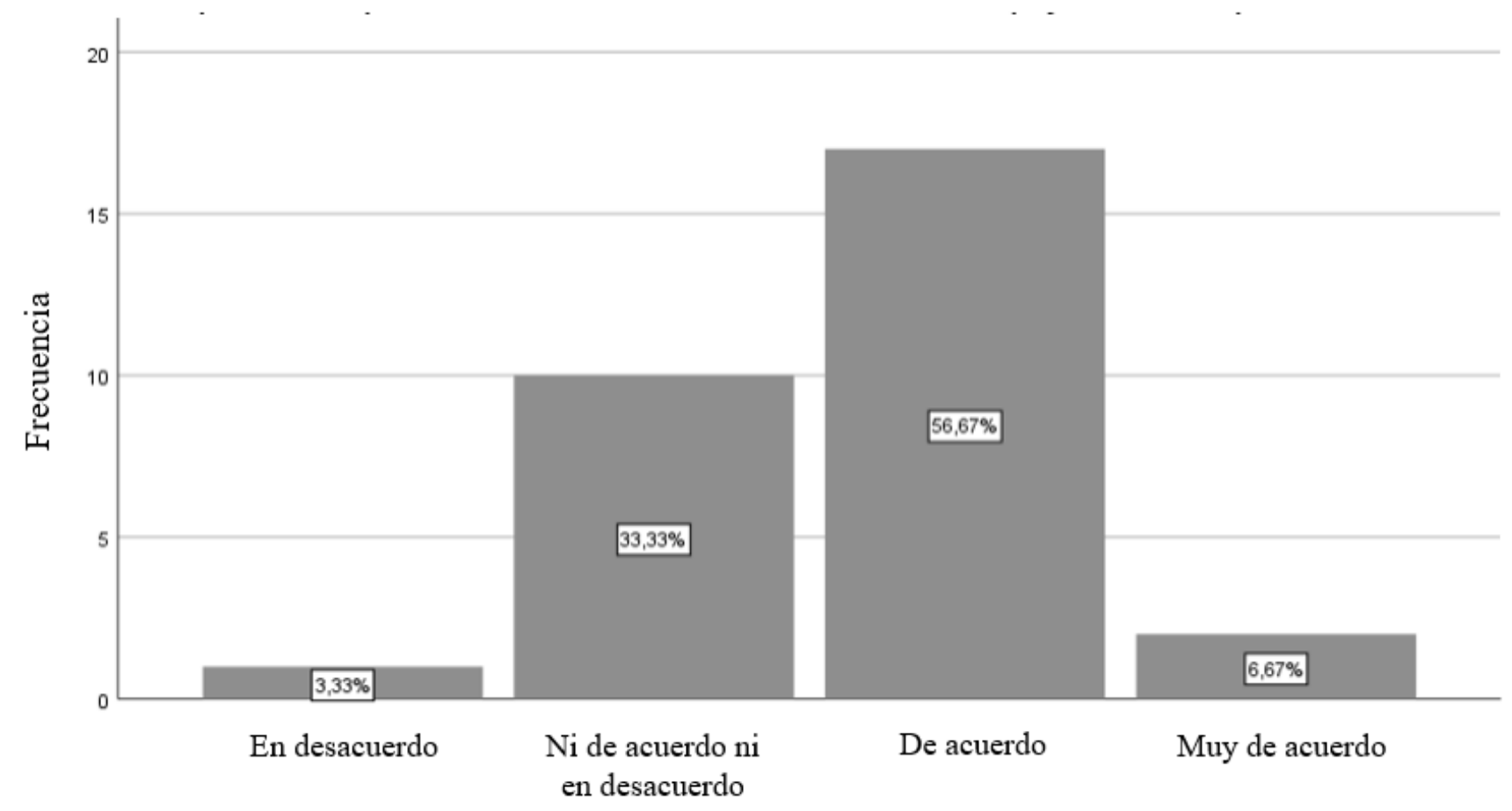

Figura 21

El precio de exportación no se ha visto beneficiado debido al apoyo del estado peruano.

Adaptado de "Encuesta de colorante de maíz morado", por fuente propia, 2020.

Interpretación: 
La mayoría de encuestados $(56.7 \%)$ está de acuerdo con que el precio de exportación no se ha visto beneficiado debido al apoyo del estado peruano. Seguido por un $33.3 \%$ que se encuentra ni de acuerdo ni en desacuerdo.

- Pregunta 22: Debido al aumento de oferta de empresas exportadoras de colorante de maíz morado, el costo de materia prima se ha visto afectado negativamente.

Tabla 28

Pregunta 22.

\begin{tabular}{lrrrr}
\hline & Frecuencia & Porcentaje & $\begin{array}{c}\text { Porcentaje } \\
\text { válido }\end{array}$ & $\begin{array}{c}\text { Porcentaje } \\
\text { acumulado }\end{array}$ \\
\hline En desacuerdo & 13 & 43,3 & 43,3 & 43,3 \\
Ni de acuerdo ni en desacuerdo & 9 & 30,0 & 30,0 & 73,3 \\
De acuerdo & 8 & 26,7 & 26,7 & 100,0 \\
\hline Total & 30 & 100,0 & 100,0 & \\
\hline
\end{tabular}

Nota: Resultado de la pregunta 22: Debido al aumento de oferta de empresas exportadoras de colorante de maíz morado, el costo de materia prima se ha visto afectado negativamente. Adaptado de "Encuesta de colorante de maíz morado", por fuente propia, 2020.

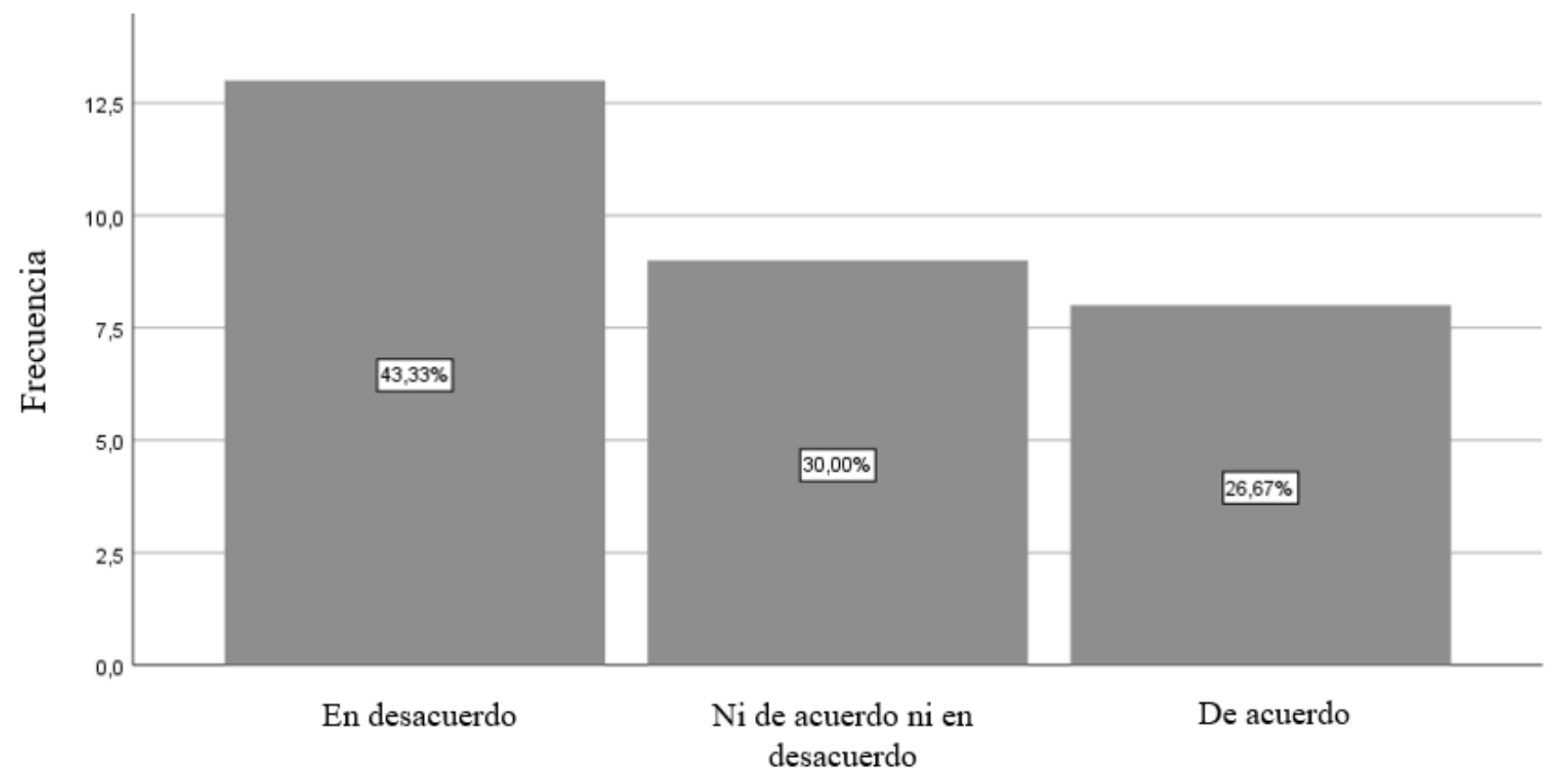


Figura 22

Debido al aumento de oferta de empresas exportadoras de colorante de maíz morado, el costo de materia prima se ha visto afectado negativamente. Adaptado de "Encuesta de colorante de maíz morado", por fuente propia, 2020.

Interpretación:

El 43.3\% de los encuestados indicó que se encuentra en desacuerdo con que, debido al aumento de oferta de empresas exportadoras de colorante de maíz morado, el costo de materia prima se ha visto afectado negativamente; por ende, el costo de materia prima se ha mantenido o se ha afectado de manera positiva.

- Pregunta 23: El aumento de demanda del colorante de maíz morado en el mercado de Estados Unidos no afecta al costo de exportación.

Tabla 29

Pregunta 23.

\begin{tabular}{lrrrr}
\hline & Frecuencia & Porcentaje & $\begin{array}{c}\text { Porcentaje } \\
\text { válido }\end{array}$ & $\begin{array}{c}\text { Porcentaje } \\
\text { acumulado }\end{array}$ \\
\hline Muy en desacuerdo & 1 & 3,3 & 3,3 & 3,3 \\
En desacuerdo & 11 & 36,7 & 36,7 & 40,0 \\
Ni de acuerdo ni en desacuerdo & 7 & 23,3 & 23,3 & 63,3 \\
De acuerdo & 9 & 30,0 & 30,0 & 93,3 \\
Muy de acuerdo & 2 & 6,7 & 6,7 & 100,0 \\
\hline Total & 30 & 100,0 & 100,0 & \\
\hline
\end{tabular}

Nota: Resultado de la pregunta 23: El aumento de demanda del colorante de maíz morado en el mercado de Estados Unidos no afecta al costo de exportación. Adaptado de "Encuesta de colorante de maíz morado", por fuente propia, 2020 . 


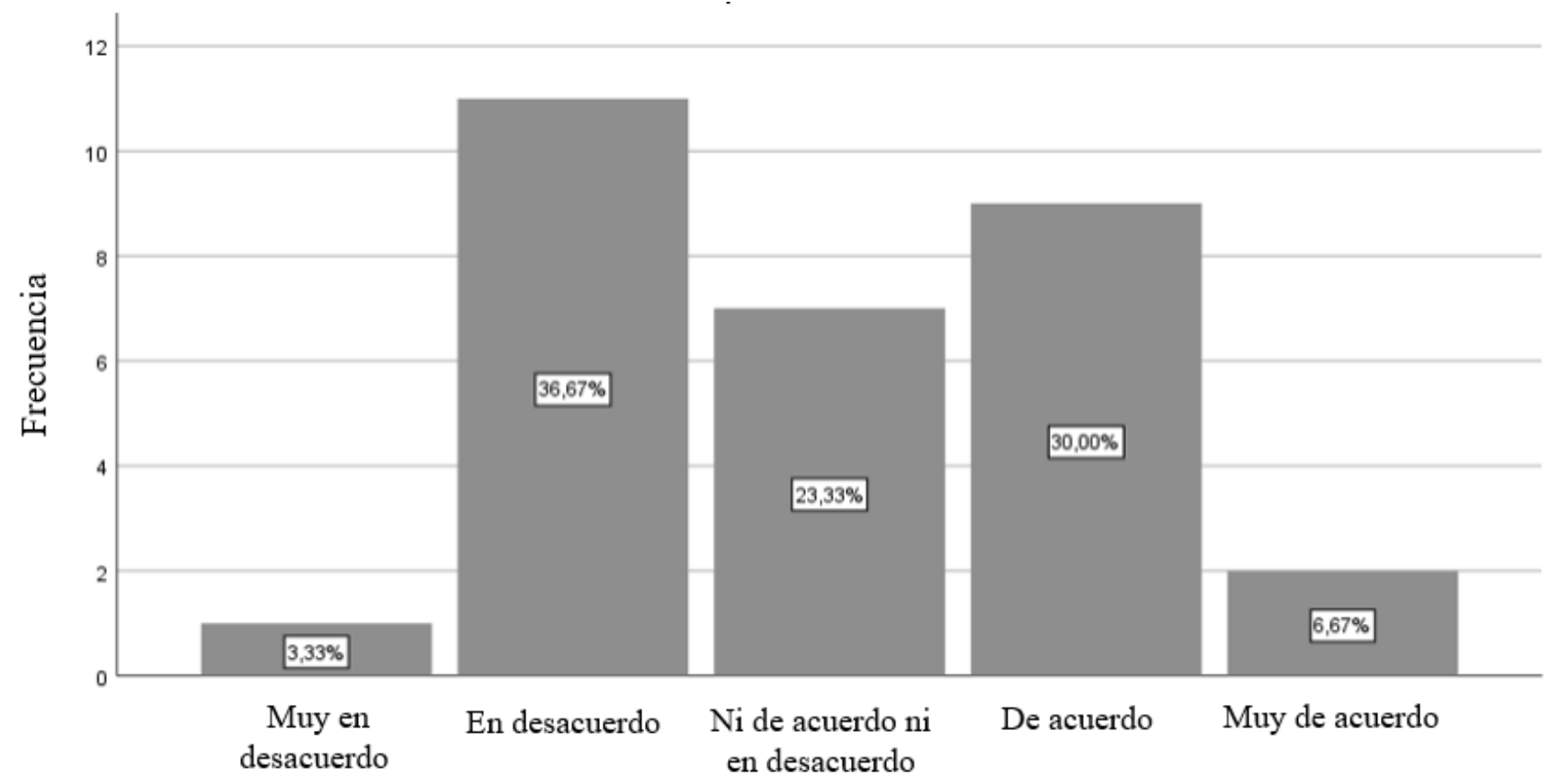

Figura 23

El aumento de demanda del colorante de maíz morado en el mercado de Estados Unidos no afecta al costo de exportación. Adaptado de "Encuesta de colorante de maíz morado", por fuente propia, 2020.

Interpretación:

Por un lado, un $36.7 \%$ opina que el aumento de demanda del colorante de maíz morado en el mercado de Estados Unidos sí afecta al costo de exportación y por el contrario, un 30\% opina que el aumento de demanda del colorante de maíz morado en el mercado de Estados Unidos no afecta al costo de exportación.

\subsubsection{Análisis Estadístico.}

Se analizó la confiabilidad del instrumento de investigación, empleando el estadístico Alfa de Cronbach, obteniéndose el valor de 0.752 que se muestra en la Tabla 28 a continuación y que se considera como un coeficiente de confiabilidad alto (De Franco \& Josefina, 2009).

Tabla 30 
Alfa de Cronbach Instrumento Completo.

\begin{tabular}{ll}
\hline \multicolumn{2}{c}{ Alfa de Cronbach } \\
\hline Instrumento Completo & 0.752 \\
\hline
\end{tabular}

Asimismo, se analizó en Alfa de Cronbach para la Variable Independiente Factores asociados a la comercialización del colorante de maíz morado y para la Variable Dependiente Exportaciones a Estados Unidos obteniéndose los resultados que se muestran en la Tabla 29.

Tabla 31

Alfa de Cronbach de Variables.

\begin{tabular}{cc}
\hline Variables/Dimensiones & $\begin{array}{c}\text { Alfa } \\
\text { Cronbach }\end{array}$ \\
\hline Factores & 0.647 \\
Exportaciones & 0.538 \\
\hline
\end{tabular}

El valor del Alfa de Cronbach de la Variable Independiente se considera como alto, mientras que el valor de la Variable Dependiente se considera como moderado (De Franco \& Josefina, 2009).

Cabe mencionar que según Nunnally (1994) los valores obtenidos del Alfa de Cronbach se consideran como aceptables para el presente tipo de investigación.

- Contrastación de Hipótesis:

La contrastación de las Hipótesis se efectuó empleando el análisis no paramétrico de correlación de Spearman al tratarse de variables ordinales (Díaz et al, 2014). Se consideró como regla de decisión un nivel de significancia estadística de p $<0.05$ para la aceptación de las hipótesis. 


\section{Hipótesis General:}

Los factores asociados a la comercialización del colorante de maíz morado y las exportaciones a Estados Unidos tienen una relación significativa durante el periodo 2015-2019.

Para efectos del análisis, se consideró como variable independiente a los Factores asociados a la comercialización del colorante de maíz morado y como variable dependiente las Exportaciones a Estados Unidos.

El resultado obtenido se muestra en la Tabla 30 y en la Figura 24 se muestra el diagrama de dispersión.

Tabla 32

Correlación de Spearman entre VI-VD.

\begin{tabular}{cccc} 
& VD & $\begin{array}{c}\text { Sig. } \\
\text { (bilateral) }\end{array}$ & $\begin{array}{c}\text { Contrastación } \\
\text { Hipótesis }\end{array}$ \\
\hline VI & $\mathbf{0 , 5 9 8}$ & 0.000 & Aceptada \\
\hline
\end{tabular}

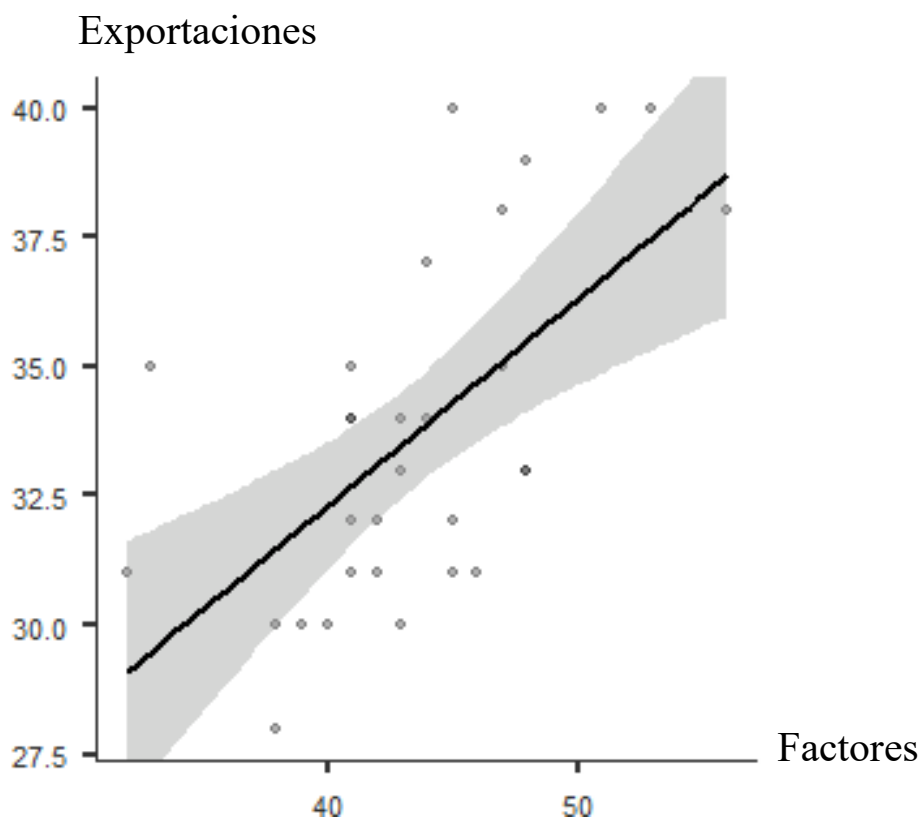


Figura 24

Correlación VI-VD.

Se obtuvo un coeficiente de correlación positiva de 0.598 . Este valor de correlación se considera como moderado (Martínez et al, 2009; Diaz, 2014). Presento una significancia estadística de 0.000 menor a 0.05 , por lo que se acepta la hipótesis y se concluye que existe una correlación positiva y moderada entre la Variable Independiente y la Variable Dependiente.

* Hipótesis Especificas:

H1: El apoyo del gobierno peruano y las exportaciones de colorante de maíz morado tienen relación significativa.

El resultado obtenido se muestra en la Tabla 31 y la Figura 25.

Tabla 33

Correlación de Spearman entre Apoyo del GP y Exportaciones.

\begin{tabular}{cccc} 
& Exportaciones & $\begin{array}{c}\text { Sig. } \\
\text { (bilateral) }\end{array}$ & $\begin{array}{c}\text { Contrastación } \\
\text { Hipótesis }\end{array}$ \\
\hline Apoyo GP & $\mathbf{0 , 4 6 3}$ & 0.010 & Aceptada \\
\hline
\end{tabular}




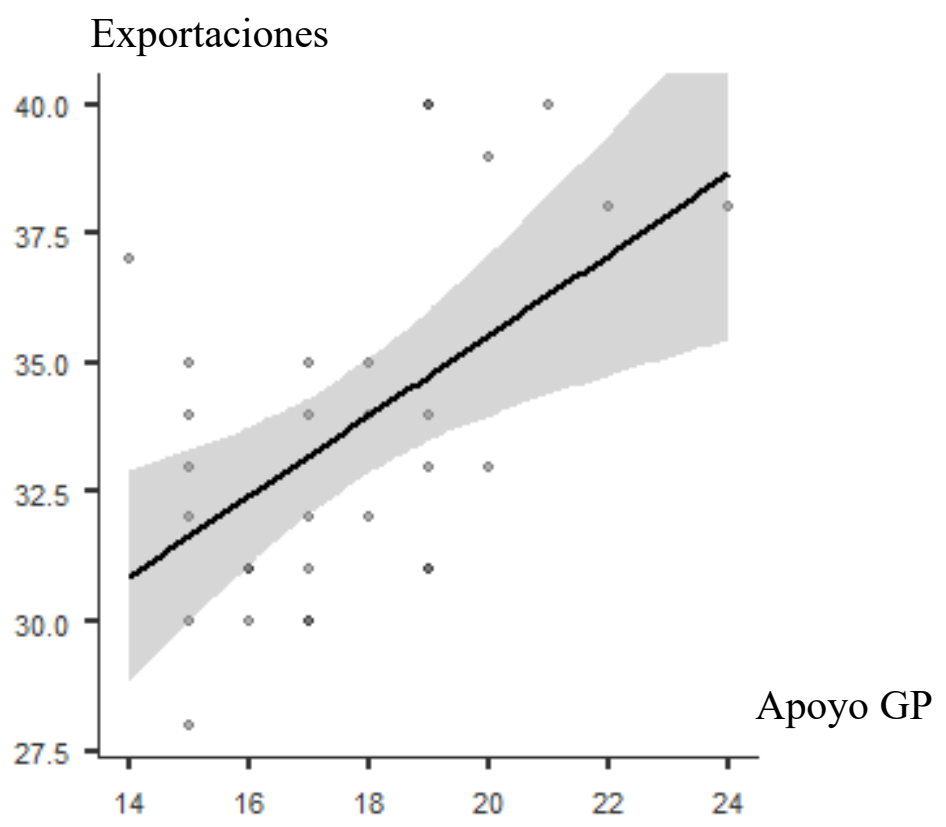

Figura 25

Correlación entre Apoyo del GP y Exportaciones.

Se obtuvo un coeficiente de correlación positivo de 0.463 . Este valor de correlación se considera moderado (Martínez et al, 2009; Diaz, 2014). Presento una significancia estadística de 0.010 menor a 0.05 , por lo que se acepta la hipótesis y se concluye existe una correlación positiva y moderada entre el Apoyo del Gobierno Peruano y las Exportaciones.

H2: La competitividad entre productores orgánicos y las exportaciones de colorante de maíz morado tienen relación significativa.

El resultado obtenido se muestra en la Tabla 32 y la Figura 26.

Tabla 34

Correlación de Spearman entre Competitividad y Exportaciones. 


\begin{tabular}{cccc}
\cline { 2 - 4 } & Exportaciones & $\begin{array}{c}\text { Sig. } \\
\text { (bilateral) }\end{array}$ & $\begin{array}{c}\text { Contrastación } \\
\text { Hipótesis }\end{array}$ \\
\hline Competitividad & $\mathbf{0 , 3 3 2}$ & 0.073 & Rechazada \\
\hline
\end{tabular}

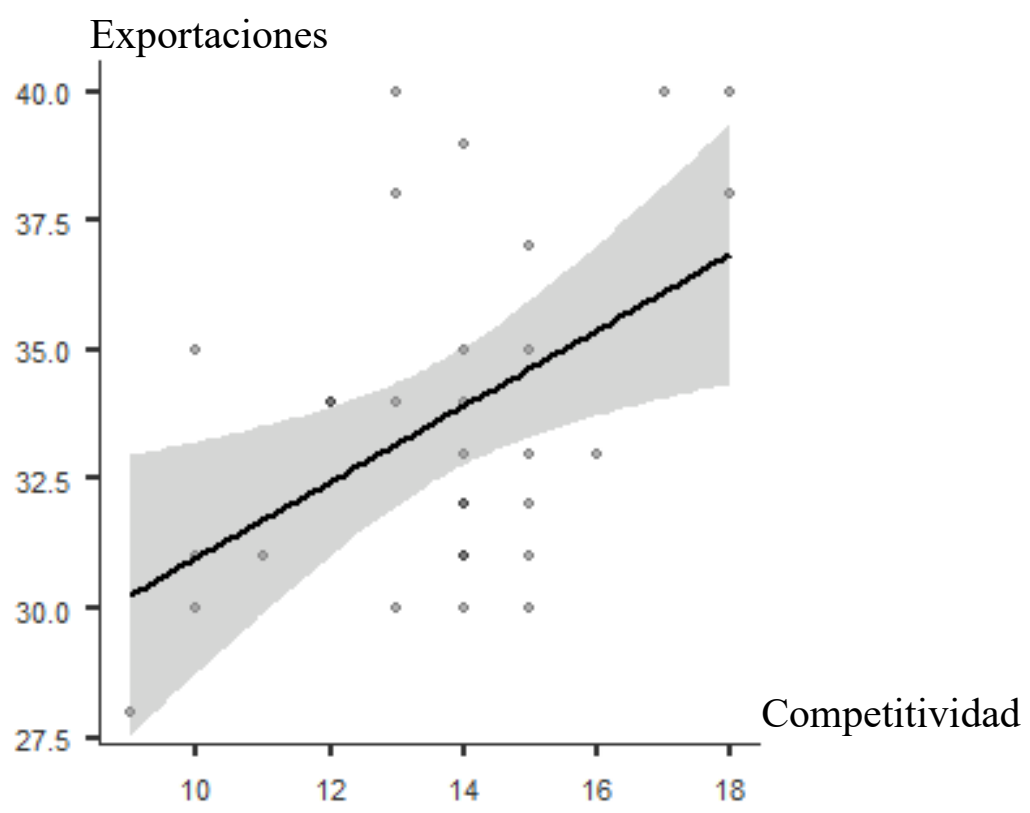

Figura 26

Correlación entre Competitividad y Exportaciones.

Se obtuvo un coeficiente de correlación positivo de 0.332. Este valor de correlación se considera como débil (Martínez et al, 2009; Diaz, 2014). Presento una significancia estadística de 0.073 mayor a 0.05 , por lo que se rechaza la hipótesis y se concluye no existe correlación entre la Competitividad y las Exportaciones.

H3: El daño que ocasionan los colorantes artificiales en la salud humana y las exportaciones de colorante de maíz morado tienen relación significativa.

El resultado obtenido se muestra en la Tabla 33 y la Figura 27. 
Tabla 35

Correlación de Spearman entre Boom Saludable y Exportaciones.

\begin{tabular}{lcc}
\hline Exportaciones & $\begin{array}{c}\text { Sig. } \\
\text { (bilateral) }\end{array}$ & $\begin{array}{c}\text { Contrastación } \\
\text { Hipótesis }\end{array}$ \\
\hline
\end{tabular}

\begin{tabular}{llll}
\hline Boom Saludable & $\mathbf{0 , 4 5 6}$ & 0.011 & Aceptada \\
\hline
\end{tabular}

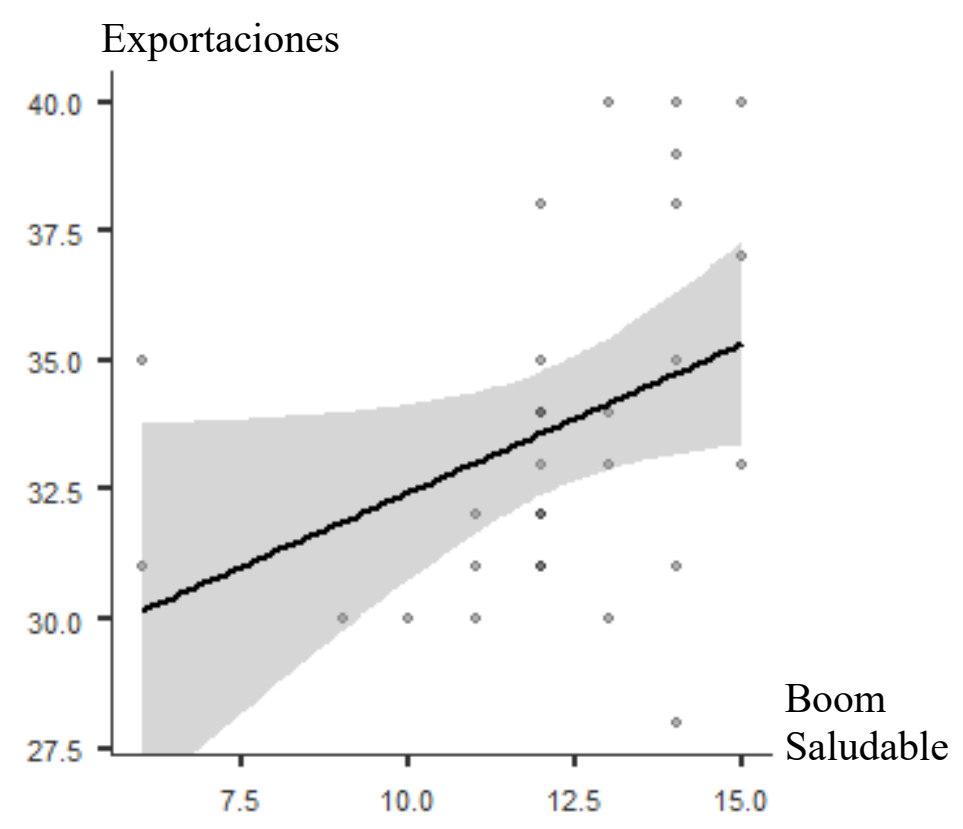

Figura 27

Correlación entre Responsabilidad Social y Exportaciones.

Se obtuvo un coeficiente de correlación positivo de 0.456 . Este valor de correlación se considera como moderado (Martínez et al, 2009; Diaz, 2014). Presento una significancia estadística de 0.011 menor a 0.05 , por lo que se acepta la hipótesis y se concluye existe una correlación positiva y moderada entre el Boom Saludable y las Exportaciones. 
A manera de resumen, la Tabla 34 muestra el resultado de la contrastación de la Hipótesis General y las Hipótesis específicas.

Tabla 36

Contrastación de Hipótesis General e Hipótesis Específicas.

\begin{tabular}{lcc}
\hline & Correlación & \\
Correlación Evaluada & de & Sig. (p- \\
& Spearman & valor)
\end{tabular}

\begin{tabular}{llcccc}
\hline $\begin{array}{l}\text { Hipótesis } \\
\text { General }\end{array}$ & VI-VD & 0.598 & 0.000 & + & Aceptada \\
H1 & Apoyo GP - Exportaciones & 0.463 & 0.010 & + & Aceptada \\
$\mathbf{H 2}$ & Competitividad - Exportaciones & 0.332 & 0.073 & na & Rechazada \\
$\mathbf{H 3}$ & Boom,Saludable - Exportaciones & 0.456 & 0.011 & + & Aceptada \\
\hline
\end{tabular}




\subsubsection{Discusión.}

La presente tesis tuvo como propósito comprobar los factores asociados a la comercialización de colorante de maíz morado a Estados Unidos en la industria alimentaria en el periodo 2015 2019. Los factores que se consideraron en dicha investigación fueron: el apoyo del estado peruano, la competitividad y el boom saludable pues luego de revisar investigaciones previas, estos tres factores fueron los más resaltantes. A continuación, se presentarán los principales hallazgos de este estudio.

Según lo presentado por Gallardo (2016), la evolución de la exportación de colorante de maíz morado al mercado de Estados Unidos 2008-2014 ha tenido una tendencia positiva, esto se visualizó en la investigación hasta el 2018; no obstante, según lo mostrado en el último año 2019 se ve una disminución del valor FOB. Esta disminución se debe al decrecimiento de empresas exportadoras del producto. Sin embargo, a pesar de que son menos empresas, el decrecimiento en el valor FOB no es significativo. Con esto podemos concluir que hay un interés de compra por parte de Estados Unidos hacia este producto.

De los resultados obtenidos en esta investigación, podemos apoyar la tesis de Rojas y Vergara (2018), pues al igual que ellas, la presente investigación muestra que hay una relación significativa entre el apoyo del estado peruano y las exportaciones de colorante de maíz morado a Estados Unidos. A pesar de que en el PDM de Estados Unidos y el PENX 2015 - 2025 no se muestra explícitamente un detalle de colorante de maíz morado o el rubro colorantes naturales, los exportadores de alguna u otra manera sí perciben el apoyo del estado peruano.

Por otro lado, si bien es cierto el colorante de maíz morado es altamente competitivo y según la data de Palaco (2018), en Estados Unidos el consumo per cápita de antocianinas es de 26 mg/día, 
con lo cual se proyectaba una demanda insatisfecha promedio de $46 \mathrm{Tn}$ para el periodo 2018 al 2027. Los resultados de competitividad de las empresas compradoras de colorante de maíz morado en la investigación demuestran que estos no representan ser un factor determinante para la comercialización del producto.

En la última década, la tendencia por lo saludable ha tenido cada vez mayor presencia en los hábitos de consumo de las personas. Considerando lo expuesto por Salas y Tovalino (2018) en su investigación respecto al alto potencial que posee la antocianina para reemplazar a los colorantes artificiales y su acogida en el mercado estadounidense. Con la presente investigación se refuerza dicho potencial pues la tendencia por lo saludable sí representa un factor relacionado a la comercialización del colorante de maíz morado a Estado Unidos.

Gracias a lo expuesto por Bonilla y Guamán (2019), el Perú tiene un alto potencial en el mercado internacional para lo referente a colorantes naturales. Esto es debido a las buenas prácticas que aplica Perú para que el colorante de maíz morado pueda cumplir con los estándares de calidad de los diferentes mercados. Finalmente, se puede concluir que la investigación aún se puede seguir profundizando en el tema considerando distintos factores a los planteados. Además, el objetivo no especificado es continuar fomentando en los exportadores el interés por exportar el colorante de maíz morado a los diferentes mercados internacionales. 


\subsubsection{Conclusiones.}

A partir de la investigación realizada se han encontrado las siguientes conclusiones:

En primer lugar, se tuvo como principal objetivo identificar los factores asociados a la comercialización del colorante de maíz morado en la industria alimentaria y las exportaciones a Estados Unidos durante en el periodo 2015 - 2019. Se concluye que los factores: apoyo del estado peruano y tendencia saludable han influenciado en la exportación de colorante de maíz morado debido a que han presentado un grado moderado de significancia en la investigación cuantitativa realizada. En contraste, el factor de competitividad de empresas compradoras no mostró una relación significativa con las exportaciones a Estados Unidos.

En segundo lugar, el factor apoyo del estado peruano es correcto concluir que sí está asociado a la comercialización de colorantes de maíz morado en las exportaciones a Estados Unidos. Sin embargo, este factor no está orientado hacia el PDM de Estados Unidos y/o el PENX 2015 - 2025, sino que los exportadores perciben el apoyo mediante otros medios. Entre estos se encuentra que el estado peruano brinda distintas herramientas que facilitan la exportación del producto. Asimismo, el exportador puede acogerse al beneficio del drawback y recibir información en general sobre otros beneficios arancelarios.

En tercer lugar, el factor competitividad entre las empresas compradoras no está asociada a la comercialización de colorantes de maíz morado en las exportaciones a Estados Unidos en esta investigación, debido a que no alcanzó el nivel de significancia requerido. Este factor tuvo un error mayor a 0.05 ; con lo cual, estadísticamente no es aceptado. Por lo tanto, podemos concluir que es un factor importante, mas no relevante en esta investigación. 
Por último, el factor tendencias saludables se encuentra asociado a la comercialización de colorantes de maíz morado en las exportaciones a Estados Unidos, a causa de que esta tendencia ha estado en aumento en estos últimos años especialmente en el mercado estadounidense. Prueba de ello, es el mayor interés de los consumidores por productos orgánicos y naturales. Con esto se puede concluir, que es un factor con un moderado nivel de significancia en la investigación.

\subsubsection{Recomendaciones.}

Luego de esta investigación podemos recomendar que, desde el punto de vista metodológico, para obtener información a mayor profundidad sobre estos factores se incluya como complemento a las encuestas realizar entrevistas a profundidad a personas del rubro, para tener un punto de vista cualitativo en la investigación.

Desde el punto de vista académico, recomendamos que se realice una nueva investigación considerando otros factores y así determinar qué otros están asociados a la comercialización de colorante de maíz morado y las exportaciones a Estados Unidos. Adicional a ello, se recomienda profundizar en el factor de competitividad, incluso darle un enfoque distinto al realizado en esta investigación para determinar la relevancia que tiene en la comercialización del producto.

Por último, desde el punto de vista práctico, se recomienda principalmente que se incluya el rubro de colorantes naturales dentro de la información brindada sobre el mercado estadounidense, ya sea en el PDM a Estados Unidos u otro similar. Todo esto, con la finalidad de que sirva como fuente de información y así generar mayor interés por el producto a los exportadores actuales y sobre todo a potenciales exportadores. 


\section{Bibliografía}

Aguilera-Otíz, M; Reza-Vargas, M; Chew-Madinaveita, R y Meza-Velázquez, J. (2011). PROPIEDADES FUNCIONALES DE LAS ANTOCIANINAS. Biotecnia, 13(2), 16. doi: 10.18633/bt.v13i2.81.

Aguirre, N. (2018). Desarrollo de un Colorante Natural desde el fruto del Saúco Negro (Sambucus nigra) para uso en la Industria Alimentaria (Licenciatura en Ingeniera Agroindustrial y de Alimentos). Universidad de Las Américas, Quito. Recuperado de: http://dspace.udla.edu.ec/bitstream/33000/10101/1/UDLA-EC-TIAG-2018-24.pdf.

Alejos, L y Ríos, A. (2019). Competitividad y los factores que influyen en las exportaciones de cacao de Perú (Licenciado en Negocios Internacionales). Universidad Peruana de Ciencias Aplicadas (UPC), Lima. Recuperado de: https://doi.org/10.19083/tesis/625705.

Alfaro, J., González, C., \& Pina, M. (2013). Economía de la empresa (2nd ed., pp. 61-81). Madrid: McGraw-Hill.

Araujo, M. (1995). Estudio de la extracción del colorante de maíz morado (Zea mays L.) con el uso de enzimas (en línea). Tesis para optar el grado de Magister Sc en Tecnología de Alimentos. Lima - Perú. Universidad Nacional Agraria La Molina. Recuperado de: http://www.sidalc.net/cgi-

bin/wxis.exe/?IsisScript=CEDIIA.xis \&method=post $\&$ formato $=2 \&$ cantidad $=1 \&$ expresion $=\mathrm{mf}$ $\mathrm{n}=000443$.

Arbaiza, L. (2014). Cómo elaborar una tesis de grado. Lima: Esan ediciones.

Bonilla, V y Guamán, J. (2019). Comparación del Mercado de Carmín de Cochinilla entre Ecuador y Perú y su potencial de comercialización hacia la Unión Europea (Ingeniero). Universidad de las Fuerzas Armadas - ESPE. Recuperado de: http://repositorio.espe.edu.ec/bitstream/21000/15855/1/T-ESPE-040780.pdf.

Burneo, K., \& Larios, J. (2015). Principios de Economía (2nd ed., pp. 33-42). Lima: Fondo Editorial. 
Bustillo, R. (2000). Comercio exterior (p. 11). [S.1.]: Universidad del País Vasaco, Servicio Editorial $=$ Euskal Herriko Unibertsitiatea, Argitalpen Zerbitzua.

Carmona, I. (2013). De colorantes sintéticos a naturales en la industria alimentaria (pp. 1 - 6). Santiago de Chile: ODEPA. Recuperado de: http://www.agrimundo.gob.cl/wpcontent/uploads/130426_reporte_alimentos_procesados_n51.pdf.

Carrasco, S. (2002). El comercio internacional, Segunda edición. Recuperado de: https://www.google.com/search?q=(Lic.Eco.+Carrasco\%2C+2002\%2C+p\%C3\%A1gs.+4-.

Castro, F. (2003). El proyecto de investigación y su esquema de elaboración. (2da. ed., pp. 69). Caracas: Uyapal.

Ching, S; Ingram, D; Hahnel, R y Rossi, E. (2002). Los niveles séricos de micronutrientes, antioxidantes y el estado antioxidante total predecir el riesgo de cáncer de mama en un estudio de casos y controles. Diario de nutrición.

D’alessio, F. (2004). Administración y Dirección de la Producción (2da. ed.). Lima, Perú: Pearson Educación Ltda.

Daniels, J; Radebaugh, L; Sullivan, D; Pineda, L y Jasso, E. (2018). Negocios internacionales. Ambientes y Operaciones (15th ed., pp. 360-373). Ciudad de México: Pearson Educación de México S.A. de C.V.

De Franco, C., \& Josefina, Y. (2009). Validez y confiabilidad de los instrumentos de investigación para la recolección de datos.

Díaz, I., García, C., León, M., Ruiz, F., \& Torres, F. (2014). Guía de Asociación entre variables (Pearson y Spearman en SPSS). Universidad de Chile FACSO.

«Diccionario de la lengua española» - Edición del Tricentenario. 2014. Comercialización | Diccionario De La Lengua Española. [online] Recuperado de: $<$ https://dle.rae.es/comercializaci\%C3\%B3n>.

Durak, L; Kacmaz, M; Cimen, M; Buyukkock, U. y Ozturk, H. (2001). Oxidante de sangre/el estado antioxidante de las pacientes arterioscleróticas, diario de la cardiología. 
El Comercio (2019). Repasa la historia del comercio exterior. Recuperado de: https://elcomercio.pe/suplementos/contratado/adex/repasa-historia-comercio-exterior1003908.

FDA. (2004). Overview of Food Ingredients, Additives \& Colors. Recuperado de: https://www.fda.gov/food/food-ingredients-packaging/overview-food-ingredients-additivescolors\#coloradd.

FDA. (2018). The History of FDA's Fight for Consumer Protection. Recuperado de: https://www.fda.gov/about-fda/history-fdas-fight-consumer-protection-and-public-health.

FDA. (2019). Colorantes y Cosméticos. Recuperado de: https://www.fda.gov/media/96248/download.

FDA. (2020). Electronic Code of Federal Regulations (eCFR). Recuperado de: https://www.ecfr.gov/cgi-bin/textidx?c=ecfr\&SID=0f29870bbafc6ae3d1efc78d9927d918\&tpl=/ecfrbrowse/Title21/21cfr73_ma in_02.tpl.

Fernández, N. A. (1995). Estudio de la extracción y pre - purificación de antocianinas de maíz morado (lea mays L.). Tesis lng. En Industrias Alimentarias. UNALM. Lima- Perú. 116 pp.

Gallardo, W. (2016). Exportación de maíz morado al mercado de Estados Unidos 2008-2014, tesis para obtener el título profesional de licenciado en negocios internacionales, de la Universidad Cesar Vallejo, Lima. Recuperado de: http://repositorio.ucv.edu.pe/handle/UCV/1632.

Garzón, G. (2008). Las antocianinas como colorantes naturales y compuestos bioactivos: Revisión. Acta Biológica Colombiana, 13(3), 27-36. Recuperado de: https://www.redalyc.org/pdf/3190/319028004002.pdf.

Google (2016). Estilo de vida: la nueva tendencia hacia un consumo saludable. Recuperado de: https://www.thinkwithgoogle.com/intl/es-419/recursos-y-herramientas/video/estilo-vidasaludable-tendencia-consumo/. 
Hayes, B. (1999). Cómo medir la satisfacción del cliente: Diseño de encuestas, uso y métodos de análisis estadístico (2nd ed., pp. 20-25). México: UNIVERSIDAD IBEROAMERICANA.

Hernández, R; Fernández, C. y Baptista, M. (2014). Metodología de la investigación. (6a. ed., pp. 150-157). México D.F.: McGraw-Hill Interamericana.

Hill, C. (2015). Negocios internacionales (10th ed., pp. 158-180). México: McGraw-Hill Interamericana.

Ibáñez, C. y Troncoso, C. (2001). Algunas teorías e instrumentos para el análisis de la competitividad. IICA, San José, C. R. 74 pp.

Joseph, J; Arendas, G; Gordon, M. (2003). La administración de suplementos de arándanos mejora la señalización y evita anomalías de comportamiento en un modelo de la enfermedad de Alzheimer neurociencia. 153-162 p.

Justiniano, E. (2010). Fenología e Intensidad de color en corontas del Maíz Morado (Zea mayz L.) en sus diferentes Estados de Desarrollo en la Localidad de La Molina (Magister). Universidad Nacional Agraria La Molina. Recuperado de: http://repositorio.lamolina.edu.pe/bitstream/handle/UNALM/1716/PAG11.139T.pdf?sequence $=1 \&$ is Allowed=y.

Kraft, T. (2008). Composición fitoquímica y la actividad metabólica de máximo rendimiento de las bayas de la dieta. Diario de la agricultura y química de los alimentos. 654-660 p.

Lizano, A. (2012). Efecto del proceso de fritura en el contenido de antocianinas en empanadas elaboradas con mezclas de harina de trigo - maíz morado, Tesis de grado presentada como requisito para la obtención del título de Ingeniería de Alimentos, de la Universidad San Francisco de Quito, Ecuadorrepositorio.usfq.edu.ec > bitstream

López, C. (2002). Los factores claves de éxito - GestioPolis. Recuperado de: https://www.gestiopolis.com/factores-claves-exito/.

Manrique, A. (1995). PPMCT-INIA Lima-Perú. Maíz morado peruano. 24 pp. 
Manrique, A. (1997). El maíz en el Perú. Segunda edición, ediciones CONCYTEC Lima - Perú.

Márquez, L. (2010). Plan de Negocios para Exportación (Licenciado en Comercio Exterior). Universidad Autónoma de Baja California Sur. Recuperado de: http://biblio.uabcs.mx/tesis/TE\%202634.pdf.

Martínez Ortega, R. M., Tuya Pendás, L. C., Martínez Ortega, M., Pérez Abreu, A., \& Cánovas, A. M. (2009). El coeficiente de correlación de los rangos de Spearman caracterización. Revista Habanera de Ciencias Médicas, 8(2), 0-0.

Mendoza, C; Mendoza, M; Delgado, A; Castillo, F; Kato, T y Cruz, S. (2017). Antocianinas Totales y Parámetros de Color en Líneas de Maíz Morado. Revista Fitotecnia Mexicana, 40(4), 471-479. Recuperado de: https://www.revistafitotecniamexicana.org/documentos/404/11a.pdf.

MINCETUR (2015). Plan de Desarrollo de Mercado: Estados Unidos. Recuperado de: https://www.mincetur.gob.pe/wpcontent/uploads/documentos/comercio_exterior/plan_exportador/Penx_2025/PDM/EstadosUn idos/PDM_EEUU.pdf.

MINCETUR (2015). Plan Exportador - Plan Estratégico Nacional Exportador 2003-2013 Mincetur. Recuperado de: https://www.mincetur.gob.pe/plan-estrategico-nacional-exportador/.

MINCETUR (2019). Comercio Exterior - Mincetur. Recuperado de: https://www.mincetur.gob.pe/comercio-exterior/.

MINCETUR (n.d). Plan Estratégico Nacional Exportador 2025. Recuperado de: https://www.mincetur.gob.pe/wpcontent/uploads/documentos/comercio_exterior/plan_exportador/Penx_2025/PENX_FINAL_ 101215.pdf.

Ministerio de Agricultura y Riego (2017). Maíz Morado. Lima: Minagri. Recuperado de: http://agroaldia.minagri.gob.pe/biblioteca/download/pdf/tematicas/f-taxonomia_plantas/f01cultivo/maiz_morado.pdf.

Nunnally, Jum C. 1994. Psychometric theory 3E. Tata McGraw-Hill Education. 
Olsson, E; Gustavsson, K; Duan, R. (2004). La inhibición de la proliferación de células cancerosas in vitro por extractos y correlaciones con los niveles de antioxidantes. Diario de la química agrícola y alimentaria. 7264-7271 p.

Otzen, T. y Manterola, C. (2017). Técnicas de Muestreo sobre una Población a Estudio. Int. J. Morphol, 35(1), 227-232. Recuperado de: https://scielo.conicyt.cl/pdf/ijmorphol/v35n1/art37.pdf.

Palaco J. (2018). Proyecto para la instalación de una planta de procesamiento de maíz morado de la variedad Morado Canteño para la obtención y exportación de antocianinas 2018. Recuperado de: http://repositorio.ucsp.edu.pe/handle/UCSP/15934.

Parra, V. (2004). Estudio comparativo en el uso de colorantes naturales y sintéticos en alimentos, desde el punto de vista funcional y toxicológico (Licenciatura). Universidad Austral de Chile. Recuperado de: http://cybertesis.uach.cl/tesis/uach/2004/fap259e/pdf/fap259e.pdf.

Quintela del Rio, A. (2019). Estadística Básica Edulcorada (1st ed., pp. 305-308). Electrónico: Creative Commons License.

Rafael, E. (2017). Extracción y CUANTIFICACIÓN DE ANTOCIANINAS DE MAÍZ MORADO (Zea mays L.) utilizando dos solventes a diferentes temperaturas y tiempos de extracción (Licenciatura). Universidad Nacional de Cajamarca. Recuperado de: http://repositorio.unc.edu.pe/bitstream/handle/UNC/1726/EXTRACCI\%C3\%93N\%20Y\%20C UANTIFICACI\%C3\%93N\%20DE\%20ANTOCIANINAS\%20DE\%20MA\%C3\%8DZ\%20M ORADO\%20\%28ZEA\%20MAYZ\%20L.\%29\%20UTILIZANDO\%20DOS\%20SOLVENTES .pdf? sequence $=1 \&$ isAllowed $=\mathrm{y}$.

Risco, M; Reland, D; Avendaño, T; Martínez, A; Quispe, P; Pérez, Ch;...Valdez, R. (2007). Conociendo la cadena productiva del maíz morado en Ayacucho. Solid-Perú. Recuperado de: https://es.scribd.com/document/84836125/Cadena-Productiva-de-maiz-morado.

Robles, B. (2019). Población y muestra. Pueblocont., 30(1), 245-246.

Rojas, F y Vergara, B. (2018). Plan de Negocio de Exportación de la Antocianina de Maíz Morado de la Empresa Industria y Comercio Lambayeque (INCOLAM) para el Mercado Nutraceútico 
de Estados Unidos 2016 (Licenciatura). Universidad Señor de Sipán. Recuperado de: http://repositorio.uss.edu.pe/bitstream/handle/uss/4825/Rojas\%20Menor\%20\%26\%20Vergara \%20Leython.pdf?sequence=1\&isAllowed=y.

Salas, D y Tovalino, S. (2018). Obtención de antocianinas de papa nativa "Yawar Wayku" (solanum stenotomum) para la elaboración de un colorante natural aplicable a alimentos (licenciatura). Universidad San Ignacio de Loyola. Recuperado de: http://repositorio.usil.edu.pe/handle/USIL/3988.

Salinas, Y, Rubio, D; Díaz, A. (2005). Extracción y uso de pigmentos del maíz (Zea mays L) como colorantes en yogur. Departamento de ingeniería agroindustrial. Universidad autónoma Chapingo, México. 293-298 p.

Sarduy, Y. (2007). El análisis de información y las investigaciones cuantitativa y cualitativa. Recuperado de: https://www.scielosp.org/article/rcsp/2007.v33n3/10.1590/S0864$34662007000300020 / \mathrm{pt} /$.

Secilio, G. (2005). La calidad en alimentos como barrera para-arancelaria. Buenos Aires: Naciones Unidas, CEPAL, Oficina de la CEPAL en Buenos Aires.

Sevilla, P; Valdez, M. (1985). Fopex Lima-Perú. Manual del cultivo. Maíz morado.

Solís, S. (2017). Comercio internacional y competitividad de colorantes de maíz morado peruano 2008 - 2016, tesis para optar al título de profesional Licenciada en negocios Internacionales, de la Universidad Cesar Vallejo, Lima. Recuperado de: http://repositorio.ucv.edu.pe/handle/UCV/1966.

Suárez, P. (2018). Plan de Desarrollo de Mercado - PDM. Recuperado de: http://repositorio.promperu.gob.pe/bitstream/handle/123456789/3590/Plan_Desarrollo_Merca do_Italia_2018_keyword_principal.pdf?sequence=1\&isAllowed=y.

SUNAT (2008). Normas Aduaneras. Recuperado de: http://www.sunat.gob.pe/legislacion/procedim/normasadua/gja-03normasoc.htm. 
Urrutia, M. (1994). Productividad y competitividad. Revista Banco de la República. No 17. Bogotá, D.C.

Villanueva, R y Yrala, G. (2018). Vida Saludable. Recuperado de: http://www.datum.com.pe/new_web_files/files/pdf/Vida-Saludable.pdf. 
Anexos

ANEXO 1: Matriz de consistencia.

\section{MATRIZ DE CONSISTENCIA}

\section{"FACTORES ASOCIADOS A LA COMERCIALIZACIÓN DE COLORANTE DE MAÍZ MORADO EN LA INDUSTRIA ALIMENTARIA Y SU RELACIÓN CON LAS EXPORTACIONES A ESTADOS UNIDOS PERIODO 2015 - 2019”}

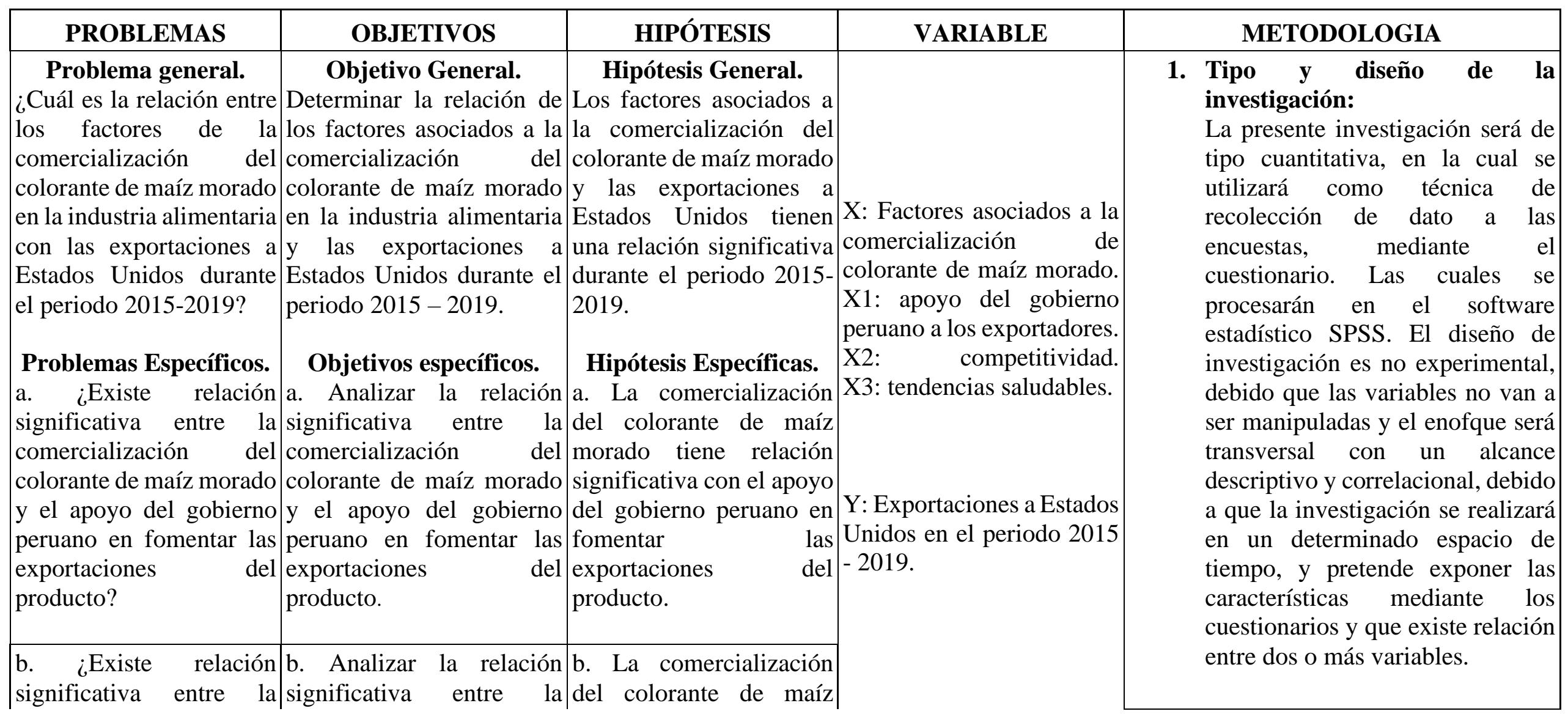




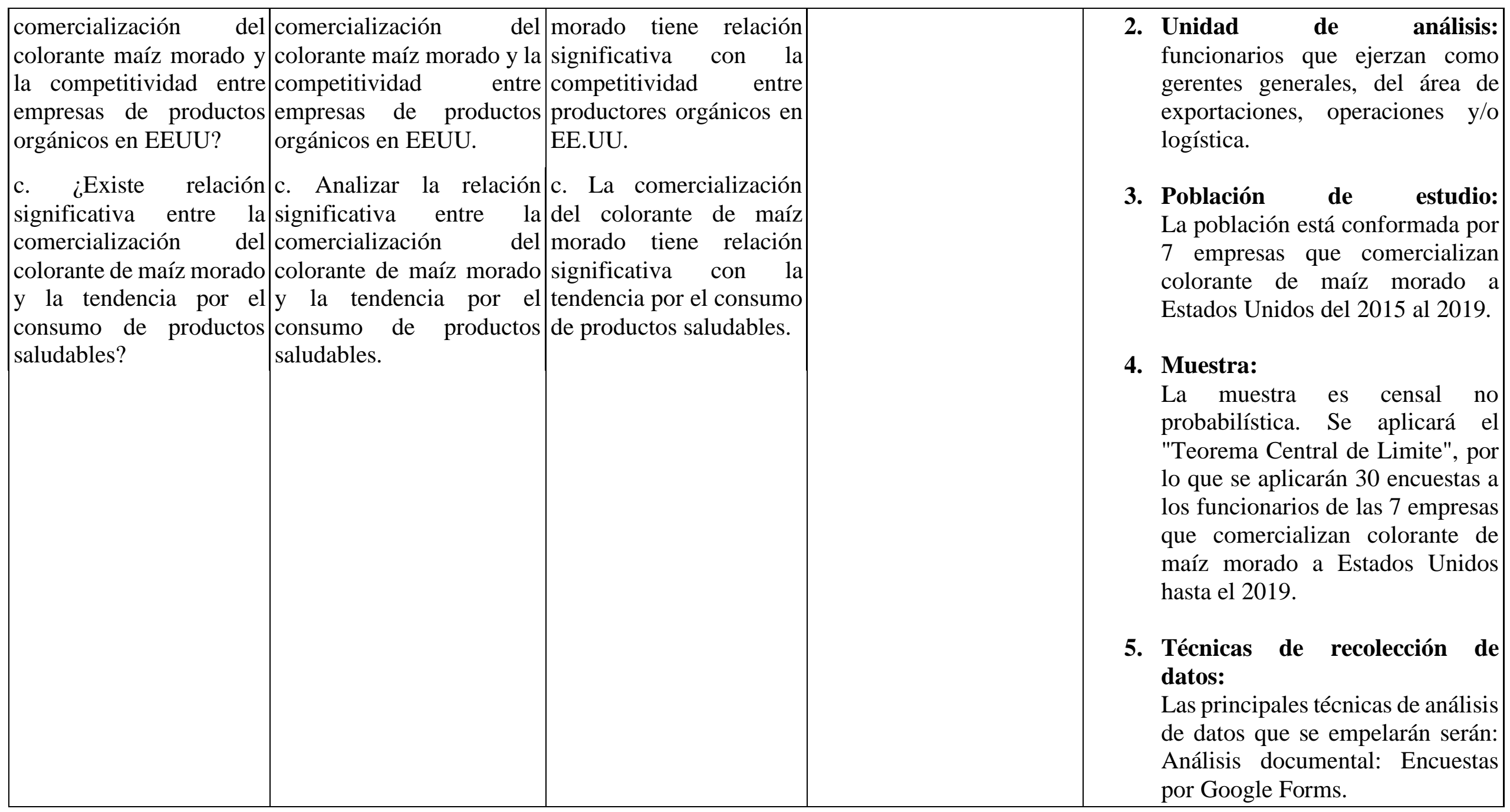




\section{ANEXO 2: Formato de validez de contenido.}

Lima, 20 de marzo de 2020

Estimado:

Presente:

Me dirijo a usted con la finalidad de solicitar su valiosa colaboración en calidad de JUEZ para validar el contenido del instrumento Cuestionario. Instrumento que lleva por título: Formulario de Validación de Instrumento de Tesis.

Para dar cumplimiento a lo anteriormente expuesto se hace entrega formal de la operacionalización de variables involucradas en el estudio, el cuestionario, la tabla de especificaciones respectivas, y los dos formatos de validación, el cual deberá llenar de acuerdo a sus observaciones, a fin de orientar y verificar la claridad, congruencia, control de la tendenciosidad y dominio de los contenidos de los diversos ítems de los cuestionarios.

Agradezco de antemano su receptividad y colaboración. Su apoyo nos permitirá adquirir habilidades y competencias profesionales y científicas que forman parte del proceso de investigación.

Quedo de Ud. en espera del feedback respectivo para mejorar el presente trabajo.

Muy Atentamente:

Romero Ortega, Doris. Scamarone Cornejo, Priscilla. 


\section{INSTRUMENTO PARA LA VALIDEZ DE CONTENIDO (JUICIO DE EXPERTOS)}

El presente instrumento tiene como finalidad validar el cuestionario de la tesis titulada: "Factores de éxito de las exportaciones de colorante de maíz morado en la industria alimentaria a Estados Unidos periodo $2014-2018$ ".

El mismo será aplicado en un diseño cuantitativo no probabilístico. La cual será aplicada a la muestra en estudio para la validación del instrumento a utilizar titulado: Formulario de Validación de Instrumento de Tesis.

\section{Instrucciones}

La evaluación requiere de la lectura detallada y completa de cada uno de los ítems propuestos a fin de cotejarlos de manera cualitativa con los criterios propuestos relativos a: relevancia o congruencia con el contenido, claridad en la redacción, tendenciosidad o sesgo en su formulación y dominio del contenido. Para ello deberá asignar una valoración si el ítem presenta o no los criterios propuestos, y en caso necesario se ofrece un espacio para las observaciones si hubiera.

Juez $\mathrm{N}^{\mathrm{o}}$ :

Fecha actual:

Nombres y Apellidos de Juez:

Institución donde labora:

Años de experiencia profesional o científica: 


\section{FORMULARIO DE VALIDACIÓN DE TESIS}

Cuestionario dirigido a empresas exportadores de colorante de maíz morado a Estados Unidos, años 2014 - 2018 Número de empresa:

Número de

cuestionario:

Estimado (a), la información que proporcione a través de este instrumento de recolección de información será utilizada de manera confidencial y con fines meramente científicoacadémicos, los cuales serán procesados y presentados de forma general en una tesis. Por ello le agradecemos anticipadamente su tiempo y atención en el llenado del presente cuestionario.

I. INFORMACIÓN SOCIODEMOGRÁFICA:

$\begin{array}{lll}\text { Nombre } & : & \text { Cargo } \\ \text { que ocupa }: \_ \text {Empresa } & :\end{array}$

II. CUESTIONARIO: Lea cuidadosamente todo el documento y elija la opción que se ajuste más a su respuesta.

\begin{tabular}{|c|c|c|c|c|c|}
\hline Preguntas & $\begin{array}{c}\text { Totalmente } \\
\text { en desacuerdo }\end{array}$ & $\begin{array}{c}\text { De } \\
\text { desacuerdo }\end{array}$ & $\begin{array}{l}\text { Ni de acuerdo } \\
\text { ni en } \\
\text { desacuerdo }\end{array}$ & De acuerdo & $\begin{array}{l}\text { Totalmente } \\
\text { de acuerdo }\end{array}$ \\
\hline \multicolumn{6}{|l|}{$\begin{array}{l}\text { Factores de éxito: Apoyo del estado } \\
\text { peruano }\end{array}$} \\
\hline $\begin{array}{l}\text { 1. Considera que el estado peruano } \\
\text { promociona el producto a los } \\
\text { diversos mercados internacionales. } \\
\text { Usted está... }\end{array}$ & ( ) & ) & ( & ( & ) \\
\hline $\begin{array}{l}\text { 2. Considera que el estado le brinda } \\
\text { facilidades para la exportación del } \\
\text { producto. Usted está... }\end{array}$ & $(\quad)$ & ( & ( & ( ) & ) \\
\hline $\begin{array}{l}\text { 3. Considera que el PENX no aporta } \\
\text { positivamente al volumen } \\
\text { exportado durante el periodo } \\
\text { mencionado. Usted } \\
\text { está... }\end{array}$ & $(\quad)$ & ( & ( & ( & ) \\
\hline
\end{tabular}




\begin{tabular}{|c|c|c|c|c|c|c|c|c|c|c|}
\hline $\begin{array}{l}\text { 4. El PENX no ha aportado al aumento } \\
\text { de la competitividad de su empresa } \\
\text { en el mercado americano. Usted } \\
\text { está... }\end{array}$ & ( & ) & & ) & & ) & & ) & ( & ) \\
\hline $\begin{array}{l}\text { 5. El estado peruano le brinda } \\
\text { información sobre las tendencias y } \\
\text { necesidades del mercado } \\
\text { americano. Usted está... }\end{array}$ & ( & ) & ( & ) & ( & ) & ( & ) & ( & ) \\
\hline $\begin{array}{l}\text { 6. El PDM de Estados Unidos debe } \\
\text { incluir el rubro de colorantes } \\
\text { naturales y darle mayor } \\
\text { importancia. Usted está... }\end{array}$ & ( & ) & & ) & ( & ) & ( & ) & ( & ) \\
\hline \multicolumn{11}{|l|}{ Factores de éxito: Competitividad } \\
\hline $\begin{array}{l}\text { 7. Mi volumen exportado ha } \\
\text { aumentado debido al incremento } \\
\text { de empresas de productos } \\
\text { orgánicos o saludables en Estados } \\
\text { Unidos. Usted está... }\end{array}$ & ( & ) & ( & ) & ( & ) & ( & ) & ( & ) \\
\hline $\begin{array}{l}\text { 8. Considera que uno de los factores del } \\
\text { aumento de su volumen exportado es } \\
\text { gracias al incremento de la demanda } \\
\text { de colorantes naturales. Usted está... }\end{array}$ & ( & ) & & ) & ( & ) & ( & ) & ( & ) \\
\hline $\begin{array}{l}\text { 9. Mi volumen exportado ha } \\
\text { disminuido debido al aumento de } \\
\text { empresas peruanas exportadoras de } \\
\text { colorante de maíz morado. Usted } \\
\text { está... }\end{array}$ & ( & ) & ( & ) & ( & ) & ( & ) & ( & ) \\
\hline $\begin{array}{l}\text { 10. Considera que su precio de } \\
\text { exportación se ha visto afectado } \\
\text { negativamente debido al } \\
\text { incremento de empresas } \\
\text { exportadoras de colorante de maíz } \\
\text { morado. Usted está... } \\
\end{array}$ & ( & ) & ( & ) & ( & ) & ( & ) & ( & ) \\
\hline \multicolumn{11}{|l|}{ Factores de éxito: Boom saludable } \\
\hline $\begin{array}{l}\text { 11. El aumento de su volumen } \\
\text { exportado se debe a que el } \\
\text { consumidor final actualmente se } \\
\text { encuentra más interesado en los } \\
\text { productos orgánicos o } \\
\text { saludables. Usted está... }\end{array}$ & & ) & & ) & ( & ) & ( & ) & ( & ) \\
\hline
\end{tabular}




\begin{tabular}{|c|c|c|c|c|c|c|c|c|c|c|}
\hline $\begin{array}{l}\text { 12. El precio de exportación se ha visto } \\
\text { beneficiado debido a que las } \\
\text { personas consumen mayor cantidad } \\
\text { de productos orgánicos o saludables } \\
\text { Usted está... }\end{array}$ & & ) & & ) & & ) & & & ( & ) \\
\hline $\begin{array}{l}\text { 13. La obesidad es un problema que } \\
\text { actualmente afecta a la } \\
\text { población de Estados Unidos y } \\
\text { debido a ello muchas personas } \\
\text { están haciendo cambios en sus } \\
\text { hábitos alimenticios. Como } \\
\text { consecuencia, el incremento de } \\
\text { sus ventas se debe al aumento } \\
\text { de conciencia sobre la obesidad } \\
\text { en Estados Unidos. Usted } \\
\text { está.... }\end{array}$ & & ) & & ) & & ) & & ) & ( & ) \\
\hline \multicolumn{11}{|l|}{ Exportaciones a USA: Exportación } \\
\hline $\begin{array}{l}\text { 14. Los factores de: competitividad, } \\
\text { boom saludable y apoyo del Estado } \\
\text { peruano han influido positivamente } \\
\text { en el valor exportado de colorantes } \\
\text { de maíz morado. Usted está... } \\
\end{array}$ & ( & ) & ( & ) & ( & ) & ( & ) & ( & ) \\
\hline $\begin{array}{l}\text { 15. El aumento de sus } \\
\text { exportaciones se debe al valor } \\
\text { agregado que aporta el } \\
\text { colorante de maíz morado. } \\
\text { Usted está... } \\
\end{array}$ & ( & ) & ( & ) & ( & ) & ( & ) & ( & ) \\
\hline $\begin{array}{l}\text { 16. El valor agregado que aporta } \\
\text { el colorante de maíz morado } \\
\text { no es el causante del aumento } \\
\text { de sus exportaciones. Usted } \\
\text { está... } \\
\end{array}$ & ( & ) & ( & ) & ( & ) & ( & ) & ( & ) \\
\hline $\begin{array}{l}\text { 17. La cantidad de toneladas de } \\
\text { colorante de maíz morado } \\
\text { se ha incrementado desde } \\
\text { la aparición de la tendencia } \\
\text { por el consumo de } \\
\text { productos saludables. } \\
\text { Usted está... } \\
\end{array}$ & ( & ) & & ) & ( & ) & ( & ) & ( & ) \\
\hline \begin{tabular}{|l|} 
18. El aumento en la competitividad \\
entre empresas de productos \\
orgánicos o saludables en Estado \\
Unidos ha influido positivamente en \\
la cantidad exportada de colorante de
\end{tabular} & & ) & & ) & ( & ) & ( & ) & ( & ) \\
\hline
\end{tabular}




\begin{tabular}{|c|c|c|c|c|c|c|c|c|c|}
\hline maíz morado. Usted está... & & & & & & & & & \\
\hline $\begin{array}{l}\text { 19. Desde el cambio del nuevo PENX } \\
\text { 2015-2025, el volumen exportado ha } \\
\text { aumentado. Usted está... }\end{array}$ & & ) & & ) & & ) & & ) & ( \\
\hline $\begin{array}{l}\text { 20. El precio de venta del colorante } \\
\text { de maíz morado ha disminuido } \\
\text { desde el aumento de la cantidad } \\
\text { de empresas productoras de este } \\
\text { producto. Usted está... }\end{array}$ & & & & ) & ( & ) & & ) & $(\quad)$ \\
\hline $\begin{array}{l}\text { 21. El precio de venta del colorante de } \\
\text { maíz morado ha incrementado } \\
\text { desde el aumento de la cantidad de } \\
\text { empresas de productos orgánicos y } \\
\text { saludables en Estados Unidos. } \\
\text { Usted está... } \\
\end{array}$ & ( & ) & & ) & ( & ) & & ) & ( \\
\hline $\begin{array}{l}\text { 22. El precio de exportación no se ha } \\
\text { visto beneficiado debido al apoyo } \\
\text { del estado peruano. Usted está... }\end{array}$ & ( & ) & ( & ) & ( & ) & ( & ) & ( \\
\hline $\begin{array}{l}\text { 23. Debido al aumento de oferta de } \\
\text { empresas exportadoras de colorante } \\
\text { de maíz morado, el costo de materia } \\
\text { prima se ha visto afectado } \\
\text { negativamente. Usted está... }\end{array}$ & & ) & ( & ) & ( & ) & ( & ) & ( \\
\hline $\begin{array}{l}\text { 24. El aumento de demanda del } \\
\text { colorante de maíz morado en el } \\
\text { mercado de Estados Unidos no } \\
\text { afecta al costo de exportación. Usted } \\
\text { está... }\end{array}$ & & & & ) & ( & ) & & ) & ( \\
\hline Pregunta de cierre: & & & & & & & & & \\
\hline $\begin{array}{l}\text { 25. Califique del } 1 \text { al } 5 \text { los factores de } \\
\text { éxito que más influyan en el } \\
\text { aumento de exportaciones de } \\
\text { colorante de maíz morado a } \\
\text { Estados Unidos. Donde } 1 \text { es el } \\
\text { puntaje más bajo y } 5 \text { el puntaje } \\
\text { más alto. }\end{array}$ & 1 & & 2 & & 3 & & 4 & & 5 \\
\hline $\begin{array}{c}\text { Competitividad de empresas } \\
\text { compradoras }\end{array}$ & & ) & & ) & & ) & & ) & $(\quad)$ \\
\hline
\end{tabular}




\begin{tabular}{|c|l|l|l|l|l|}
\hline Tendencia de vida saludable & $($ ) & $($ ) & $($ ) & $($ ) & $($ ) \\
\hline Apoyo del estado peruano & $(\quad)$ & $($ ) & $($ ) & $(\quad)$ & $(\quad)$ \\
\hline
\end{tabular}




\section{CRITERIOS GENERALES PARA VALIDEZ DE CONTENIDO DEL INSTRUMENTO}

\section{DICTAMINADO POR EL JUEZ}

1) ¿Está de acuerdo con las características, forma de aplicación y estructura del INSTRUMENTO?

$$
\text { SI ( ) NO ( ) }
$$

Observaciones:.

Sugerencias:

2) A su parecer, ¿el orden de las preguntas es el adecuado?

$$
\text { SI ( ) NO ( ) }
$$

Observaciones:

Sugerencias:

3) ¿Existe dificultad para entender las preguntas del INSTRUMENTO?

$$
\text { SI ( ) NO ( ) }
$$

Observaciones:

Sugerencias:

4) ¿Existen palabras difíciles de entender en los ítems o reactivos del INSTRUMENTO?

$$
\text { SI ( ) NO ( ) }
$$

Observaciones:

Sugerencias:

5) ¿Las opciones de respuesta están suficientemente graduados y pertinentes para cada ítem (cada pregunta) o reactivo del INSTRUMENTO?
SI ( )
NO ( )

Observaciones:

Sugerencias:

6) ¿Los ítems o reactivos del instrumento tienen correspondencia con la dimensión al que pertenece en el constructo?
SI ( )
NO ( )

Observaciones:.

Sugerencias: 
FORMULARIO PARA VALIDACIÓN DE INSTRUMENTO DE TESIS

INSTRUMENTO PARA FINES ESPECIFICOS DE LA VALIDACION DE CONTENIDO (JUICIO DEL EXPERTO)

\begin{tabular}{|c|c|c|c|c|c|c|c|c|c|c|}
\hline \multirow[t]{2}{*}{$\mathbf{N}^{\mathbf{o}}$} & \multirow[t]{2}{*}{ Ítems (PREGUNTAS) } & \multicolumn{2}{|c|}{ Claridad $^{1}$} & \multicolumn{2}{|c|}{ Congruencia $^{2}$} & \multicolumn{2}{|c|}{ Contexto $^{3}$} & \multicolumn{2}{|c|}{$\begin{array}{c}\text { Dominio del } \\
\text { Constructo }\end{array}$} & \multirow{2}{*}{ Sugerencias } \\
\hline & & SI & NO & SI & NO & SI & NO & SI & NO & \\
\hline & $\begin{array}{l}\text { Factores de éxito: Apoyo del estado } \\
\text { peruano }\end{array}$ & & & & & & & & & \\
\hline 1 & $\begin{array}{c}\text { Considera que el estado peruano promociona } \\
\text { el producto a los diversos mercados } \\
\text { internacionales. Usted está... }\end{array}$ & & & & & & & & & \\
\hline 2 & $\begin{array}{l}\text { Considera que el estado le brinda facilidades } \\
\text { para la exportación del producto. Usted } \\
\text { está... }\end{array}$ & & & & & & & & & \\
\hline 3 & $\begin{array}{l}\text { Considera que el PENX aporta } \\
\text { positivamente al volumen exportado } \\
\text { durante el periodo mencionado. Usted } \\
\text { está... }\end{array}$ & & & & & & & & & \\
\hline 4 & $\begin{array}{c}\text { El PENX ha aportado al aumento de la } \\
\text { competitividad de su empresa en el } \\
\text { mercado americano. Usted está... }\end{array}$ & & & & & & & & & \\
\hline 5 & $\begin{array}{c}\text { El estado peruano le brinda información } \\
\text { sobre las tendencias y necesidades del } \\
\text { mercado americano. Usted está... }\end{array}$ & & & & & & & & & \\
\hline 6 & $\begin{array}{l}\text { El PDM de Estados Unidos debe incluir el } \\
\text { rubro de colorantes naturales y darle } \\
\text { mayor importancia. Usted está... }\end{array}$ & & & & & & & & & \\
\hline & Factores de éxito: Competitividad & & & & & & & & & \\
\hline
\end{tabular}




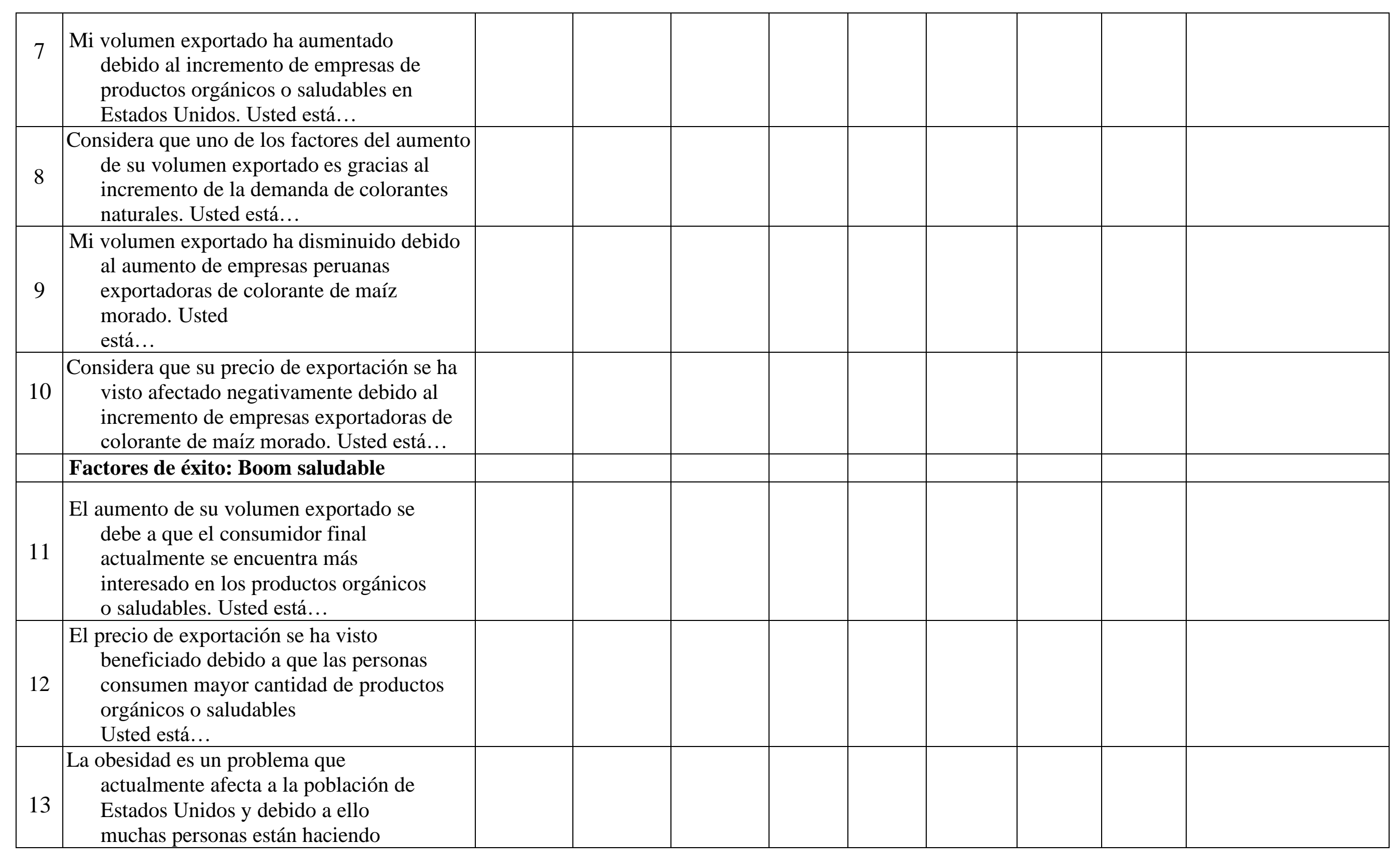




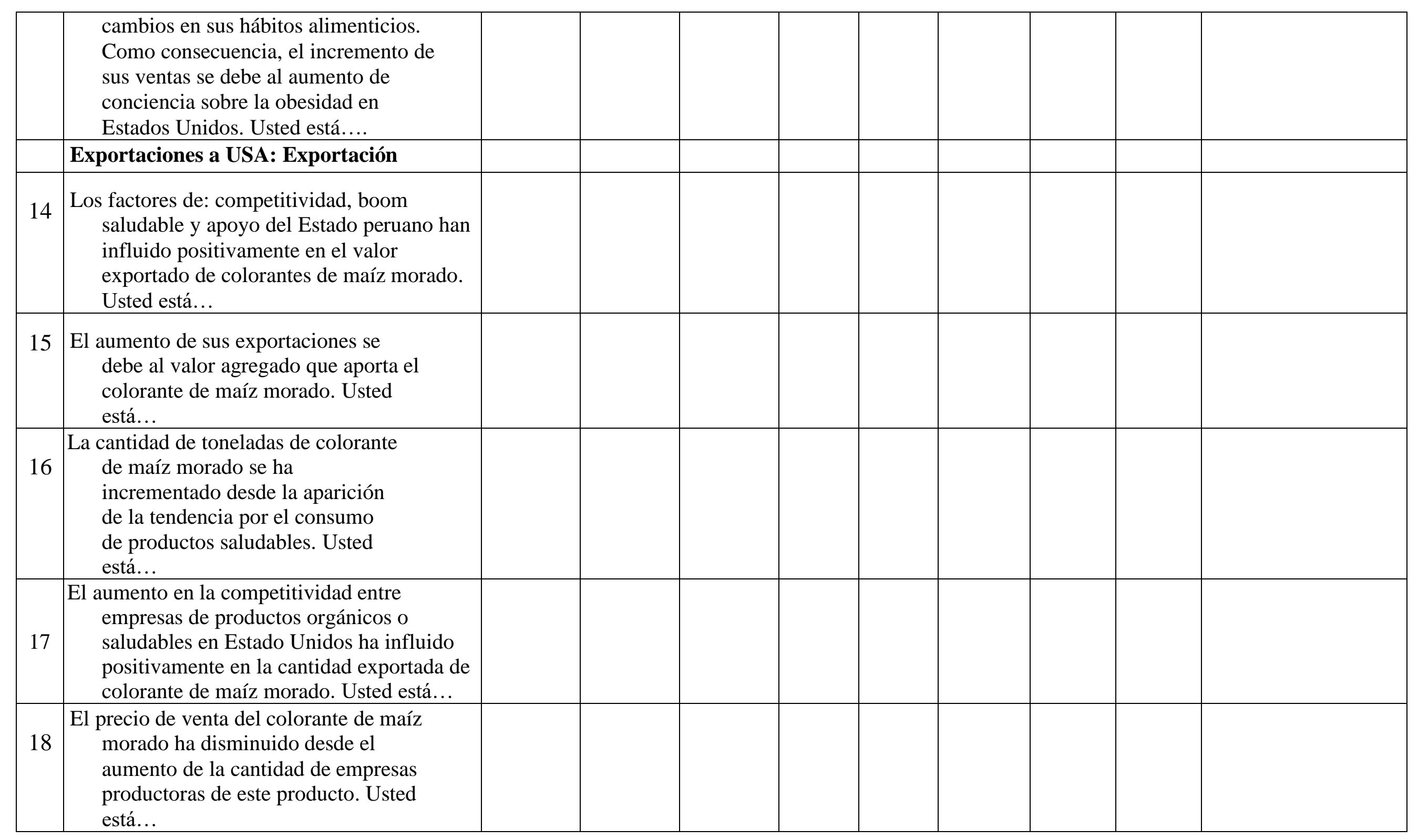




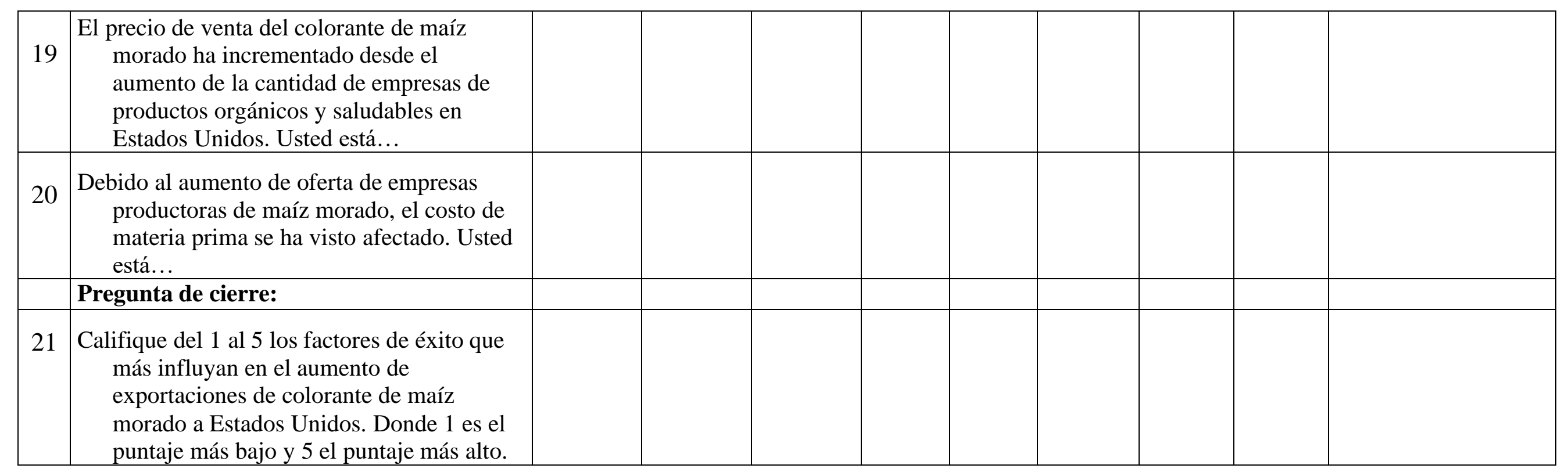

${ }^{1}$ Se entiende sin dificultad alguna el enunciado del ítem.

${ }^{2}$ El ítem tiene relación con el constructo (Comprensión Oral de Estructuras Gramaticales)

${ }^{3}$ En el ítem todas las palabras son usuales para nuestro contexto

${ }^{4}$ El ítem evalúa el componente o dimensión específica del constructo (bloque) 
Estimado:

Sr. Juan Adriazola

Presente:

Me dirijo a usted con la finalidad de solicitar su valiosa colaboración en calidad de JUEZ para validar el contenido del instrumento Cuestionario. Instrumento que lleva por título: Formulario de Validación de Instrumento de Tesis.

Para dar cumplimiento a lo anteriormente expuesto se hace entrega formal de la operacionalización de variables involucradas en el estudio, el cuestionario, la tabla de especificaciones respectivas, y los dos formatos de validación, el cual deberá llenar de acuerdo a sus observaciones, a fin de orientar y verificar la claridad, congruencia, control de la tendenciosidad y dominio de los contenidos de los diversos ítems de los cuestionarios.

Agradezco de antemano su receptividad y colaboración. Su apoyo nos permitirá adquirir habilidades y competencias profesionales y científicas que forman parte del proceso de investigación.

Quedo de Ud. en espera del feedback respectivo para mejorar el presente trabajo.

Muy Atentamente:

Romero Ortega, Doris. Scamarone Cornejo, Priscilla. 


\section{INSTRUMENTO PARA LA VALIDEZ DE CONTENIDO \\ (JUICIO DE EXPERTOS)}

El presente instrumento tiene como finalidad validar el cuestionario de la tesis titulada: "Factores de éxito de las exportaciones de colorante de maíz morado en la industria alimentaria a Estados Unidos periodo 2015 - 2019".

El mismo será aplicado en un diseño cuantitativo no probabilístico. La cual será aplicada a la muestra en estudiopara la validación del instrumento a utilizar titulado: Formulario de Validación de Instrumento de Tesis.

\section{Instrucciones}

La evaluación requiere de la lectura detallada y completa de cada uno de los ítems propuestos a fin de cotejarlos de manera cualitativa con los criterios propuestos relativos a: relevancia o congruencia con el contenido, claridad en la redacción, tendenciosidad o sesgo en su formulación y dominio del contenido. Para ello deberá asignar una valoración si el ítem presenta o no los criterios propuestos, y en caso necesario se ofrece un espacio para las observaciones si hubiera.

Grado de Instrucción: Abogado - MBA - Doctor en Administración

Fecha actual: 13 de abril de 2020

Nombres y Apellidos de Juez: Juan Carlos Adriazola Zevallos

Institución donde labora: Adriazola \& Asociados, UESAN, UTP

Años de experiencia profesional o científica: 22 años

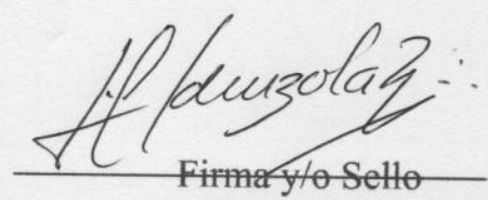

$$
\begin{aligned}
& \text { Fum Cortos Adrionla Zovillas } \\
& \text { ABOCADO } \\
& \text { REG. CAL. N० } 13599
\end{aligned}
$$




$\begin{array}{cc}\text { Definición } & \text { Definición } \\ \text { Conceptual } & \text { Operacional }\end{array}$

\section{Dimensiones}

Indicadores

Items

(preguntas)

Competitividad

$$
\begin{gathered}
\text { Aumento de } \\
\text { demanda }
\end{gathered}
$$

7 y 8

"Factor: Elemento

o causa que actúan

junto con otros. El

"Los factores claves

de éxito son los

elementos que le

permiten al

Boom Saludable

Aumento de oferta

9 y 10

Cambio en hábitos

alimenticios

empresario alcanzar

los objetivos que se

ha trazado y

distinguen a la

empresa de la

Éxito: Resultado

feliz de un

competencia

negocio, actuación,

etc." (RAE, 2020)

haciéndola única"

(Lopez, 2002)

Apoyo del

Gobierno Peruano

Facilidades de

exportación

2,3 y 4

Consumo de

productos orgánicos

11 y 12

Promoción del producto

Información sobre el mercado americano

5 y 6

1

Gobierno Peruano

"Régimen aduanero

Valor exportado

14,15 y 16

que permite la salida

"La exportación es del territorio

la venta de bienes

o servicios

producidos por una

empresa que tiene

su sede en un país

a clientes que

residen en otro

país". (Daniels et

al, 2018) aduanero de las

mercancías

nacionales o

nacionalizadas para

su uso o consumo

definitivo en el

exterior. $\mathrm{La}$

exportación

definitiva no está

afecta a ningún

tributo". (SUNAT, 2008)
Volumen exportado

17,18 y 19

Exportaciones

Precio de

exportación

20,21 y 22

Costo de exportación $\quad 23$ y 24 


\section{FORMULARIO DE VALIDACIÓN DE TESIS}

Cuestionario dirigido a empresas exportadores de colorante de maíz morado a

Estados Unidos, años 2015 - 2019 Número de empresa:

Número

de

cuestionario:

Estimado (a), la información que proporcione a través de este instrumento de recolección de información será utilizada de manera confidencial y con fines meramente científico-académicos, los cuales serán procesados y presentados de forma general en una tesis. Por ello le agradecemos anticipadamente su tiempo y atención en el llenado del presente cuestionario.

I. INFORMACIÓN SOCIODEMOGRÁFICA:

Nombre

Cargo que ocupa :

Empresa

II. CUESTIONARIO: Lea cuidadosamente todo el documento y elija la opción que se ajuste más a su respuesta.

\begin{tabular}{|c|c|c|c|c|c|}
\hline Preguntas & $\begin{array}{l}\text { Totalmente } \\
\text { en desacuerdo }\end{array}$ & $\begin{array}{c}\text { De } \\
\text { desacuerdo }\end{array}$ & $\begin{array}{l}\text { Ni de acuerdo } \\
\text { ni en } \\
\text { desacuerdo }\end{array}$ & De acuerdo & $\begin{array}{l}\text { Totalmente } \\
\text { de acuerdo }\end{array}$ \\
\hline \multicolumn{6}{|l|}{$\begin{array}{l}\text { Factores de éxito: Apoyo del estado } \\
\text { peruano }\end{array}$} \\
\hline $\begin{array}{l}\text { 1. Considera que el estado peruano } \\
\text { promociona el producto a los } \\
\text { diversos mercados internacionales. } \\
\text { Usted está... }\end{array}$ & $(\quad)$ & ) & $(\quad)$ & ( & ( \\
\hline $\begin{array}{l}\text { 2. Considera que el estado le brinda } \\
\text { facilidades para la exportación del } \\
\text { producto. Usted está... }\end{array}$ & $(\quad)$ & ) & $(\quad)$ & ( & ( \\
\hline $\begin{array}{l}\text { 3. Considera que el PENX no aporta } \\
\text { positivamente al volumen } \\
\text { exportado durante el periodo } \\
\text { mencionado. Usted } \\
\text { está... }\end{array}$ & $(\quad)$ & ) & & ) & ( \\
\hline $\begin{array}{l}\text { 4. El PENX no ha aportado al aumento } \\
\text { de la competitividad de su empresa } \\
\text { en el mercado americano. Usted } \\
\text { está... }\end{array}$ & $(\quad)$ & ) & ( & ) & ( \\
\hline $\begin{array}{l}\text { 5. El estado peruano le brinda } \\
\text { información sobre las tendencias y } \\
\text { necesidades del mercado } \\
\text { americano. Usted está... }\end{array}$ & $(\quad)$ & ) & $(\quad)$ & ( & ( \\
\hline
\end{tabular}


6. El PDM de Estados Unidos debe incluir el rubro de colorantes naturales y darle mayor importancia. Usted está. .

\section{Factores de éxito: Competitividad}

7. Mi volumen exportado ha aumentado debido al incremento de empresas de productos orgánicos o saludables en Estados Unidos. Usted está...

8. Considera que uno de los factores del aumento de su volumen exportado es gracias al incremento de la demanda de colorantes naturales. Usted está..

9. Mi volumen exportado ha disminuido debido al aumento de empresas peruanas exportadoras de colorante de maíz morado. Usted está...

10. Considera que su precio de exportación se ha visto afectado negativamente debido al incremento de empresas exportadoras de colorante de maíz morado. Usted está...

\section{Factores de éxito: Boom saludable}

11. El aumento de su volumen exportado se debe a que el consumidor final actualmente se encuentra más interesado en los productos orgánicos o saludables. Usted está..

12. El precio de exportación se ha visto beneficiado debido a que las personas consumen mayor cantidad de productos orgánicos o saludables Usted está...

13. La obesidad es un problema que actualmente afecta a la población de Estados Unidos y debido a ello muchas personas están haciendo cambios en sus hábitos alimenticios. Como consecuencia, el incremento de sus ventas se debe al aumento de conciencia sobre la obesidad en Estados Unidos. Usted está....

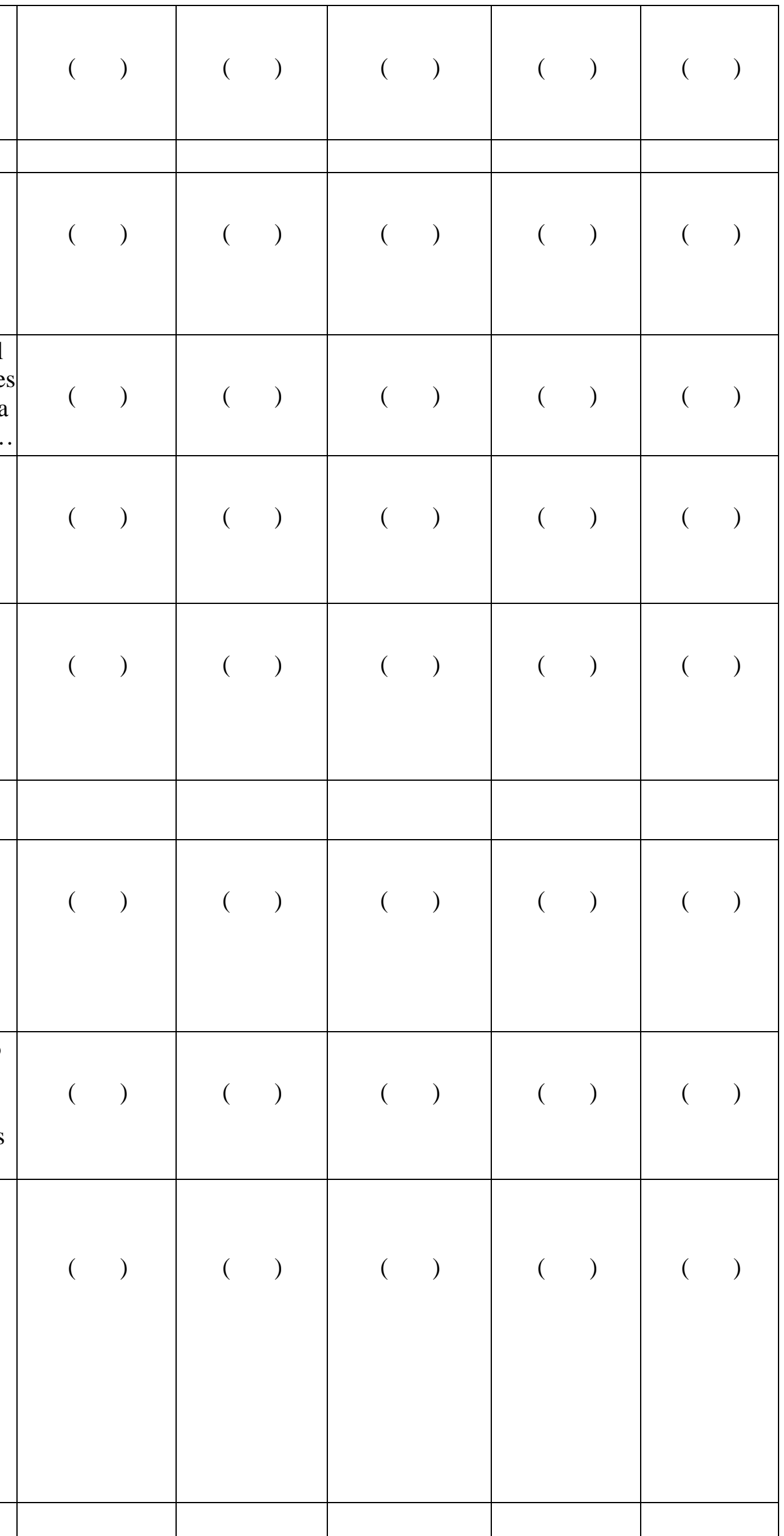


14. Los factores de: competitividad, boom saludable y apoyo del Estado peruano han influido positivamente en el valor exportado de colorantes de maíz morado. Usted está...

15. El aumento de sus exportaciones se debe al valor agregado que aporta el colorante de maíz morado. Usted está...

16. El valor agregado que aporta el colorante de maíz morado no es el causante del aumento de sus exportaciones. Usted está...

17. La cantidad de toneladas de colorante de maíz morado se ha incrementado desde la aparición de la tendencia por el consumo de productos saludables. Usted está...

18. El aumento en la competitividad entre empresas de productos orgánicos o saludables en Estado Unidos ha influido positivamente en la cantidad exportada de colorante de maíz morado. Usted está...

19. Desde el cambio del nuevo PENX 2015-2025, el volumen exportado ha aumentado. Usted está...

20. El precio de venta del colorante de maíz morado ha disminuido desde el aumento de la cantidad de empresas productoras de este producto. Usted está...

21. El precio de venta del colorante de maíz morado ha incrementado desde el aumento de la cantidad de empresas de productos orgánicos y saludables en Estados Unidos. Usted está...

22. El precio de exportación no se ha visto beneficiado debido al apoyo del estado peruano. Usted está...

\begin{tabular}{|c|c|c|c|c|c|c|c|c|c|}
\hline ( & ) & ( & ) & ( & ) & ( & ) & ( & ) \\
\hline ( & ) & ( & ) & ( & ) & ( & ) & ( & ) \\
\hline ( & ) & ( & ) & ( & ) & ( & ) & ( & ) \\
\hline ( & ) & ( & ) & ( & ) & ( & ) & ( & ) \\
\hline ( & ) & ( & ) & ( & ) & ( & ) & ( & ) \\
\hline ( & ) & ( & ) & ( & ) & ( & ) & ( & ) \\
\hline ( & ) & ( & ) & ( & ) & ( & ) & ( & ) \\
\hline ( & ) & ( & ) & ( & ) & ( & ) & ( & ) \\
\hline & ) & ( & ) & ( & ) & ( & ) & ( & ) \\
\hline
\end{tabular}


23. Debido al aumento de oferta de empresas exportadoras de colorante de maíz morado, el costo de materia prima se ha visto afectado negativamente. Usted está...

24. El aumento de demanda del colorante de maíz morado en el mercado de Estados Unidos no afecta al costo de exportación. Usted está...

\section{Pregunta de cierre:}

25. Califique del 1 al 5 los factores de éxito que más influyan en el aumento de exportaciones de colorante de maíz morado a Estados Unidos. Donde 1 es el puntaje más bajo y 5 el puntaje más alto.

\begin{tabular}{|c|c|c|c|c|c|}
\hline $\begin{array}{l}\text { Competitividad de empresas } \\
\text { compradoras }\end{array}$ & $(\quad)$ & $(\quad)$ & $(\quad)$ & $(\quad)$ & $(\quad)$ \\
\hline Tendencia de vida saludable & $(\quad)$ & $(\quad)$ & $(\quad)$ & $(\quad)$ & $(\quad)$ \\
\hline Apoyo del estado peruano & $(\quad)$ & $(\quad)$ & $(\quad)$ & $(\quad)$ & $(\quad)$ \\
\hline
\end{tabular}




\section{CRITERIOS GENERALES PARA VALIDEZ DE CONTENIDO}

\section{DEL INSTRUMENTO DICTAMINADO POR EL JUEZ}

1) ¿Está de acuerdo con las características, forma de aplicación y estructura del INSTRUMENTO?

$$
\mathrm{SI}(\mathrm{x}) \quad \mathrm{NO}(\mathrm{l}
$$

Observaciones: Resulta importante considerar el apoyo del Estado a través de incentivos monetarios y fiscales, como son el Drawback, y el régimen aduanero de reposición de mercancías en franquicia.

Sugerencias:

2) A su parecer, ¿el orden de las preguntas es el adecuado?

$$
\text { SI }(\mathrm{x}) \quad \mathrm{NO}(\mathrm{)}
$$

Observaciones:

Sugerencias:

3) ¿Existe dificultad para entender las preguntas del INSTRUMENTO?
SI ( )
$\mathrm{NO}(\mathrm{x})$

Observaciones:

Sugerencias:

4) ¿Existen palabras difíciles de entender en los ítems o reactivos del INSTRUMENTO?

$$
\text { SI ( ) N N } \quad \text { NO (x ) }
$$

Observaciones:

Sugerencias: 
5) ¿Las opciones de respuesta están suficientemente graduados y pertinentes para cada ítem (cada pregunta) o reactivo del INSTRUMENTO?
$\mathrm{SI}(\mathrm{x})$
$\mathrm{NO}($ )

Observaciones:

Sugerencias:

6) ¿Los ítems o reactivos del instrumento tienen correspondencia con la dimensión al que pertenece en el constructo?
SI $(\mathrm{x})$
NO ( )

Observaciones:

Sugerencias: 
FORMULARIO PARA VALIDACIÓN DE INSTRUMENTO DE TESIS

INSTRUMENTO PARA FINES ESPECIFICOS DE LA VALIDACION DE CONTENIDO (JUICIO DEL EXPERTO)

\begin{tabular}{|c|c|c|c|c|c|c|c|c|c|c|}
\hline \multirow[t]{2}{*}{$\mathbf{N}^{o}$} & \multirow{2}{*}{ Ítems (PREGUNTAS) } & \multicolumn{2}{|c|}{ Claridad $^{1}$} & \multicolumn{2}{|c|}{ Congruencia $^{2}$} & \multicolumn{2}{|c|}{ Contexto $^{3}$} & \multicolumn{2}{|c|}{$\begin{array}{c}\text { Dominio del }^{4} \\
\text { Constructo }\end{array}$} & \multirow[t]{2}{*}{ Sugerencias } \\
\hline & & SI & NO & SI & NO & SI & NO & SI & NO & \\
\hline & $\begin{array}{l}\text { Factores de éxito: Apoyo del estado } \\
\text { peruano }\end{array}$ & & & & & & & & & $\begin{array}{l}\text { Sería interesante saber si } \\
\text { es de conocimiento de los } \\
\text { exportadores la existencia } \\
\text { de los regímenes } \\
\text { aduaneros de incentivo a } \\
\text { las exportaciones y su } \\
\text { aplicación, y su resultado, } \\
\text { por lo que podrían } \\
\text { formularse preguntas al } \\
\text { respecto. }\end{array}$ \\
\hline 1 & $\begin{array}{l}\text { Considera que el estado peruano promociona } \\
\text { el producto a los diversos mercados } \\
\text { internacionales. Usted está... }\end{array}$ & $X$ & & $X$ & & $X$ & & $X$ & & \\
\hline 2 & $\begin{array}{l}\text { Considera que el estado le brinda facilidades } \\
\text { para la exportación del producto. Usted } \\
\text { está... }\end{array}$ & $X$ & & $X$ & & $X$ & & X & & \\
\hline 3 & $\begin{array}{l}\text { Considera que el PENX no aporta } \\
\text { positivamente al volumen exportado } \\
\text { durante el periodo mencionado. Usted } \\
\text { está... }\end{array}$ & $X$ & & X & & $X$ & & X & & \\
\hline 4 & $\begin{array}{l}\text { El PENX no ha aportado al aumento de la } \\
\text { competitividad de su empresa en el } \\
\text { mercado americano. Usted está... }\end{array}$ & $X$ & & $\mathrm{X}$ & & $X$ & & $\mathrm{X}$ & & \\
\hline
\end{tabular}




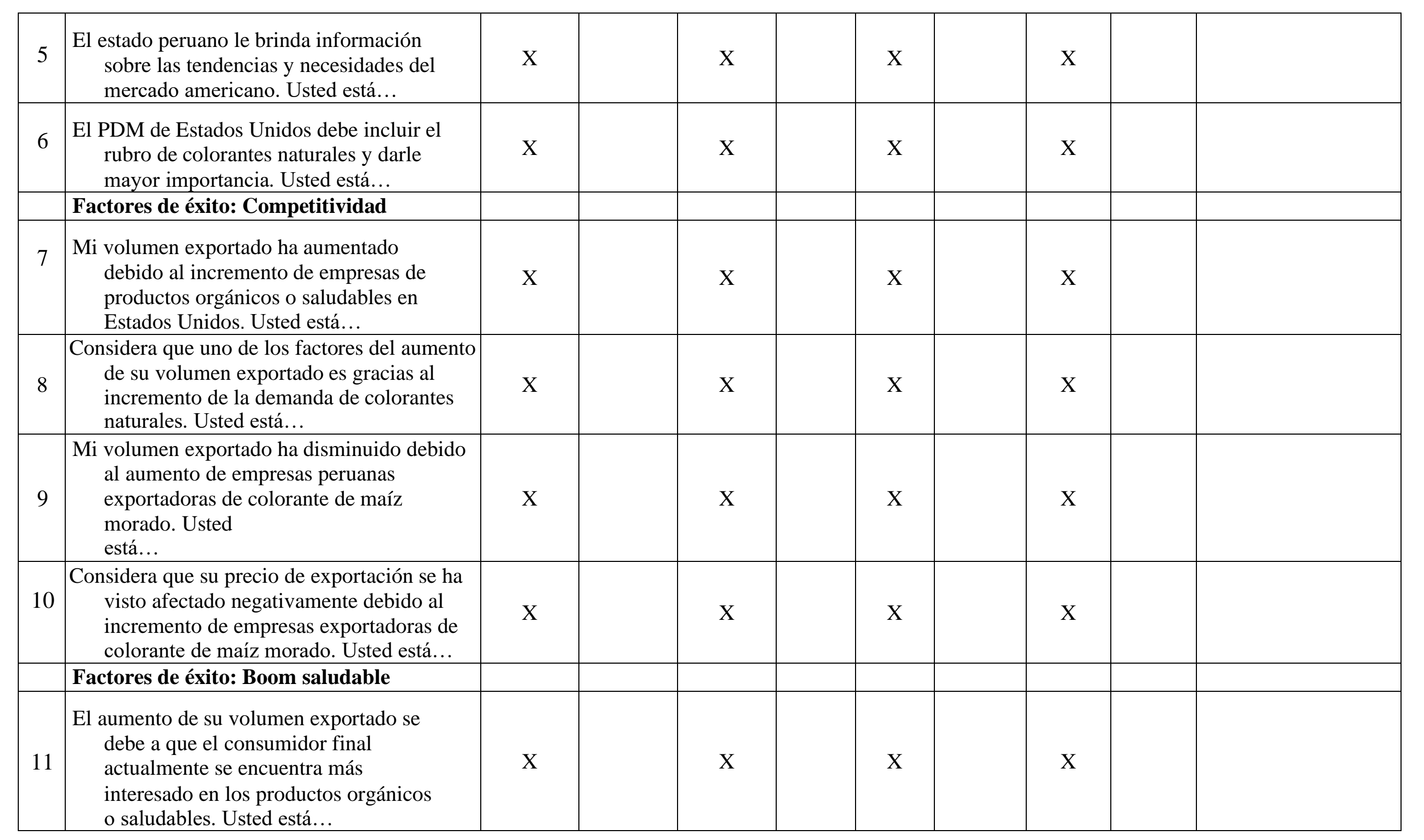




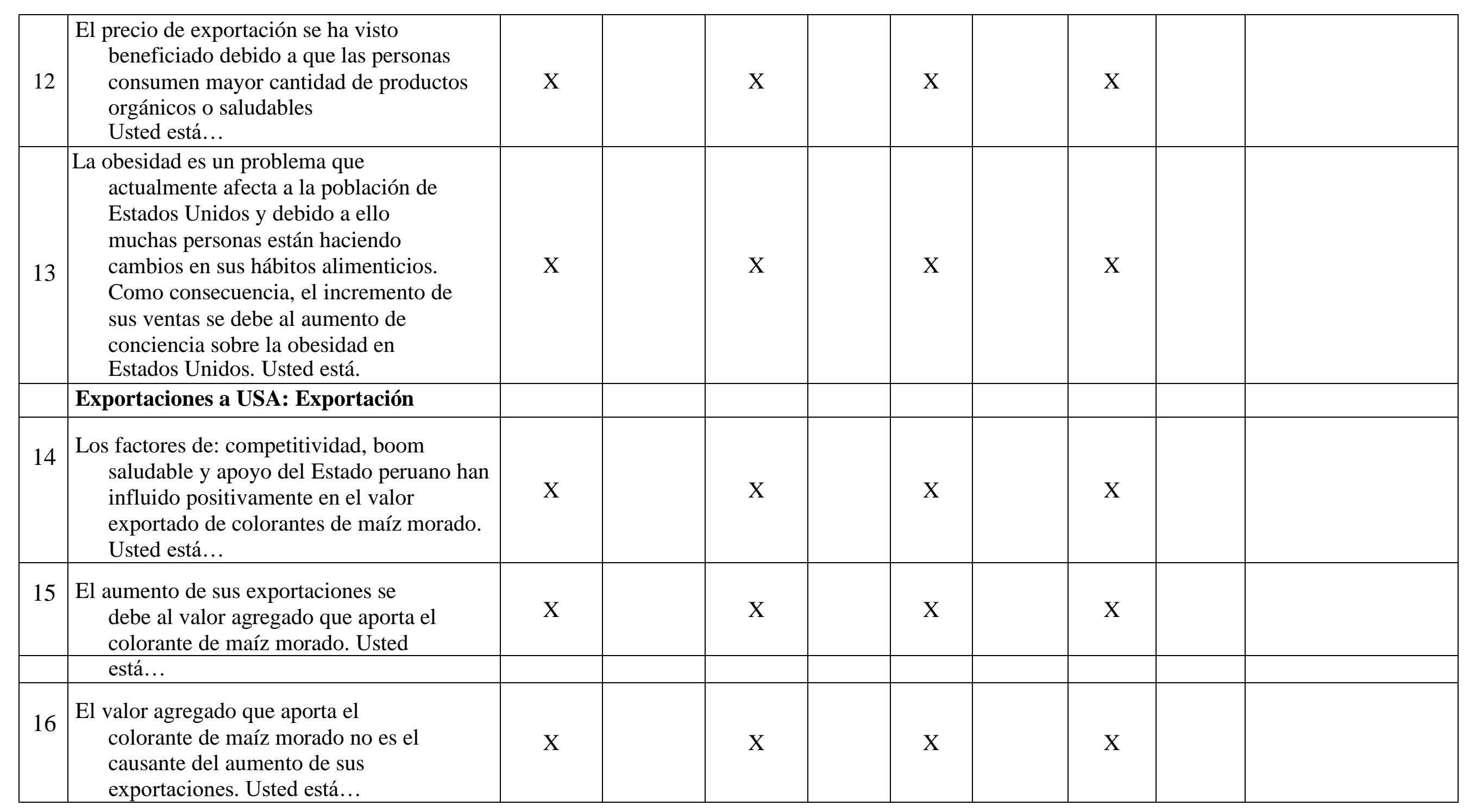




\begin{tabular}{|c|c|c|c|c|c|}
\hline 17 & $\begin{array}{l}\text { La cantidad de toneladas de colorante } \\
\text { de maíz morado se ha } \\
\text { incrementado desde la aparición } \\
\text { de la tendencia por el consumo } \\
\text { de productos saludables. Usted } \\
\text { está... }\end{array}$ & $X$ & $X$ & $X$ & $X$ \\
\hline 18 & \begin{tabular}{|c|} 
El aumento en la competitividad entre \\
empresas de productos orgánicos o \\
saludables en Estado Unidos ha influido \\
positivamente en la cantidad exportada de \\
colorante de maíz morado. Usted está...
\end{tabular} & $X$ & $X$ & $X$ & $X$ \\
\hline 19 & $\begin{array}{l}\text { Desde el cambio del nuevo PENX 2015-2025, } \\
\text { el volumen exportado ha aumentado. } \\
\text { Usted está... }\end{array}$ & $X$ & $X$ & $X$ & $X$ \\
\hline 20 & $\begin{array}{l}\text { El precio de venta del colorante de maíz } \\
\text { morado ha disminuido desde el } \\
\text { aumento de la cantidad de empresas } \\
\text { productoras de este producto. Usted } \\
\text { está... }\end{array}$ & $X$ & $X$ & $X$ & $X$ \\
\hline 21 & $\begin{array}{l}\text { El precio de venta del colorante de maíz } \\
\text { morado ha incrementado desde el } \\
\text { aumento de la cantidad de empresas de } \\
\text { productos orgánicos y saludables en } \\
\text { Estados Unidos. Usted está... }\end{array}$ & $X$ & $X$ & $X$ & $X$ \\
\hline 22 & $\begin{array}{l}\text { El precio de exportación no se ha visto } \\
\text { beneficiado debido al apoyo del estado } \\
\text { peruano. Usted está... }\end{array}$ & $X$ & $X$ & $X$ & $X$ \\
\hline 23 & \begin{tabular}{|l} 
Debido al aumento de oferta de empresas \\
exportadoras de colorante de maíz morado, \\
el costo de materia prima se ha visto \\
afectado negativamente. Usted está...
\end{tabular} & $X$ & $X$ & $X$ & $X$ \\
\hline
\end{tabular}


Estimado:

Sr Percy Freyre

Presente:

Me dirijo a usted con la finalidad de solicitar su valiosa colaboración en calidad de JUEZ para validar el contenido del instrumento Cuestionario. Instrumento que lleva por título: Formulario de Validación de Instrumento de Tesis.

Para dar cumplimiento a lo anteriormente expuesto se hace entrega formal de la operacionalización de variables involucradas en el estudio, el cuestionario, la tabla de especificaciones respectivas, y los dos formatos de validación, el cual deberá llenar de acuerdo a sus observaciones, a fin de orientar y verificar la claridad, congruencia, control de la tendenciosidad y dominio de los contenidos de los diversos ítems de los cuestionarios.

Agradezco de antemano su receptividad y colaboración. Su apoyo nos permitirá adquirir habilidades y competencias profesionales y científicas que forman parte del proceso de investigación.

Quedo de Ud. en espera del feedback respectivo para mejorar el presente trabajo.

Muy Atentamente:

Romero Ortega, Doris. Scamarone Cornejo, Priscilla. 


\section{INSTRUMENTO PARA LA VALIDEZ DE CONTENIDO (JUICIO DE EXPERTOS)}

El presente instrumento tiene como finalidad validar el cuestionario de la tesis titulada: "Factores de éxito de las exportaciones de colorante de maíz morado en la industria alimentaria a Estados Unidos periodo 2015 2019".

El mismo será aplicado en un diseño cuantitativo no probabilístico. La cual será aplicada a la muestra en estudiopara la validación del instrumento a utilizar titulado: Formulario de Validación de Instrumento de Tesis.

\section{Instrucciones}

La evaluación requiere de la lectura detallada y completa de cada uno de los ítems propuestos a fin de cotejarlos de manera cualitativa con los criterios propuestos relativos a: relevancia o congruencia con el contenido, claridad en la redacción, tendenciosidad o sesgo en su formulación y dominio del contenido. Para ello deberá asignar una valoración si el ítem presenta o no los criterios propuestos, y en caso necesario se ofrece un espacio para las observaciones si hubiera.

Grado de Instrucción: Magister

Fecha actual: 10 de junio del 2020

Nombres y Apellidos de Juez: _Percy Freyre Suarez

Institución donde labora: USIL

Años de experiencia profesional o científica: 30 años

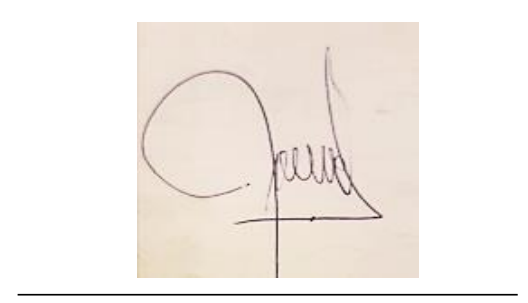

Firma y/o Sello 

Definición Conceptual

\section{Definición \\ Operacional}

Dimensiones

Indicadores

Items

(preguntas)
Aumento de
demanda

Competitividad

Aumento de oferta $\quad 9$ y 10

"Factor: Elemento "Los factores claves o causa que actúan de éxito son los junto con otros. El elementos que le permiten al empresario alcanzar los objetivos que se ha trazado y distinguen a la empresa de la competencia negocio, actuación,
etc." (RAE, 2020)
(Lopez, 2002) etc." (RAE, 2020)

Cambio en hábitos alimenticios

Boom Saludable

Información sobre el 5 y 6
"La exportación es la venta de bienes o servicios producidos por una empresa que tiene su sede en un país a clientes que residen en otro país". (Daniels et al, 2018)
"Régimen aduanero que permite la salida del territorio aduanero de las mercancías nacionales o nacionalizadas para su uso o consumo definitivo en el exterior. $\mathrm{La}$ exportación definitiva no está afecta a ningún tributo". (SUNAT, 2008)

$\begin{array}{lc}\begin{array}{c}\text { Consumo de } \\ \text { productos orgánicos }\end{array} & 11 \text { y } 12 \\ \begin{array}{c}\text { Promoción del } \\ \text { producto }\end{array} & 1\end{array}$
Apoyo del mercado americano Gobierno Peruano

$$
\begin{aligned}
& \text { Herramientas de } \\
& \text { exportación }
\end{aligned}
$$

Valor exportado 14 y 15

Volumen exportado 16,17 y 18

Exportaciones

Precio de exportación 19,20 у 21

Costo de exportación 


\section{FORMULARIO DE VALIDACIÓN DE TESIS}

Cuestionario dirigido a empresas exportadores de colorante de maíz morado a

Estados Unidos, años 2015 - 2019 Número de empresa:

Número

de cuestionario:

Estimado (a), la información que proporcione a través de este instrumento de recolección de información será utilizada de manera confidencial y con fines meramente científico-académicos, los cuales serán procesados y presentados de forma general en una tesis. Por ello le agradecemos anticipadamente su tiempo y atención en el llenado del presente cuestionario.

III. INFORMACIÓN SOCIODEMOGRÁFICA:

Nombre : Percy Freyre Suarez

Cargo que ocupa : Docente

Empresa : USIL

IV. CUESTIONARIO: Lea cuidadosamente todo el documento y elija la opción que se ajuste más a su respuesta.

\begin{tabular}{|c|c|c|c|c|c|}
\hline Preguntas & $\begin{array}{c}\text { Totalmente } \\
\text { en desacuerdo }\end{array}$ & $\begin{array}{c}\text { De } \\
\text { desacuerdo }\end{array}$ & $\begin{array}{l}\text { Ni de acuerdo } \\
\text { ni en } \\
\text { desacuerdo }\end{array}$ & De acuerdo & $\begin{array}{l}\text { Totalmente } \\
\text { de acuerdo }\end{array}$ \\
\hline \multicolumn{6}{|l|}{$\begin{array}{l}\text { Factores de éxito: Apoyo del estado } \\
\text { peruano }\end{array}$} \\
\hline $\begin{array}{l}\text { 1. Considera que el estado peruano } \\
\text { promociona el producto a los } \\
\text { diversos mercados internacionales. } \\
\text { Usted está... }\end{array}$ & $(\quad)$ & ) & $(\quad)$ & ( & ( \\
\hline $\begin{array}{l}\text { 2. Considera que el estado le brinda } \\
\text { herramientas que le faciliten la } \\
\text { exportación del producto. Usted } \\
\text { está... }\end{array}$ & ( ） & ） & ( ） & ( & ( \\
\hline $\begin{array}{l}\text { 3. Considera que el PENX no aporta } \\
\text { positivamente al volumen } \\
\text { exportado durante el periodo } \\
\text { mencionado. Usted } \\
\text { está... }\end{array}$ & $(\quad)$ & ） & ( & ( & ( \\
\hline $\begin{array}{l}\text { 4. ¿Usted importa algún insumo para la } \\
\text { elaboración del colorante de maíz } \\
\text { morado? (materia prima, envasado } \\
\text { y/o empaquetado) De ser positivo, } \\
\text { ¿percibe usted algún beneficio } \\
\text { tributario por parte del Estado } \\
\text { peruano? Ejemplo: Acogerse bajo } \\
\text { el régimen Drawback o de } \\
\text { reposición de mercancías con }\end{array}$ & $(\quad)$ & ） & $(\quad)$ & ( & ( \\
\hline
\end{tabular}




\begin{tabular}{|c|c|c|c|c|c|c|c|c|c|c|}
\hline franquicia arancelaria. Usted está... & & & & & & & & & & \\
\hline $\begin{array}{l}\text { 5. El estado peruano le brinda } \\
\text { información sobre las tendencias y } \\
\text { necesidades del mercado } \\
\text { americano. Usted está... }\end{array}$ & ( & ) & ( & ) & ( & ) & ( & ) & ( & ) \\
\hline $\begin{array}{l}\text { 6. El PDM de Estados Unidos debe } \\
\text { incluir el rubro de colorantes } \\
\text { naturales y darle mayor } \\
\text { importancia. Usted está... }\end{array}$ & ( & ) & ( & ) & ( & ) & ( & ) & ( & ) \\
\hline Factores de éxito: Competitividad & & & & & & & & & & \\
\hline $\begin{array}{l}\text { 7. Mi volumen exportado ha } \\
\text { aumentado debido al incremento } \\
\text { de empresas de productos } \\
\text { orgánicos o saludables en Estados } \\
\text { Unidos. Usted está... }\end{array}$ & ( & ) & ( & ) & ( & ) & ( & ) & ( & ) \\
\hline $\begin{array}{l}\text { 8. Considera que uno de los factores del } \\
\text { aumento de su volumen exportado es } \\
\text { gracias al incremento de la demanda } \\
\text { de colorantes naturales. Usted está... }\end{array}$ & ( & ) & ( & ) & ( & ) & ( & ) & ( & ) \\
\hline $\begin{array}{l}\text { 9. Mi volumen exportado ha } \\
\text { disminuido debido al aumento de } \\
\text { empresas peruanas exportadoras de } \\
\text { colorante de maíz morado. Usted } \\
\text { está... }\end{array}$ & ( & ) & ( & ) & ( & ) & ( & ) & ( & ) \\
\hline $\begin{array}{l}\text { 10. Considera que su precio de } \\
\text { exportación se ha visto afectado } \\
\text { negativamente debido al } \\
\text { incremento de empresas } \\
\text { exportadoras de colorante de maíz } \\
\text { morado. Usted está... }\end{array}$ & ( & ) & ( & ) & ( & ) & ( & ) & ( & ) \\
\hline Factores de éxito: Boom saludable & & & & & & & & & & \\
\hline $\begin{array}{l}\text { 11. El aumento de su volumen } \\
\text { exportado se debe a que el } \\
\text { consumidor final actualmente se } \\
\text { encuentra más interesado en los } \\
\text { productos orgánicos o } \\
\text { saludables. Usted está... }\end{array}$ & ( & ) & ( & ) & ( & ) & ( & ) & ( & ) \\
\hline $\begin{array}{l}\text { 12. El precio de exportación se ha visto } \\
\text { beneficiado debido a que las } \\
\text { personas consumen mayor cantidad } \\
\text { de productos orgánicos o saludables } \\
\text { Usted está... }\end{array}$ & ( & ) & ( & ) & ( & ) & ( & ) & ( & ) \\
\hline $\begin{array}{l}\text { 13. Como usted sabe la obesidad es } \\
\text { un problema que ha venido } \\
\text { afectando a la población de } \\
\text { Estados Unidos durante muchos } \\
\text { años y debido a ello muchas } \\
\text { personas están haciendo } \\
\end{array}$ & ( & ) & ( & ) & ( & ) & ( & ) & ( & ) \\
\hline
\end{tabular}




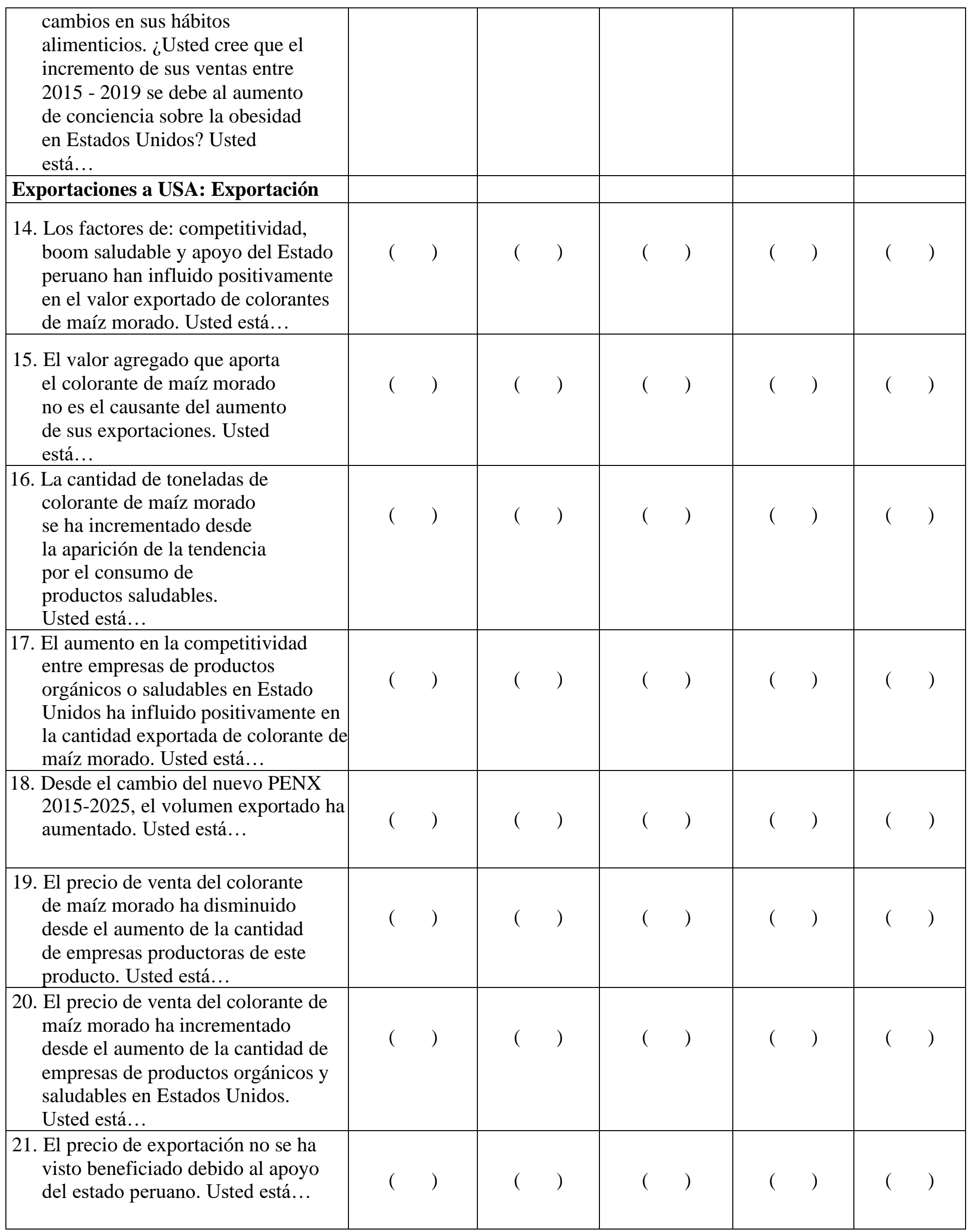


22. Debido al aumento de oferta de empresas exportadoras de colorante de maíz morado, el costo de materia prima se ha visto afectado negativamente. Usted está...

23. El aumento de demanda del colorante de maíz morado en el mercado de Estados Unidos no afecta al costo de exportación. Usted está...

\section{Pregunta de cierre:}

24. Califique del 1 al 5 los factores de éxito que más influyan en el aumento de exportaciones de colorante de maíz morado a Estados Unidos. Donde 1 es el puntaje más bajo y 5 el puntaje más alto.

\begin{tabular}{|c|c|c|c|c|c|}
\hline $\begin{array}{l}\text { Competitividad de empresas } \\
\text { compradoras }\end{array}$ & $(\quad)$ & $(\quad)$ & $(\quad)$ & ( & $(\quad)$ \\
\hline Tendencia de vida saludable & $(\quad)$ & $(\quad)$ & $(\quad)$ & ( & ( \\
\hline Apoyo del estado peruano & $(\quad)$ & $(\quad)$ & $(\quad)$ & $(\quad)$ & $(\quad)$ \\
\hline
\end{tabular}




\section{CRITERIOS GENERALES PARA VALIDEZ DE CONTENIDO DEL INSTRUMENTO DICTAMINADO POR EL JUEZ}

1) ¿Está de acuerdo con las características, forma de aplicación y estructura del INSTRUMENTO?

$$
\mathrm{SI}(\mathrm{x}) \quad \mathrm{NO}(\mathrm{l}
$$

Observaciones: Sin embargo las preguntas 7 y 8 significan lo mismo.

Sugerencias: Recomiendo que una de las preguntas profundice en la calidad esperada de los insumos exportados.

2) A su parecer, ¿el orden de las preguntas es el adecuado?

$$
\mathrm{SI}(\mathrm{x}) \quad \mathrm{NO}(\mathrm{n}
$$

Observaciones:

Sugerencias:

3) ¿Existe dificultad para entender las preguntas del INSTRUMENTO?

$$
\text { SI ( ) NO (x) }
$$

Observaciones:.

Sugerencias:

4) ¿Existen palabras difíciles de entender en los ítems o reactivos del INSTRUMENTO?

$$
\text { SI ( ) NO N } \quad \text { N }
$$

Observaciones:

Sugerencias: 
5) ¿Las opciones de respuesta están suficientemente graduados y pertinentes para cada ítem (cada pregunta) o reactivo del INSTRUMENTO?
SI ( $\mathrm{x})$
NO ( )

Observaciones:

Sugerencias:

6. ¿Los ítems o reactivos del instrumento tienen correspondencia con la dimensión al que pertenece en el constructo?
$\mathrm{SI}(\mathrm{x})$
NO ( )

Observaciones:

Sugerencias: 
FORMULARIO PARA VALIDACIÓN DE INSTRUMENTO DE TESIS

INSTRUMENTO PARA FINES ESPECIFICOS DE LA VALIDACION DE CONTENIDO (JUICIO DEL EXPERTO)

\begin{tabular}{|c|c|c|c|c|c|c|c|c|c|c|}
\hline \multirow[t]{2}{*}{$\mathbf{N}^{\mathbf{o}}$} & \multirow[t]{2}{*}{ Ítems (PREGUNTAS) } & \multicolumn{2}{|c|}{ Claridad $^{1}$} & \multicolumn{2}{|c|}{ Congruencia $^{2}$} & \multicolumn{2}{|c|}{ Contexto $^{3}$} & \multicolumn{2}{|c|}{$\begin{array}{c}\text { Dominio del }^{4} \\
\text { Constructo }\end{array}$} & \multirow[t]{2}{*}{ Sugerencias } \\
\hline & & SI & NO & SI & NO & SI & NO & SI & NO & \\
\hline & $\begin{array}{l}\text { Factores de éxito: Apoyo del estado } \\
\text { peruano }\end{array}$ & & & & & & & & & \\
\hline 1 & $\begin{array}{l}\text { Considera que el estado peruano promociona } \\
\text { el producto a los diversos mercados } \\
\text { internacionales. Usted está... }\end{array}$ & $\mathrm{X}$ & & $X$ & & $X$ & & $X$ & & \\
\hline 2 & $\begin{array}{l}\text { Considera que el estado le brinda } \\
\text { herramientas que le faciliten la } \\
\text { exportación del producto. Usted está... }\end{array}$ & X & & $X$ & & $X$ & & $X$ & & \\
\hline 3 & $\begin{array}{l}\text { Considera que el PENX no aporta } \\
\text { positivamente al volumen exportado } \\
\text { durante el periodo mencionado. Usted } \\
\text { está... }\end{array}$ & X & & $X$ & & $X$ & & $X$ & & \\
\hline 4 & $\begin{array}{l}\text { ¿Usted importa algún insumo para la } \\
\text { elaboración del colorante de maíz } \\
\text { morado? (materia prima, envasado y/o } \\
\text { empaquetado) De ser positivo, ipercibe } \\
\text { usted algún beneficio tributario por parte } \\
\text { del Estado peruano? Ejemplo: Acogerse } \\
\text { bajo el régimen Drawback o de } \\
\text { reposición de mercancías con franquicia } \\
\text { arancelaria. Usted está... }\end{array}$ & $\mathrm{X}$ & & $\mathrm{X}$ & & $\mathrm{X}$ & & $X$ & & \\
\hline 5 & $\begin{array}{l}\text { El estado peruano le brinda información } \\
\text { sobre las tendencias y necesidades del }\end{array}$ & $X$ & & $\mathrm{X}$ & & $\mathrm{X}$ & & $\mathrm{X}$ & & \\
\hline
\end{tabular}




\begin{tabular}{|c|c|c|c|c|c|c|}
\hline & mercado americano. Usted está... & & & & & \\
\hline \multirow[t]{2}{*}{6} & $\begin{array}{l}\text { El PDM de Estados Unidos debe incluir el } \\
\text { rubro de colorantes naturales y darle } \\
\text { mayor importancia. Usted está... }\end{array}$ & $\mathrm{X}$ & $\mathrm{X}$ & $\mathrm{X}$ & $\mathrm{X}$ & \\
\hline & Factores de éxito: Competitividad & & & & & \\
\hline 7 & $\begin{array}{l}\text { Mi volumen exportado ha aumentado } \\
\text { debido al incremento de empresas de } \\
\text { productos orgánicos o saludables en } \\
\text { Estados Unidos. Usted está... }\end{array}$ & $\mathrm{X}$ & $\mathrm{X}$ & $\mathrm{X}$ & $\mathrm{X}$ & \\
\hline 8 & $\begin{array}{l}\text { Considera que uno de los factores del aumento } \\
\text { de su volumen exportado es gracias al } \\
\text { incremento de la demanda de colorantes } \\
\text { naturales. Usted está... }\end{array}$ & & & & & $\begin{array}{l}\text { Debe cambiar } \\
\text { incidiendo en calidad y } \\
\text { no en volumen como } \\
\text { la pregunta } 7 \text {. }\end{array}$ \\
\hline 9 & $\begin{array}{l}\text { Mi volumen exportado ha disminuido debido } \\
\text { al aumento de empresas peruanas } \\
\text { exportadoras de colorante de maíz } \\
\text { morado. Usted } \\
\text { está... }\end{array}$ & $\mathrm{X}$ & $\mathrm{X}$ & $\mathrm{X}$ & $\mathrm{X}$ & \\
\hline 10 & $\begin{array}{l}\text { Considera que su precio de exportación se ha } \\
\text { visto afectado negativamente debido al } \\
\text { incremento de empresas exportadoras de } \\
\text { colorante de maíz morado. Usted está... }\end{array}$ & $X$ & $X$ & $X$ & $\mathrm{X}$ & \\
\hline & Factores de éxito: Boom saludable & & & & & \\
\hline 11 & $\begin{array}{l}\text { El aumento de su volumen exportado se } \\
\text { debe a que el consumidor final } \\
\text { actualmente se encuentra más } \\
\text { interesado en los productos orgánicos } \\
\text { o saludables. Usted está... }\end{array}$ & $\mathrm{X}$ & $\mathrm{X}$ & $\mathrm{X}$ & $\mathrm{X}$ & \\
\hline 12 & $\begin{array}{l}\text { El precio de exportación se ha visto } \\
\text { beneficiado debido a que las personas }\end{array}$ & $\mathrm{X}$ & $\mathrm{X}$ & $\mathrm{X}$ & $\mathrm{X}$ & \\
\hline
\end{tabular}




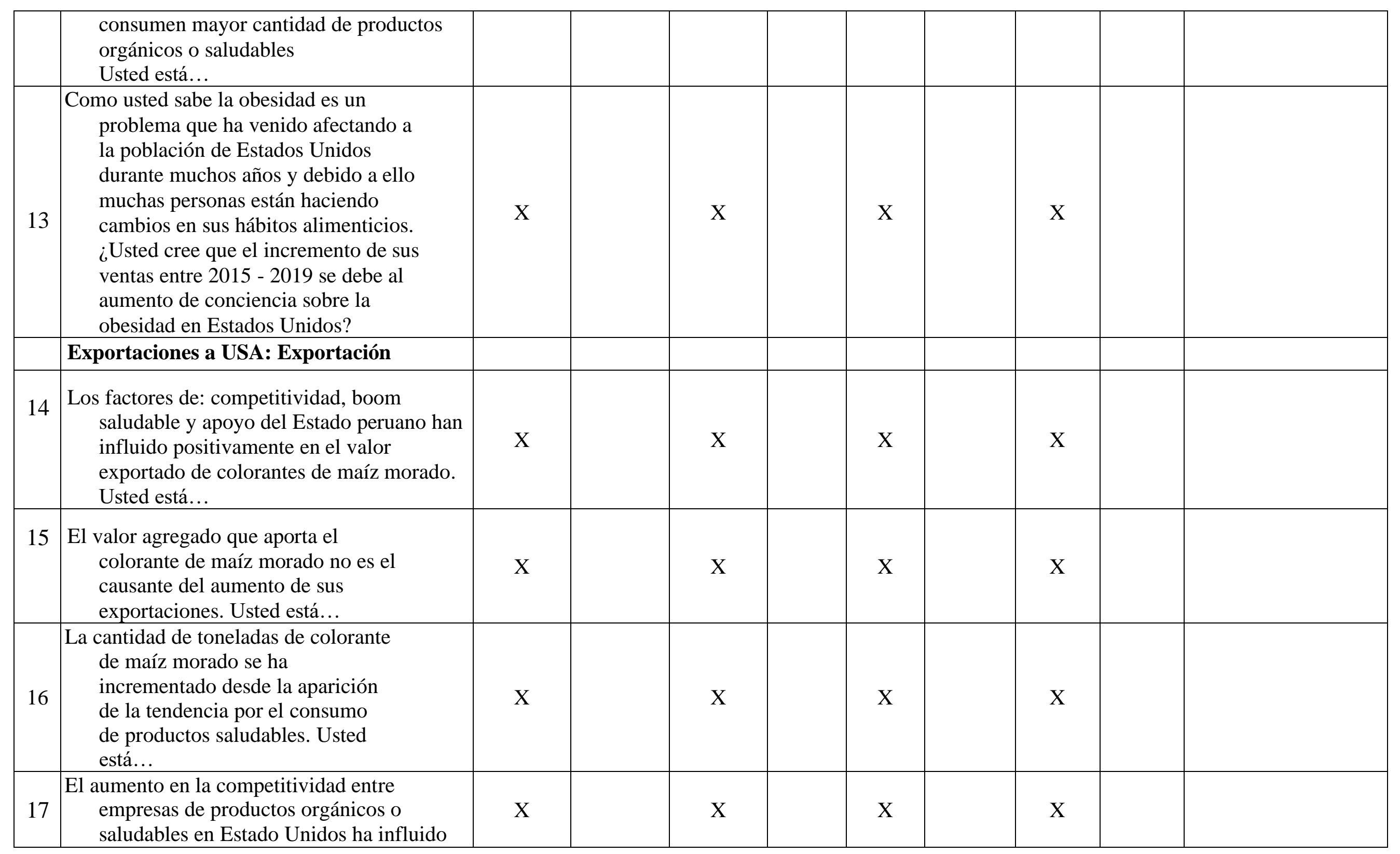




\begin{tabular}{|c|c|c|c|c|c|}
\hline & $\begin{array}{l}\text { positivamente en la cantidad exportada de } \\
\text { colorante de maíz morado. Usted está... }\end{array}$ & & & & \\
\hline 18 & \begin{tabular}{|l|} 
Desde el cambio del nuevo PENX 2015-2025, \\
el volumen exportado ha aumentado. \\
Usted está...
\end{tabular} & $X$ & $X$ & $X$ & $X$ \\
\hline 19 & $\begin{array}{l}\text { El precio de venta del colorante de maíz } \\
\text { morado ha disminuido desde el } \\
\text { aumento de la cantidad de empresas } \\
\text { productoras de este producto. Usted } \\
\text { está... }\end{array}$ & $X$ & $X$ & $X$ & $X$ \\
\hline 20 & $\begin{array}{l}\text { El precio de venta del colorante de maíz } \\
\text { morado ha incrementado desde el } \\
\text { aumento de la cantidad de empresas de } \\
\text { productos orgánicos y saludables en } \\
\text { Estados Unidos. Usted está... }\end{array}$ & $X$ & $X$ & $X$ & $X$ \\
\hline 21 & $\begin{array}{l}\text { El precio de exportación no se ha visto } \\
\text { beneficiado debido al apoyo del estado } \\
\text { peruano. Usted está... }\end{array}$ & $X$ & $X$ & $X$ & $X$ \\
\hline 22 & $\begin{array}{l}\text { Debido al aumento de oferta de empresas } \\
\text { exportadoras de colorante de maíz morado, } \\
\text { el costo de materia prima se ha visto } \\
\text { afectado negativamente. Usted está... }\end{array}$ & $X$ & $X$ & $X$ & $X$ \\
\hline 23 & $\begin{array}{l}\text { El aumento de demanda del colorante de maíz } \\
\text { morado en el mercado de Estados Unidos } \\
\text { no afecta al costo de exportación. Usted } \\
\text { está... }\end{array}$ & $X$ & $X$ & $X$ & $X$ \\
\hline & Pregunta de cierre: & & & & \\
\hline 24 & $\begin{array}{l}\text { Califique del } 1 \text { al } 5 \text { los factores de éxito que } \\
\text { más influyan en el aumento de }\end{array}$ & $X$ & $X$ & $X$ & $X$ \\
\hline
\end{tabular}




\begin{tabular}{|l|l|l|l|l|l|l|l|l|}
\hline & $\begin{array}{l}\text { exportaciones de colorante de maíz } \\
\text { morado a Estados Unidos. Donde 1 es el } \\
\text { puntaje más bajo y 5 el puntaje más alto. }\end{array}$ & & & & & & & \\
\hline
\end{tabular}
${ }^{1}$ Se entiende sin dificultad alguna el enunciado del ítem.
${ }^{2}$ El ítem tiene relación con el constructo (Comprensión Oral de Estructuras Gramaticales)
${ }^{3}$ En el ítem todas las palabras son usuales para nuestro contexto
${ }^{4}$ El ítem evalúa el componente o dimensión específica del constructo (bloques). 
Estimado:

Sr. Carlos González

Presente:

Me dirijo a usted con la finalidad de solicitar su valiosa colaboración en calidad de JUEZ para validar el contenido del instrumento Cuestionario. Instrumento que lleva por título: Formulario de Validación de Instrumento de Tesis.

Para dar cumplimiento a lo anteriormente expuesto se hace entrega formal de la operacionalización de variables involucradas en el estudio, el cuestionario, la tabla de especificaciones respectivas, y los dos formatos de validación, el cual deberá llenar de acuerdo a sus observaciones, a fin de orientar y verificar la claridad, congruencia, control de la tendenciosidad y dominio de los contenidos de los diversos ítems de los cuestionarios.

Agradezco de antemano su receptividad y colaboración. Su apoyo nos permitirá adquirir habilidades y competencias profesionales y científicas que forman parte del proceso de investigación.

Quedo de Ud. en espera del feedback respectivo para mejorar el presente trabajo.

Muy Atentamente:

Romero Ortega, Doris. Scamarone

Cornejo, Priscilla. 


\section{INSTRUMENTO PARA LA}

VALIDEZ DE

\section{CONTENIDO (JUICIO DE}

\section{EXPERTOS)}

- El presente instrumento tiene como finalidad validar el cuestionario de la tesis titulada: "Factores de éxito de las exportaciones de colorante de maíz morado en la industria alimentaria a Estados Unidos periodo 2015 - 2019".

El mismo será aplicado en un diseño cuantitativo no probabilístico. La cual será aplicada a la muestra en estudiopara la validación del instrumento a utilizar titulado: Formulario de Validación de Instrumento de Tesis.

\section{Instrucciones}

La evaluación requiere de la lectura detallada y completa de cada uno de los ítems propuestos a fin de cotejarlos de manera cualitativa con los criterios propuestos relativos a: relevancia o congruencia con el contenido, claridad en la redacción, tendenciosidad o sesgo en su formulación y dominio del contenido. Para ello deberá asignar una valoración si el ítem presenta o no los criterios propuestos, y en caso necesario se ofrece un espacio para las observaciones si hubiera.

Grado de Instrucción: Master

Fecha actual: 20/06/2020

Nombres y Apellidos de Juez: Carlos Alberto González Mendoza

Institución donde labora: Asociación de Exportadores - ADEX

Años de experiencia profesional o científica: 32

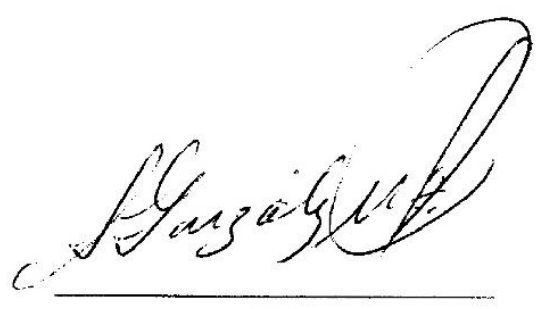

Firma y/o Sello 

Definición Conceptual

\section{Definición \\ Operacional}

Dimensiones

Indicadores

Items

(preguntas)
Aumento de
demanda

Competitividad

Aumento de oferta $\quad 9$ y 10

"Factor: Elemento "Los factores claves o causa que actúan de éxito son los junto con otros. El elementos que le permiten al empresario alcanzar los objetivos que se ha trazado y distinguen a la empresa de la competencia negocio, actuación,
etc." (RAE, 2020)
(Lopez, 2002) etc." (RAE, 2020)

Cambio en hábitos alimenticios

Boom Saludable

$$
\begin{gathered}
\text { Consumo de } \\
\text { productos orgánicos } \\
\text { Promoción del } \\
\text { producto }
\end{gathered}
$$
1

Información sobre el 5 у 6
"La exportación es la venta de bienes o servicios producidos por una empresa que tiene su sede en un país a clientes que residen en otro país". (Daniels et al, 2018)
"Régimen aduanero que permite la salida del territorio aduanero de las mercancías nacionales o nacionalizadas para su uso o consumo definitivo en el exterior. $\mathrm{La}$ exportación definitiva no está afecta a ningún tributo". (SUNAT, 2008) Apoyo del mercado americano Gobierno Peruano

$$
\begin{gathered}
\text { Herramientas de } \\
\text { exportación }
\end{gathered}
$$

Valor exportado

Volumen exportado 16,17 y 18

Exportaciones

Precio de exportación 19,20 у 21

Costo de exportación 


\section{FORMULARIO DE VALIDACIÓN DE TESIS}

Cuestionario dirigido a empresas exportadores de colorante de maíz morado a

Estados Unidos, años 2015 - 2019 Número de empresa:

Número

de cuestionario:

Estimado (a), la información que proporcione a través de este instrumento de recolección de información será utilizada de manera confidencial y con fines meramente científico-académicos, los cuales serán procesados y presentados de forma general en una tesis. Por ello le agradecemos anticipadamente su tiempo y atención en el llenado del presente cuestionario.

V. INFORMACIÓN SOCIODEMOGRÁFICA:

Nombre Cargo que ocupa : Empresa

VI. CUESTIONARIO: Lea cuidadosamente todo el documento y elija la opción que se ajuste más a su respuesta.

\begin{tabular}{|c|c|c|c|c|c|}
\hline Preguntas & $\begin{array}{c}\text { Totalmente } \\
\text { en desacuerdo }\end{array}$ & $\begin{array}{c}\text { De } \\
\text { desacuerdo }\end{array}$ & $\begin{array}{l}\text { Ni de acuerdo } \\
\text { ni en } \\
\text { desacuerdo }\end{array}$ & De acuerdo & $\begin{array}{l}\text { Totalmente } \\
\text { de acuerdo }\end{array}$ \\
\hline \multicolumn{6}{|l|}{$\begin{array}{l}\text { Factores de éxito: Apoyo del estado } \\
\text { peruano }\end{array}$} \\
\hline $\begin{array}{l}\text { 1. El estado peruano promociona el } \\
\text { producto a los diversos mercados } \\
\text { internacionales. }\end{array}$ & $(\quad)$ & ) & $(\quad)$ & $(\quad)$ & ( \\
\hline $\begin{array}{l}\text { 2. El estado le brinda herramientas que } \\
\text { le faciliten la exportación del } \\
\text { producto. }\end{array}$ & $(\quad)$ & ) & ( & ( & ( \\
\hline $\begin{array}{l}\text { 3. El PENX no aporta positivamente al } \\
\text { volumen exportado durante el } \\
\text { periodo mencionado. }\end{array}$ & $(\quad)$ & $(\quad)$ & $(\quad)$ & ( & $(\quad)$ \\
\hline $\begin{array}{l}\text { 4. Si usted importa algún insumo para } \\
\text { la elaboración del colorante de } \\
\text { maíz morado (materia prima, } \\
\text { envasado y/o empaquetado), } \\
\text { percibe algún beneficio tributario } \\
\text { por parte del Estado peruano. } \\
\text { Ejemplo: Acogerse bajo el régimen } \\
\text { Drawback o de reposición de } \\
\text { mercancías con franquicia } \\
\text { arancelaria. }\end{array}$ & $(\quad)$ & ( & $(\quad)$ & ( & ( \\
\hline
\end{tabular}


5. El estado peruano le brinda información sobre las tendencias y necesidades del mercado americano.

6. El Plan de Desarrollo de Mercado de Estados Unidos debe incluir el rubro de colorantes naturales y darle mayor importancia.

Factores de éxito: Competitividad

7. El volumen exportado ha aumentado debido al incremento de empresas de productos orgánicos o saludables en Estados Unidos.

8. Uno de los factores del aumento del volumen exportado es gracias a la calidad que aportan los colorantes naturales al producto final.

9. El volumen exportado ha disminuido debido al aumento de empresas peruanas exportadoras de colorante de maíz morado.

10. Su precio de exportación se ha visto afectado negativamente debido al incremento de empresas exportadoras de colorante de maíz morado.

Factores de éxito: Boom saludable

11. El aumento del volumen exportado se debe a que el consumidor final actualmente se encuentra más interesado en los productos orgánicos 0 saludables.

12. El precio de exportación se ha visto beneficiado debido a que las personas consumen mayor cantidad de productos orgánicos o saludables.

13. Como usted sabe la obesidad es un problema que ha venido afectando a la población de Estados Unidos durante muchos años y debido a ello muchas personas están haciendo cambios en sus hábitos alimenticios. Debido a lo 


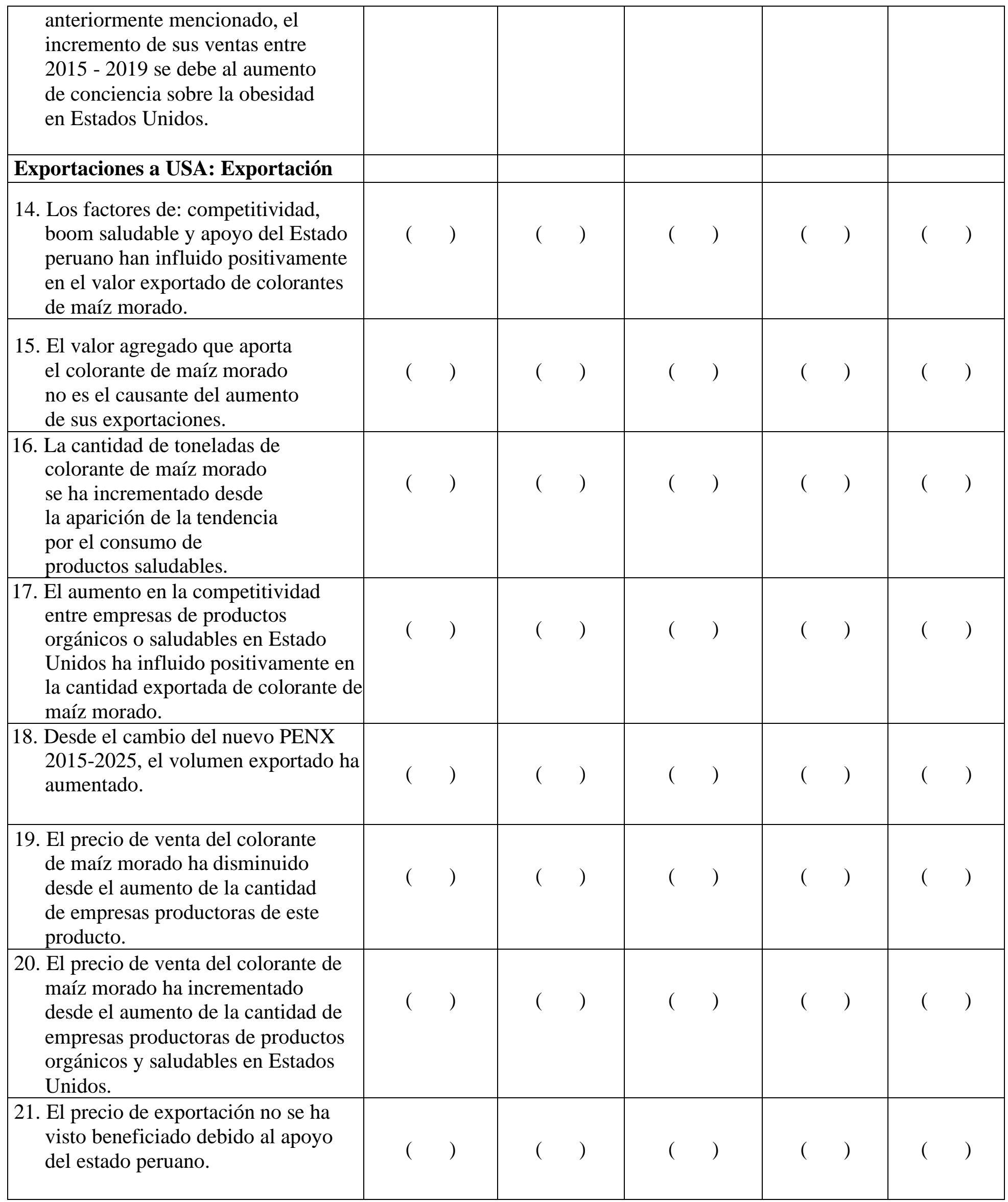


22. Debido al aumento de oferta de empresas exportadoras de colorante de maíz morado, el costo de materia prima se ha visto afectado negativamente.

23. El aumento de demanda del colorante de maíz morado en el mercado de Estados Unidos no afecta al costo de exportación.

\section{Pregunta de cierre:}

24. Califique del 1 al 5 los factores de éxito que más influyan en el aumento de exportaciones de colorante de maíz morado a Estados Unidos. Donde 1 es el puntaje más bajo y 5 el puntaje más alto.

\begin{tabular}{|c|c|c|c|c|c|}
\hline $\begin{array}{l}\text { Competitividad de empresas } \\
\text { compradoras de Estados Unidos }\end{array}$ & $(\quad)$ & $(\quad)$ & $(\quad)$ & $(\quad)$ & $(\quad)$ \\
\hline Tendencia de vida saludable & $(\quad)$ & $(\quad)$ & $(\quad)$ & $(\quad)$ & ( \\
\hline Apoyo del estado peruano & $(\quad)$ & $(\quad)$ & $(\quad)$ & $(\quad)$ & $(\quad)$ \\
\hline
\end{tabular}




\section{DICTAMINADO POR EL JUEZ}

1) ¿Está de acuerdo con las características, forma de aplicación y estructura del INSTRUMENTO?

$$
\text { SI }(X) \quad \text { NO ( ) }
$$

Observaciones:

Sugerencias:

2) A su parecer, ¿el orden de las preguntas es el adecuado?

$$
\mathrm{SI}(\mathrm{X}) \quad \mathrm{NO}(\mathrm{l}
$$

Observaciones:

Sugerencias:

3) ¿Existe dificultad para entender las preguntas del INSTRUMENTO?

$$
\text { SI ( ) NO ( ) }
$$

Observaciones:.

Sugerencias:

4) ¿Existen palabras difíciles de entender en los ítems o reactivos del INSTRUMENTO?
SI ( )
NO (X)

Observaciones:

Sugerencias: 
5) ¿Las opciones de respuesta están suficientemente graduados y pertinentes para cada ítem (cada pregunta) o reactivo del INSTRUMENTO?
SI $(X)$
NO ( )

Observaciones:

Sugerencias:

6) ¿Los ítems o reactivos del instrumento tienen correspondencia con la dimensión al que pertenece en el constructo?
SI ( X )
NO ( )

Observaciones:.

Sugerencias: 
FORMULARIO PARA VALIDACIÓN DE INSTRUMENTO DE TESIS

INSTRUMENTO PARA FINES ESPECIFICOS DE LA VALIDACION DE CONTENIDO (JUICIO DEL EXPERTO)

\begin{tabular}{|c|c|c|c|c|c|c|c|c|c|c|}
\hline \multirow[t]{2}{*}{$\mathbf{N}^{\mathbf{o}}$} & \multirow[t]{2}{*}{ Ítems (PREGUNTAS) } & \multicolumn{2}{|c|}{ Claridad $^{1}$} & \multicolumn{2}{|c|}{ Congruencia $^{2}$} & \multicolumn{2}{|c|}{ Contexto $^{3}$} & \multicolumn{2}{|c|}{$\begin{array}{c}\text { Dominio del } \\
\text { Constructo }\end{array}$} & \multirow[t]{2}{*}{ Sugerencias } \\
\hline & & SI & NO & SI & NO & SI & NO & SI & NO & \\
\hline & $\begin{array}{l}\text { Factores de éxito: Apoyo del estado } \\
\text { peruano }\end{array}$ & & & & & & & & & \\
\hline 1 & $\begin{array}{l}\text { El estado peruano promociona el producto a } \\
\text { los diversos mercados internacionales. }\end{array}$ & $\mathrm{X}$ & & $\mathrm{X}$ & & $\mathrm{X}$ & & $\mathrm{X}$ & & \\
\hline 2 & $\begin{array}{l}\text { El estado le brinda herramientas que le } \\
\text { faciliten la exportación del producto. }\end{array}$ & $X$ & & $\mathrm{X}$ & & $X$ & & $\mathrm{X}$ & & \\
\hline 3 & $\begin{array}{l}\text { El PENX no aporta positivamente al } \\
\text { volumen exportado durante el periodo } \\
\text { mencionado. }\end{array}$ & $\mathrm{X}$ & & & $\mathrm{X}$ & $\mathrm{X}$ & & $\mathrm{X}$ & & $\begin{array}{l}\text { Supone que no aporta. } \\
\text { Adelanta juicio }\end{array}$ \\
\hline 4 & $\begin{array}{l}\text { Si usted importa algún insumo para la } \\
\text { elaboración del colorante de maíz } \\
\text { morado (materia prima, envasado y/o } \\
\text { empaquetado), percibe algún beneficio } \\
\text { tributario por parte del Estado peruano. } \\
\text { Ejemplo: Acogerse bajo el régimen } \\
\text { Drawback o de reposición de mercancías } \\
\text { con franquicia arancelaria. }\end{array}$ & $\mathrm{X}$ & & $\mathrm{X}$ & & $\mathrm{X}$ & & $\mathrm{X}$ & & \\
\hline 5 & $\begin{array}{l}\text { El estado peruano le brinda información } \\
\text { sobre las tendencias y necesidades del } \\
\text { mercado americano. }\end{array}$ & $\mathrm{X}$ & & $\mathrm{X}$ & & $\mathrm{X}$ & & $\mathrm{X}$ & & \\
\hline
\end{tabular}




\begin{tabular}{|c|c|c|c|c|c|c|c|}
\hline 6 & $\begin{array}{l}\text { El Plan de Desarrollo de Mercado de Estados } \\
\begin{array}{l}\text { Unidos debe incluir el rubro de } \\
\text { colorantes naturales y darle mayor } \\
\text { importancia. }\end{array} \\
\end{array}$ & $\mathrm{X}$ & & $\mathrm{X}$ & $\mathrm{X}$ & $\mathrm{X}$ & \\
\hline & Factores de éxito: Competitividad & & & & & & \\
\hline 7 & $\begin{array}{l}\text { El volumen exportado ha aumentado debido } \\
\text { al incremento de empresas de productos } \\
\text { orgánicos o saludables en Estados } \\
\text { Unidos. }\end{array}$ & & $\mathrm{X}$ & $\mathrm{X}$ & $\mathrm{X}$ & $\mathrm{X}$ & $\begin{array}{l}\text { Especificar "empresas } \\
\text { productoras de } \\
\text { productos }\end{array}$ \\
\hline 8 & $\begin{array}{l}\text { Uno de los factores del aumento del volumen } \\
\begin{array}{l}\text { exportado es gracias a la calidad que } \\
\text { aportan los colorantes naturales al } \\
\text { producto final. }\end{array}\end{array}$ & & $\mathrm{X}$ & $\mathrm{X}$ & $\mathrm{X}$ & $\mathrm{X}$ & $\begin{array}{l}\text { Eliminar la expresión } \\
\text { "gracias a" }\end{array}$ \\
\hline 9 & $\begin{array}{l}\text { El volumen exportado ha disminuido debido } \\
\text { al aumento de empresas peruanas } \\
\text { exportadoras de colorante de maíz } \\
\text { morado. }\end{array}$ & $\mathrm{X}$ & & $\mathrm{X}$ & $\mathrm{X}$ & $\mathrm{X}$ & \\
\hline 10 & $\begin{array}{l}\text { El precio de exportación se ha visto afectado } \\
\text { negativamente debido al incremento de } \\
\text { empresas exportadoras de colorante de } \\
\text { maíz morado. }\end{array}$ & $\mathrm{X}$ & & $\mathrm{X}$ & $\mathrm{X}$ & $\mathrm{X}$ & \\
\hline & Factores de éxito: Boom saludable & & & & & & \\
\hline 11 & $\begin{array}{l}\text { El aumento de su volumen exportado se } \\
\text { debe a que el consumidor final } \\
\text { actualmente se encuentra más } \\
\text { interesado en los productos orgánicos } \\
\text { o saludables. }\end{array}$ & $\mathrm{X}$ & & $\mathrm{X}$ & $\mathrm{X}$ & $\mathrm{X}$ & \\
\hline 12 & $\begin{array}{l}\text { El precio de exportación se ha visto } \\
\text { beneficiado debido a que las personas } \\
\text { consumen mayor cantidad de productos }\end{array}$ & $\mathrm{X}$ & & $\mathrm{X}$ & $\mathrm{X}$ & $\mathrm{X}$ & \\
\hline
\end{tabular}




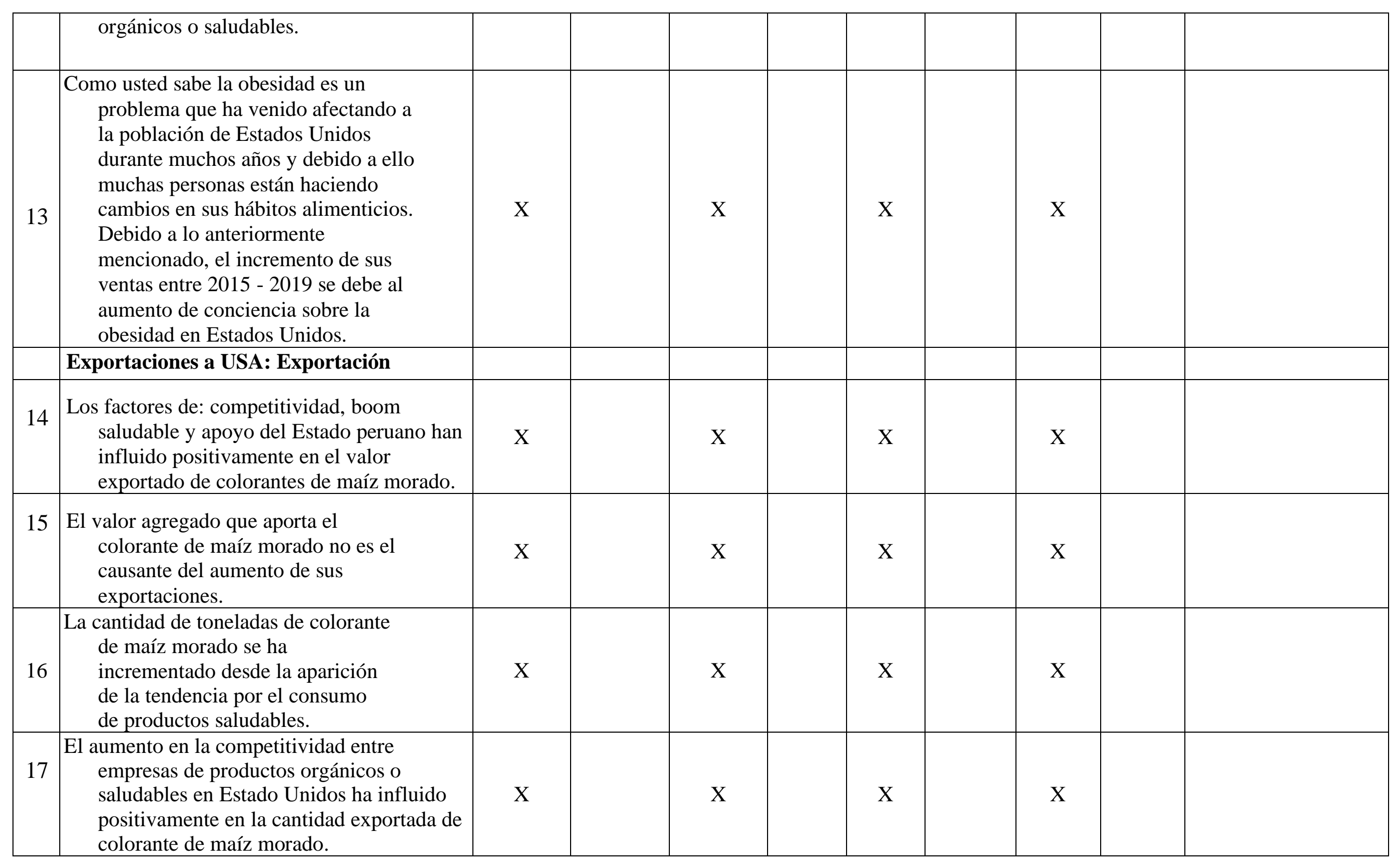




\begin{tabular}{|c|c|c|c|c|c|}
\hline 18 & $\begin{array}{c}\text { Desde el cambio del nuevo PENX 2015-2025, } \\
\text { el volumen exportado ha aumentado. }\end{array}$ & $X$ & $X$ & $X$ & $X$ \\
\hline 19 & $\begin{array}{l}\text { El precio de venta del colorante de maíz } \\
\text { morado ha disminuido desde el } \\
\text { aumento de la cantidad de empresas } \\
\text { productoras de este producto. }\end{array}$ & $\mathrm{X}$ & $X$ & $X$ & $X$ \\
\hline 20 & $\begin{array}{l}\text { El precio de venta del colorante de maíz } \\
\text { morado ha incrementado desde el } \\
\text { aumento de la cantidad de empresas } \\
\text { productoras de productos orgánicos y } \\
\text { saludables en Estados Unidos. }\end{array}$ & $X$ & $X$ & $X$ & $X$ \\
\hline 21 & $\begin{array}{l}\text { El precio de exportación no se ha visto } \\
\text { beneficiado debido al apoyo del estado } \\
\text { peruano. }\end{array}$ & $X$ & $\mathrm{X}$ & $\mathrm{X}$ & $\mathrm{X}$ \\
\hline 22 & $\begin{array}{l}\text { Debido al aumento de oferta de empresas } \\
\text { exportadoras de colorante de maíz morado, } \\
\text { el costo de materia prima se ha visto } \\
\text { afectado negativamente. }\end{array}$ & $X$ & $X$ & $X$ & $X$ \\
\hline \multirow[t]{2}{*}{23} & $\begin{array}{l}\text { El aumento de demanda del colorante de maíz } \\
\text { morado en el mercado de Estados Unidos } \\
\text { no afecta al costo de exportación. }\end{array}$ & $X$ & $X$ & $X$ & $X$ \\
\hline & Pregunta de cierre: & & & & \\
\hline 24 & $\begin{array}{l}\text { Califique del } 1 \text { al } 5 \text { los factores de éxito que } \\
\text { más influyan en el aumento de } \\
\text { exportaciones de colorante de maíz } \\
\text { morado a Estados Unidos. Donde } 1 \text { es el } \\
\text { puntaje más bajo y } 5 \text { el puntaje más alto. }\end{array}$ & $\mathrm{X}$ & $\mathrm{X}$ & $X$ & $X$ \\
\hline
\end{tabular}

${ }^{1}$ Se entiende sin dificultad alguna el enunciado del ítem.

${ }^{2}$ El ítem tiene relación con el constructo (Comprensión Oral de Estructuras Gramaticales)

${ }^{3}$ En el ítem todas las palabras son usuales para nuestro contexto constructo (bloques).

${ }^{4}$ El ítem evalúa el componente o dimensión específica del 
Estimado:

Sra. Adriana Velarde

Presente:

Me dirijo a usted con la finalidad de solicitar su valiosa colaboración en calidad de JUEZ para validar el contenido del instrumento Cuestionario. Instrumento que lleva por título: Formulario de Validación de Instrumento de Tesis.

Para dar cumplimiento a lo anteriormente expuesto se hace entrega formal de la operacionalización de variables involucradas en el estudio, el cuestionario, la tabla de especificaciones respectivas, y los dos formatos de validación, el cual deberá llenar de acuerdo a sus observaciones, a fin de orientar y verificar la claridad, congruencia, control de la tendenciosidad y dominio de los contenidos de los diversos ítems de los cuestionarios.

Agradezco de antemano su receptividad y colaboración. Su apoyo nos permitirá adquirir habilidades y competencias profesionales y científicas que forman parte del proceso de investigación.

Quedo de Ud. en espera del feedback respectivo para mejorar el presente trabajo.

Muy Atentamente:

Romero Ortega, Doris. Scamarone Cornejo, Priscilla. 


\section{INSTRUMENTO PARA LA VALIDEZ DE CONTENIDO}

\section{(JUICIO DE EXPERTOS)}

El presente instrumento tiene como finalidad validar el cuestionario de la tesis titulada: "Factores de éxito de las exportaciones d colorante de maiz morado en la industria alimentaria a Estados Unidos periodo 2015 - 2019"

El mismo será aplicado en un diseño cuantitativo no probabilistico. La cual será aplicada a la muestra en estudiopara la validación del instrumento a utilizar titulado: Formulario de Validación de Instrumento de Tesis.

\section{Instrucciones}

La evaluación requiere de la lectura detallada y completa de cada uno de los ítems propuestos a fin de cotejarlos de manera cualitativa con los criterios propuestos relativos a: relevancia o congruencia con el contenido, claridad en la redacción, tendenciosidad o sesgo en su formulación y dominio del contenido. Para ello deberá asignar una valoración si el ítem presenta o no los criterios propuestos, y en caso necesario se ofrece un espacio para las observaciones si hubiera.

Grado de Instrucción:

Fecha actual: $2 0 / 6 \longdiv { 2 0 2 0 }$

Nombres y Apellidos de Juez: Adriane Velarde Rivas

Institución donde labora: Ministerio de Rebacienes Fxteriores

Años de experiencia profesional o cientifica: 16

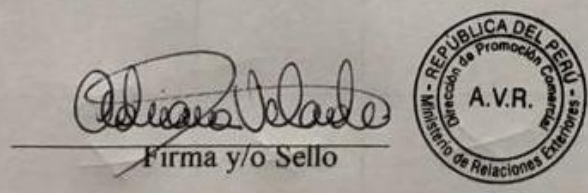




\section{CRITERIOS GENERALES PARA VALIDEZ DE CONTENIDO DEL INSTRUMENTO}

\section{DICTAMINADO POR EL JUEZ}

1) Está de acuerdo con las características, forma de aplicación y estructura del INSTRUMENTO?

$$
\operatorname{Si}(\text { NO() }
$$

Observaciones

Sugerencias

2) A su parecer, ¿el orden de las preguntas es el adecuado?

$$
\text { SI }(X) \quad \text { NO( ) }
$$

Observaciones

Sugerencias

3) Existe dificultad para entender las preguntas del INSTRUMENTO?

$$
\text { SI ( ) Noty }
$$

Observaciones

Sugerencias

4) ¿Existen palabras difíciles de entender en los ítems o reactivos del INSTRUMENTO?

$$
\text { SI ( ) NOK }
$$

Observaciones

\section{Sugerencias}

5) ¿Las opciones de respuesta están suficientemente graduados y perfinentes para cada ítem (cada pregunta) o reactivo del INSTRUMENTO?

$$
\operatorname{six}(\quad \text { NO( ) }
$$

Observaciones

Sugerencias

6) ¿Los ítems o reactivos del instrumento tienen correspondencia con la dimensión al que pertenece en el constructo?

$$
\text { SIX NO( ) }
$$

Observaciones :

Sugerencias 
INSTRUMENTO PARA FINES FSPECITICO VALIDACIÓN DE INSTRUMENTO DE TESIS

\begin{tabular}{|c|c|c|c|c|c|c|c|c|c|c|}
\hline \multirow[t]{2}{*}{$\mathbf{N}^{0}$} & \multirow[t]{2}{*}{ Ítems (PREGUNTAS) } & \multicolumn{2}{|c|}{ Claridad $^{1}$} & \multicolumn{2}{|c|}{ Congruencia $^{2}$} & \multicolumn{2}{|c|}{ Contexto $^{3}$} & \multicolumn{2}{|c|}{$\begin{array}{c}\text { Dominio del } \\
\text { Constructo }\end{array}$} & \multirow[t]{2}{*}{ Sugerencias } \\
\hline & & SI & NO & SI & NO & SI & NO & SI & NO & \\
\hline & $\begin{array}{l}\text { Factores de éxito: Apoyo del estado } \\
\text { peruano }\end{array}$ & & & & & & & & & \\
\hline 1 & $\begin{array}{l}\text { Considera que el estado peruano promociona } \\
\text { el producto a los diversos mercados } \\
\text { internacionales. Usted está... }\end{array}$ & $x$ & & $x$ & & $x$ & & $x$ & & \\
\hline 2 & $\begin{array}{l}\text { Considera que el estado le brinda } \\
\text { herramientas que le faciliten la } \\
\text { exportación del producto. Usted está... }\end{array}$ & $x$ & & $x$ & & 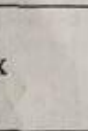 & & $x$ & & \\
\hline 3 & $\begin{array}{l}\text { Considera que el PENX no aporta } \\
\text { positivamente al volumen exportado } \\
\text { durante el periodo mencionado. Usted } \\
\text { está... }\end{array}$ & & $x$ & X & & $x$ & & $x$ & & $\begin{array}{l}\text { Precisalquese } \\
\text { refiere a obje- } \\
\text { tives strategiós } \\
\text { del PENX }\end{array}$ \\
\hline 4 & $\begin{array}{l}\text { ¿Usted importa algún insumo para la } \\
\text { elaboración del colorante de maiz } \\
\text { morado? (materia prima, envasado y/o } \\
\text { empaquetado) De ser positivo, ¿percibe } \\
\text { usted algún beneficio tributario por parte } \\
\text { del Estado peruano? Ejemplo: Acogerse } \\
\text { bajo el régimen Drawback o de } \\
\text { reposición de mercancías con franquicia } \\
\text { arancelaria. Usted está... }\end{array}$ & & & & & & & & & \\
\hline 5 & $\begin{array}{c}\text { El estado peruano le brinda información } \\
\text { sobre las tendencias y necesidades del } \\
\text { mercado americano. Usted está... }\end{array}$ & & & & & & & & & $\begin{array}{l}\text { mercado } \\
\text { estedounidense }\end{array}$ \\
\hline 6 & $\begin{array}{l}\text { El PDM de Estados Unidos debe incluir el } \\
\text { rubro de colorantes naturales y darle } \\
\text { mayor importancia. Usted está... }\end{array}$ & & & & & & & & & \\
\hline & Factores de éxito: Competitividad & & & & & & & & & \\
\hline 7 & $\begin{array}{l}\text { Mi volumen exportado ha aumentado } \\
\text { debido al incremento de empresas de }\end{array}$ & & & & & & & & & \\
\hline
\end{tabular}




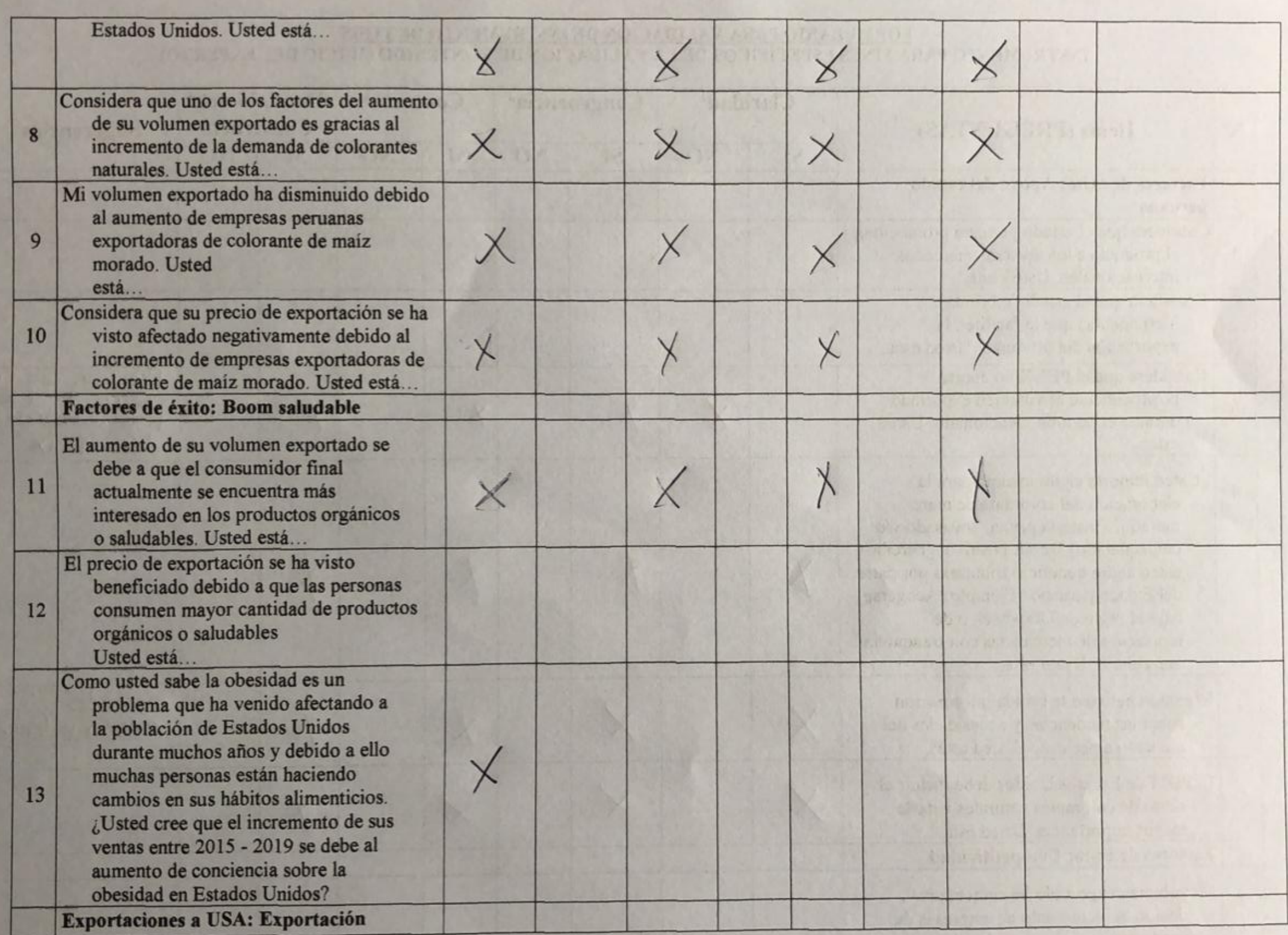




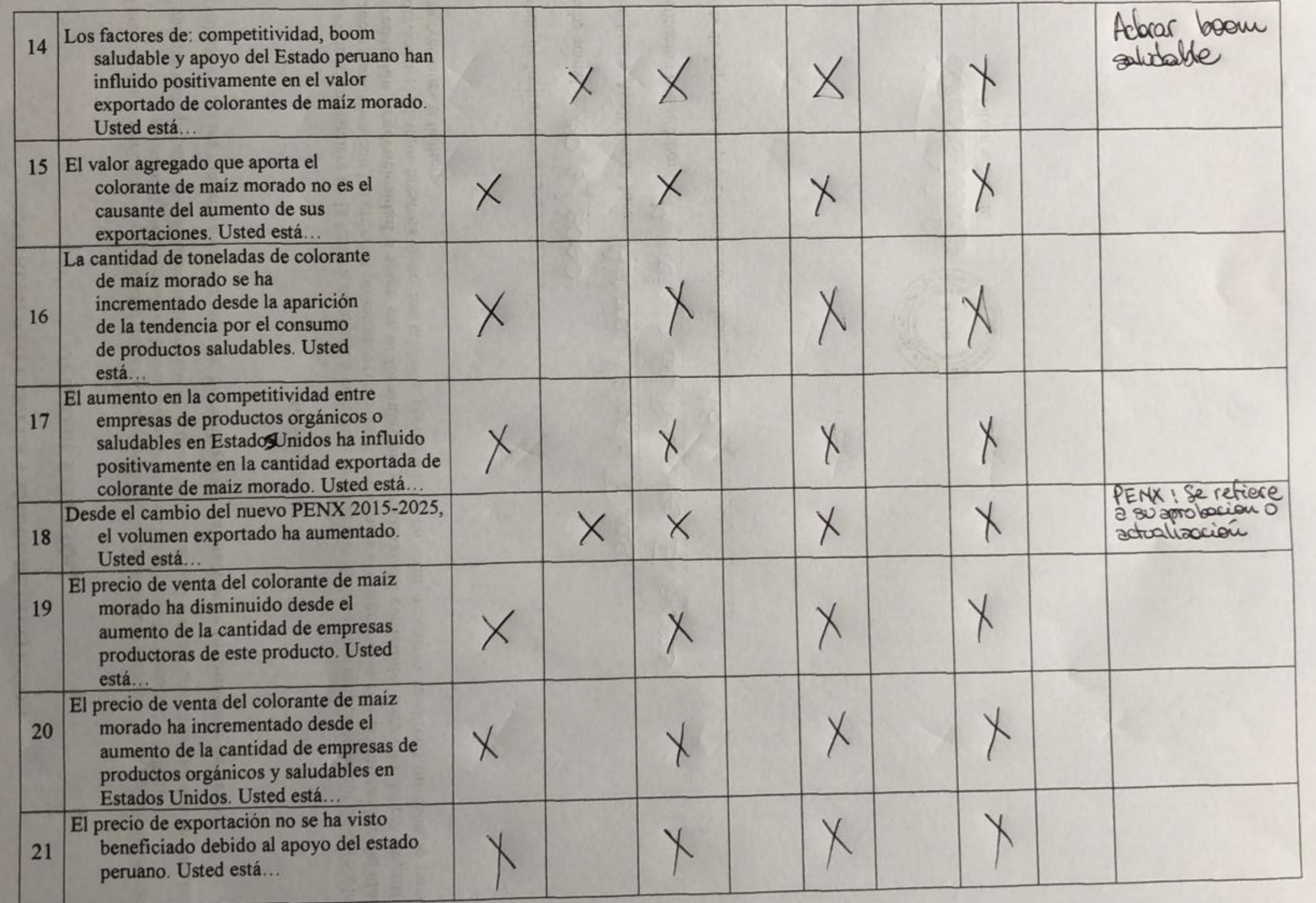


Debido al aumento de oferta de empresas exportadoras de colorante de maíz morado, el costo de materia prima se ha visto afectado negativamente. Usted está.

El aumento de demanda del colorante de maíz morado en el mercado de Estados Unidos no afecta al costo de exportación. Usted está.

Pregunta de cierre:

24 Califique del 1 al 5 los factores de éxito que más influyan en el aumento de

exportaciones de colorante de maíz

morado a Estados Unidos. Donde 1 es el puntaje más bajo y 5 el puntaje más alto.

' Se entiende sin dificultad alguna el enunciadodel item.

${ }^{3}$ En el item todas las palabras son usuales para nuestro contexto

${ }^{2}$ El ftem tiene relación con el constructo (Comprensión Oral de Estructuras Gramaticales)

El item evalúa el componente o dimensión específica del constructo (bloques). 